\title{
Hierarchically Structured Nanomaterials for Electrochemical Energy Conversion
}

\author{
Panagiotis Trogadas ${ }^{\mathrm{a}^{*}}$, Vijay Ramani ${ }^{\mathrm{b}}$, Peter Strasser ${ }^{\mathrm{c}}$, Thomas F. Fuller ${ }^{\mathrm{d}}$, and Marc-Olivier \\ Coppens $^{\mathrm{a}^{*}}$
}

\author{
${ }^{a}$ Department of Chemical Engineering and EPSRC Centre for Nature Inspired Engineering \\ University College London, Torrington Place London WC1E 7JE UK \\ ${ }^{\mathrm{b}}$ Center for Electrochemical Science and Engineering \\ Department of Chemical and Biological Engineering, \\ Illinois Institute of Technology, Chicago, IL 60616 USA \\ ${ }^{\mathrm{c}}$ The Electrochemical Energy, Catalysis, and Materials Science Laboratory \\ Department of Chemistry, Chemical Engineering Division \\ Technical University Berlin, Berlin 10623 Germany \\ ${ }^{d}$ School of Chemical \& Biomolecular Engineering, \\ Georgia Institute of Technology Atlanta, GA 30332-0100 USA \\ *Corresponding authors: p.trogadas@ucl.ac.uk; m.coppens@ucl.ac.uk
}

\begin{abstract}
Hierarchical nanomaterials are highly suitable as electrocatalysts and electrocatalyst supports in electrochemical energy conversion devices. The intrinsic kinetics of an electrocatalyst are associated with the nanostructure of the active phase and the support, while the overall properties are also affected by the mesostructure. Therefore, both structures need to be controlled. A comparative state-of-the-art review of catalysts and supports is provided along with detailed synthesis methods. To further improve the design of these hierarchical nanomaterials, in-depth research on the effect of materials architecture on reaction and transport kinetics is necessary. Inspiration can be derived from nature, which is full of very effective hierarchical structures. Developing fundamental understanding of how desired properties of biological systems are related to their hierarchical architecture can guide the development of novel catalytic nanomaterials and nature-inspired electrochemical devices.
\end{abstract}

\section{Table of Contents}

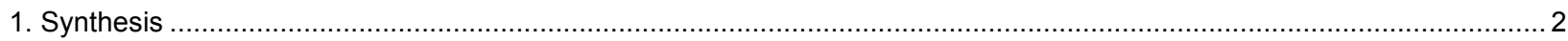

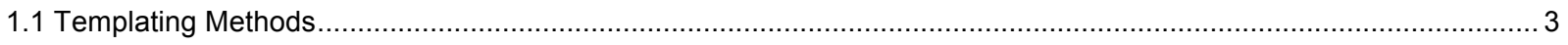

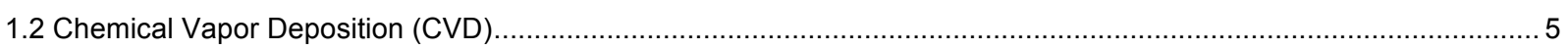

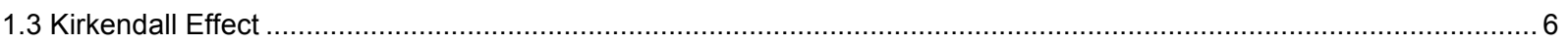

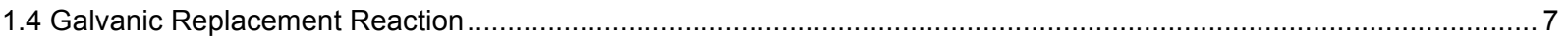

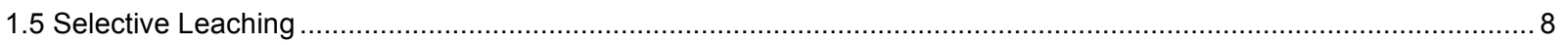

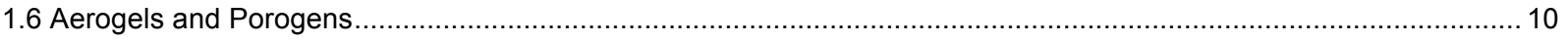

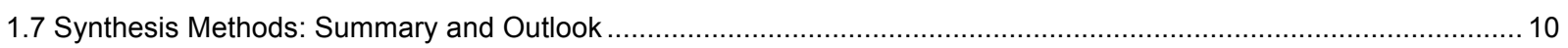

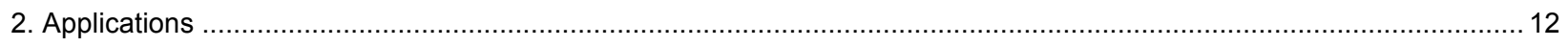

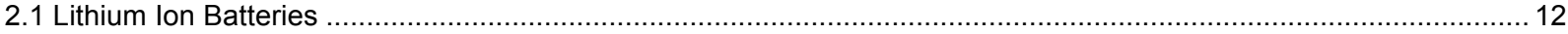

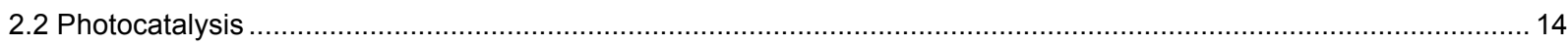

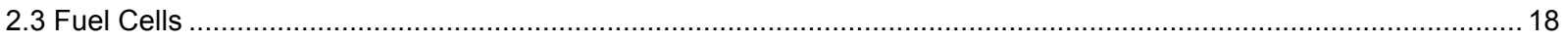

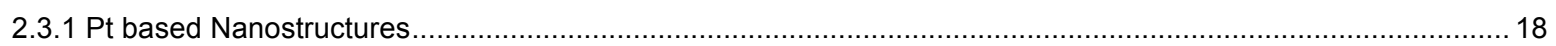




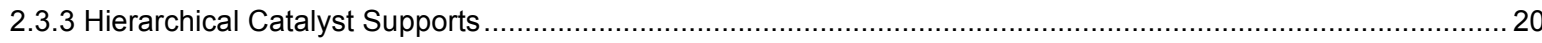

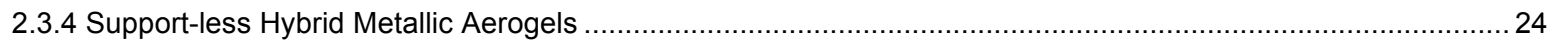

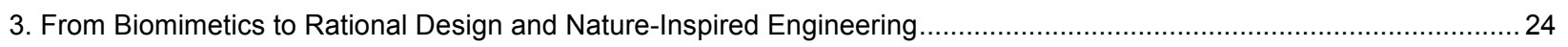

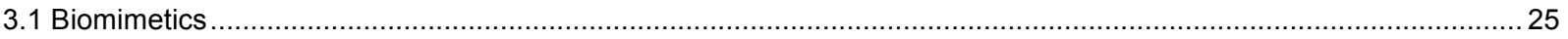

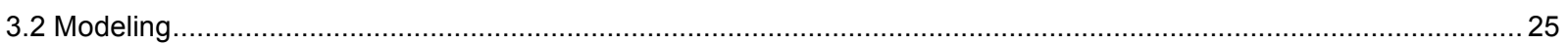

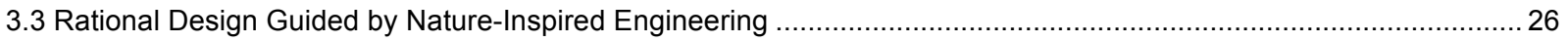

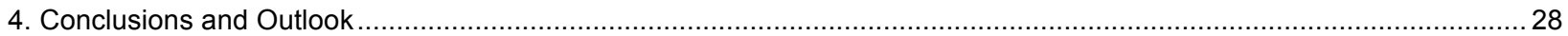

Introduction. Hierarchy is derived from the Greek words hieros (sacred) and archein (rule), and it refers to an organizational structure in which items are ranked according to levels of importance. In the case of hierarchically structured materials, an organizational structure exists consisting of $n$ scales of a recognized structure. In nature, structural hierarchy is a prevailing feature observed in numerous biological materials from macroscopic to microscopic length scales. ${ }^{[2]}$ The properties of these biological materials result from a complex interplay between surface structure, morphology, and physical and chemical properties. $^{[3]}$ A significant difference between structural control in traditional and biological materials is the geometrical occurrence of defects. Defects tend to be randomly distributed over the volume of engineered materials, whereas biological materials consist of a much more ordered structure that reaches down to the nanoscale. ${ }^{[4]}$ The defects are judiciously placed throughout the structure and significantly affect the properties of the biological material. ${ }^{[4]}$ Cytoskeletons, bone, shells, sea sponge exoskeletons and spider silk ${ }^{[4-5]}$ are examples of biological materials with superior mechanical properties, such as strength, robustness, toughness and elasticity, due to their precise architecture, comprising structurally inferior building blocks, arranged along multiple hierarchical levels. ${ }^{[2 b]}$ The cytoskeleton of cells controls their shape and structural integrity via an interplay between intricate protein structures and hierarchically arranged signaling cascades. ${ }^{[4]}$ The nanostructure of bones consists of mineral crystal platelets embedded in a collagen matrix, resulting in high overall toughness of the material, several orders of magnitude higher than that of the constituting minerals. ${ }^{[6]}$

The unique characteristics of such biological materials has directed research towards the utilization of hierarchically structured nanomaterials in applications that require fast and efficient transport through high surface area porous frameworks, such as in separations, energy storage, catalysis and chemical sensing. ${ }^{[7]}$ In the field of catalysis in electrochemical systems in particular, the active sites are located in the micro- and mesopores (nanopores), while the macropores promote facile diffusion of species toward and away from these active sites. ${ }^{[7-8]}$ Moreover, the presence of different pore sizes results in short electron and ion transport paths as well as large surface areas leading to enhanced catalytic activity. ${ }^{[7-8]}$ However, the design of such multi-scaled porous materials with controllable ordered pore sizes and structures still remains a challenge; the majority of synthesis techniques of hierarchical materials used nowadays are complex and expensive. ${ }^{[9]}$

In this review, we critically discuss the state of the art in research on the synthesis of hierarchically mesoporousmacroporous structured materials and their applications in various electrochemical devices, such as batteries, photoelectrochemical cells and fuel cells. We present for the first time a novel approach to improve the design of these hierarchical materials by taking inspiration from nature. Nowadays, a biomimetic rather than a truly nature-inspired approach is often used to synthesize new hierarchical materials with sub-optimal results since this mimetic approach is focused on imitating isolated features of biological structures and the actual physical processes that govern the system are neglected. Developing fundamental understanding of how desired properties of biological systems are related to their hierarchical architecture is crucial and can guide the development of novel, highly efficient catalytic nanomaterials and nature-inspired electrochemical devices.

\section{Synthesis}

A range of experimental methods is used to optimally combine electrochemical functionalities into hierarchical porous materials. Examples, discussed below, include (sacrificial) templating, galvanic replacement reactions, and the Kirkendall effect. 


\subsection{Templating Methods}

Templating is among the most frequently used methods to synthesize hierarchical porous materials with features ranging from nanometers to micrometers. Templating can be differentiated into soft ${ }^{[10]}$ and hard templating ${ }^{[11]}$, depending on the physical and chemical characteristics of the template used. ${ }^{[12]}$

In soft templating, amphiphilic organic surfactants or block copolymers are typically used as structure-directing agents; these molecules are self-assembled with inorganic precursors or nanoparticles into organized organic-inorganic hybrids. ${ }^{[13]}$ The soft templates are removed, often by heating, producing ordered mesoporous inorganic materials.

During hard templating, inorganic precursors adhere to the surface of the template or fill the voids of a preformed hard template (mesoporous silica, carbon or colloidal spheres). ${ }^{[13 b]}$ The template is then removed by etching with $\mathrm{HF}$ or $\mathrm{NaOH}$, or heat-treatment in $\operatorname{air}^{[11 b, 14]}$, resulting in the formation of a hollow or negative replica of the template ${ }^{[13 b]}$, depending on whether the precursor was coated on the surface or filled the vacancies of the template, respectively.

Reactive hard-templating combines the advantages of hard-templating with in-situ decomposition of the template to remove the latter. ${ }^{[15]}$ The template is synthesized from nanostructures of a solid-state reactant that vanishes completely at elevated reaction conditions. This method is very useful for high-temperature transformations, such as the synthesis of macroporous $\mathrm{Ti}_{3} \mathrm{~N}_{4} / \mathrm{C}$ composites (Figure 1). ${ }^{[16]}$ The utilization of graphitic carbon nitrides $\left(\mathrm{g}-\mathrm{C}_{3} \mathrm{~N}_{4}\right)$ as reactive hard templates enables the direct synthesis of $\mathrm{Ti}_{3} \mathrm{~N}_{4} / \mathrm{C}$, since carbon nitrides can act as nitrogen source ${ }^{[15,17]}$, releasing nitrogen in the form of ammonia during their thermal decomposition. ${ }^{[15]}$ Macroporous $\mathrm{Ti}_{3} \mathrm{~N}_{4} / \mathrm{C}$ composites demonstrate a 5-fold increase in surface area, due to the thinner pore walls and the additional porosity created by interstitial sites between the hollow $\mathrm{Ti}_{3} \mathrm{~N}_{4} / \mathrm{C}$ spheres. ${ }^{[13 a]}$

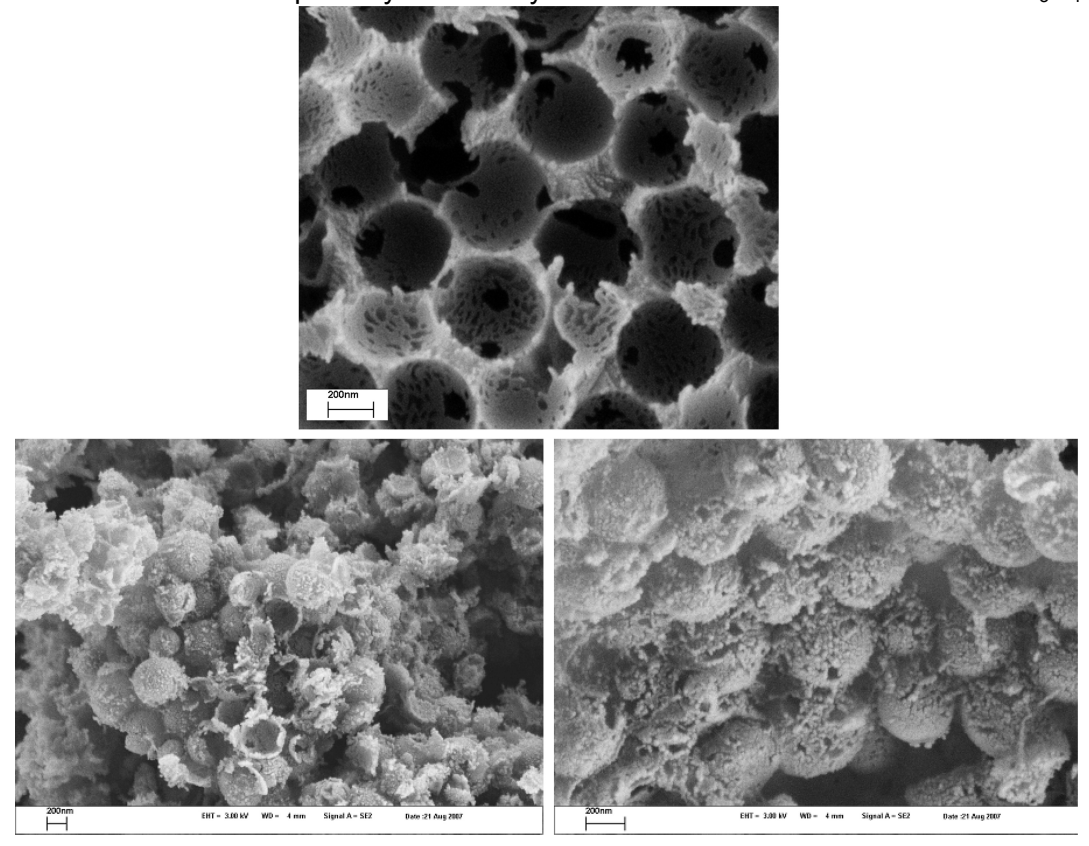

Figure 1. SEM images of the macroporous carbon nitride template with $500 \mathrm{~nm}$ pores (CN-500) (top) and the obtained TiN-500 (bottom). ${ }^{[13 a]}$ Copyright $^{\odot} 2008$ American Chemical Society.

Colloidal Crystal Templating. An example of hard templating is the colloidal crystal templating, which is used for the synthesis of 3D ordered macroporous (3DOM) nanomaterials. ${ }^{[18]}$ This templating method comprises three simple steps: i) a colloidal crystal is formed, consisting of uniformly sized spheres formed via various chemical processes, such as chemical vapor deposition $(C V D)^{[19]}$, sol-gel synthesis ${ }^{[20]}$, polymerization ${ }^{[21]}$ and electrodeposition ${ }^{[22]}$; ii) the interstitial spaces of the crystal are filled with a fluid precursor capable of solidification; and iii) the template is then removed to obtain a porous inverse replica (Figure 2). ${ }^{[18]}$ Despite the simplicity of this technique, optimization of precursor/template interactions as well as chemical reactions is needed to control the 3DOM (sub-)structure and meet specific goals for materials design such as pore topology and micro/mesopore shape. ${ }^{[13 \mathrm{~b}, 18]}$ 

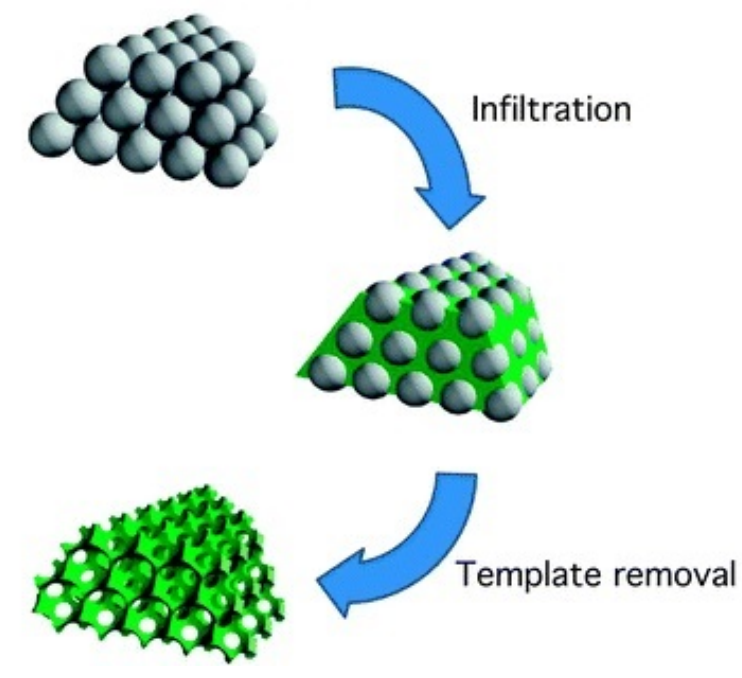

Figure 2. Schematic of the colloidal crystal templating process. The template with the structure of an opal is infiltrated with precursor material. Processing and template removal produce the inverted (3DOM) structure. ${ }^{[23]}$ Copyright ${ }^{\odot} 2013$ American Chemical Society.

The diameter of the ordered macropores can be altered by varying the diameter of the spheres in the colloidal crystal template ${ }^{[13 b]}$, while the diameter of the windows that connect each macropore to its neighbor can be tuned by controlling the synthesis conditions. ${ }^{[2]}$ The main parameters controlling the entrance size of the macropores are the acid concentration and the sintering conditions of the colloidal crystal templates. ${ }^{[24]}$ As the acid concentration increases, the mesopore size slightly decreases $(\sim 4.7$ to $3.6 \mathrm{~nm})$ and the macropore entrance size gradually increases from 0 to $\sim 200 \mathrm{~nm}$ (Figure 3). ${ }^{[2]} \mathrm{A}$ similar effect is observed upon increasing the sintering temperature of the polymeric colloidal crystal template $\left(\sim 90^{\circ} \mathrm{C}\right)$, as it leads to a wide macropore entrance of $\sim 150 \mathrm{~nm} \cdot{ }^{[24]}$ The resultant material is characterized by 3D ordered macropores $(\sim 1 \mu \mathrm{m})$ with tunable entrance size, 2D hexagonally packed mesopores $(\sim 4 \mathrm{~nm})$, high surface area $\left(\sim 330 \mathrm{~m}^{2} \mathrm{~g}^{-1}\right)$ and large pore volume $\left(\sim 0.36 \mathrm{~cm}^{3} \mathrm{~g}^{-1}\right) \cdot{ }^{[2]}$ These tunable materials with adjustable entrance size can be used in various applications, such as drug delivery and nanofiltration.

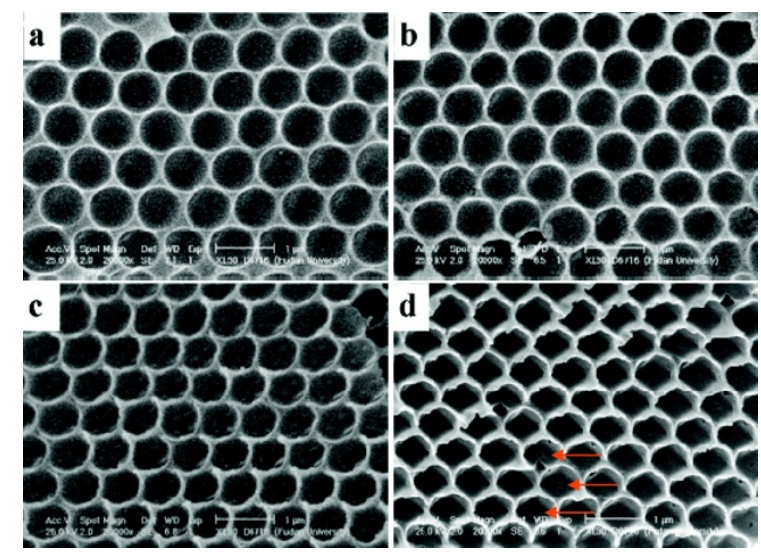

Figure 3. SEM images of the hierarchically ordered meso/macroporous silica samples using a) 0.1 , b) $0.3, \mathrm{c}) 0.5$, and d) $0.8 \mathrm{~g}$ of $2 \mathrm{M} \mathrm{HCl}$ solution. ${ }^{[24]}$ Copyright $^{\odot} 2011$ American Chemical Society.

The alignment of the mesopores can be tuned via changes in solvent polarity. During the synthesis of 3D silicate materials, a polystyrene template is spin-coated with a precursor solution containing pluronic triblock copolymer P123 and tetramethyl orthosilicate (TMOS) in methanol and/or water; the resulting $\mathrm{SiO}_{2}$ mesostructure consists of hexagonally arranged pores parallel to the substrate (Figure 4a). ${ }^{[25]}$ Upon increase of the water content of the precursor solution, hexagonally arranged spherical pores are obtained (Figure $4 \mathrm{~b}, \mathrm{c}$ ) due to an increase in affinity of the polyethylene oxide (PEO) block for the wall. ${ }^{\text {[25] }}$ However, precise control over microporosity is difficult to achieve. ${ }^{[13 b]}$ 

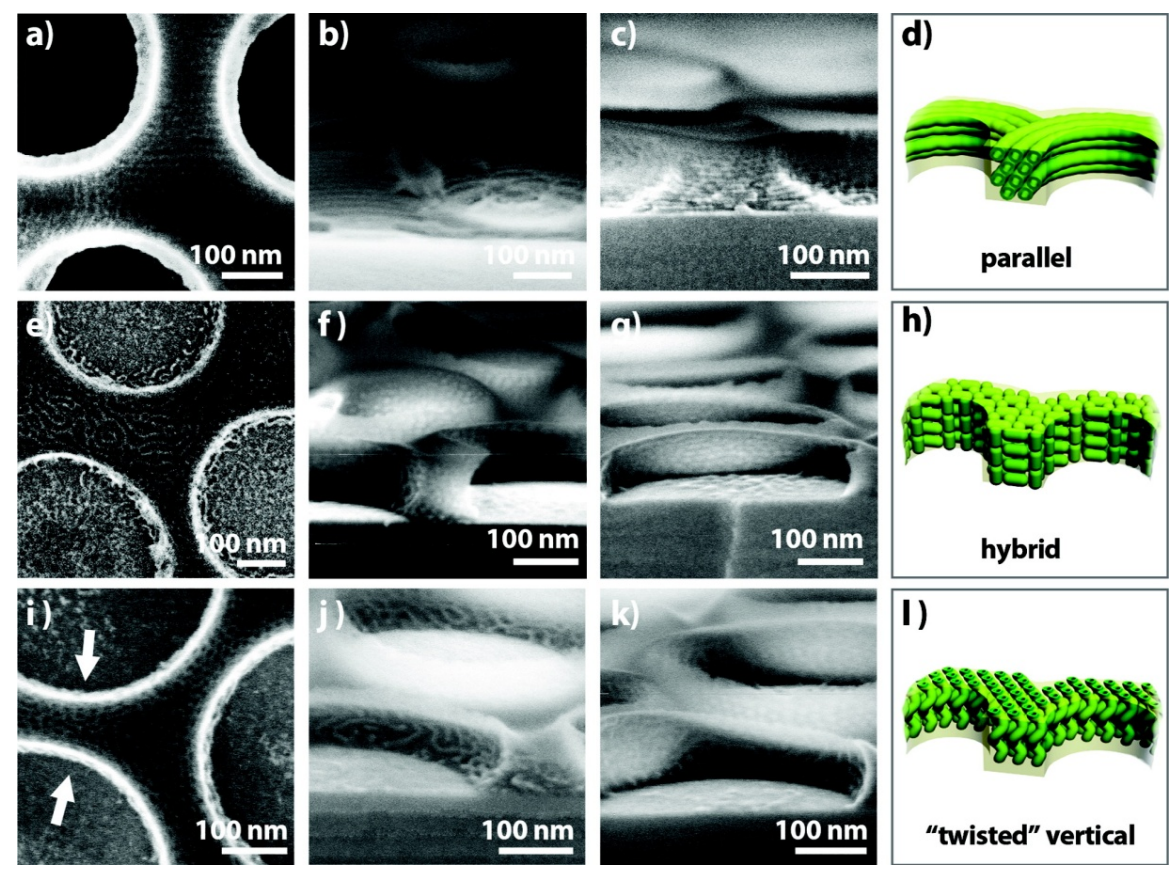

Figure 4. SEM images of textural mesoporosity of $3 \mathrm{DOM} \mathrm{SiO}_{2}$ : a-d) parallel mesopores formed with methanol as the solvent; e-h) transitional mesophases with methanol/water co-solvents; and i-l) possibly vertical mesophase and spherical mesopores formed in water. ${ }^{[25]}$ Copyright $^{\circledR} 2012$ American Chemical Society.

\subsection{Chemical Vapor Deposition (CVD)}

Well-ordered mesoporous carbon materials used as catalysts supports, electrode materials and templates are usually synthesized via sacrificial templating methods ${ }^{[26]}$; mesoporous silica/zeolite is infiltrated with carbon precursors and subjected to carbonization at high temperature and selective removal of the inorganic templates. ${ }^{[26-27]}$ Chemical vapor deposition (CVD) can be successfully used to control morphology, pore size and graphitization in well-ordered mesoporous carbons, leading to enhanced thermal stability and electrical conductivity of the material. ${ }^{[26,28]}$ In general, CVD involves chemical reactions between gaseous reactants in an activating environment, followed by the formation of stable solid product. ${ }^{[29]}$ It is a combination of heterogeneous and homogeneous chemical reactions occurring in the gas phase near a heated surface, leading to the formation of powders, coatings or films. ${ }^{[29-30]}$

As an example of CVD nanocasting, mesoporous silica SBA-15 rods $(\sim 100-400 \mathrm{~nm}$ diameter and $\sim 1-2 \mu \mathrm{m}$ length $)$ have been used as hard templates to nanocast graphitic mesostructured carbon nanotubes and nanorods with tunable pore size. ${ }^{[28 c]}$ The pore size of the carbon is tunable between $\sim 2$ and $4.5 \mathrm{~nm}$ depending on the structure of the SBA-15 template. ${ }^{[28 c]}$ The pore size of silica directs the morphology of the mesoporous carbon. CVD nanocasting of SBA-15 silica rods synthesized at low aging temperature $\left(40\right.$ and $\left.70^{\circ} \mathrm{C}\right)$ leads to the formation of hollow mesoporous carbon rods, whereas SBA-15 rods synthesized at high crystallization temperature $\left(100\right.$ and $\left.130^{\circ} \mathrm{C}\right)$ result in solid-core mesoporous carbon rods (Figure 5). ${ }^{[28 c]}$ 

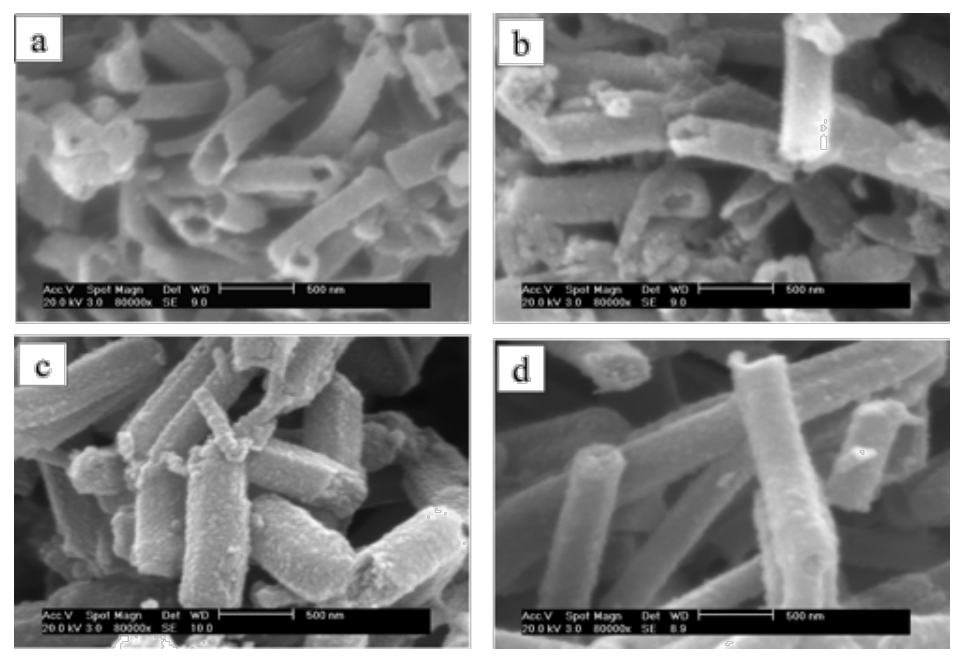

Figure 5. SEM images of graphitic mesoporous carbon materials using various mesoporous silica SBA-15 rods as templates at different aging temperatures: a) $40^{\circ} \mathrm{C}$; b) $70^{\circ} \mathrm{C}$; c) $100^{\circ} \mathrm{C}$; and d) $130^{\circ} \mathrm{C}$. $^{[28 \mathrm{C}]}$ Copyright ${ }^{\circ} 2005$ American Chemical Society.

During the CVD process, the carbon precursor is initially in contact with the surface of SBA-15 silica rods before diffusing into the interior of the rods. In the case of SBA-15 silica templates with small pore diameter, the deposition of carbon on the surface of the silica rods can quickly block the pore channels and impede the diffusion of carbon precursor into the core of the silica rods forming a carbon/silica composite with a carbon-rich, wormhole-type outer shell and an inner core of pure silica (Figure $5 \mathrm{a}, \mathrm{b}){ }^{\left[{ }^{28 c]}\right.}$ On the contrary, SBA-15 silica templates with large pore diameter allow the penetration of acetonitrile into the core of the silica rods, forming uniform carbon/silica composites and, hence, solid-core carbon rods (Figure 5c, d). ${ }^{[28 c]}$

\subsection{Kirkendall Effect}

Hollow nanoparticles with controlled interior void and shell thickness are an important class of nanoporous materials. The most popular method to synthesize hollow nanostructures is the template-mediated approach. ${ }^{[31]}$ By coating the surface of the template particles with desired materials and removing the template via post-treatment, various hollow particles can be easily obtained. ${ }^{[31 \mathrm{a}]}$ However, the main disadvantage of this method is the size limitation, as the hollow particles obtained are larger than $200 \mathrm{~nm}$; furthermore, the post-treatment necessary to remove the templates adds complexity to the whole synthesis procedure and increases the chance of structural deformation and introduction of impurities. ${ }^{[31 \mathrm{a}]}$ To overcome these limitations, novel synthetic strategies are used based on the Kirkendall effect ${ }^{[32]}$ and the galvanic replacement reaction discussed in the next section. ${ }^{[33]}$

The Kirkendall effect is a common phenomenon in metallurgy ${ }^{[34]}$, used to describe the formation of voids at the interface of two metals due to their different inter-diffusion rates. ${ }^{[34 a, 35]}$ In a nanoparticle system, the Kirkendall effect refers to preferred outward elemental diffusion, leading to a net material flux across the spherical interface and the consequent formation of a

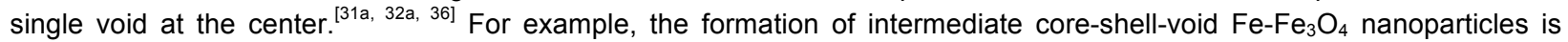
observed during the synthesis of hollow $\mathrm{Fe}_{3} \mathrm{O}_{4}$ nanoparticles. ${ }^{[35]}$ These hollow nanoparticles are prepared by controlled oxidation of amorphous core-shell $\mathrm{Fe}-\mathrm{Fe}_{3} \mathrm{O}_{4}$ obtained via high-temperature, solution-phase decomposition of $\mathrm{Fe}(\mathrm{CO})_{5}$ and air oxidation of the amorphous Fe nanoparticles at room temperature ${ }^{[35]} \mathrm{A}$ dispersion of $\mathrm{Fe}-\mathrm{Fe}_{3} \mathrm{O}_{4}$ nanoparticles in hexane is then added to a mixture of 1-octadecene and trimethylamine $\mathrm{N}$-oxide $\left(\mathrm{Me}_{3} \mathrm{NO}\right)$ and, after calcination at high temperature, hollow $\mathrm{Fe}_{3} \mathrm{O}_{4}$ nanoparticles are produced. ${ }^{[35]}$

An increase in reaction temperature and reaction time results in the formation of a series of intermediate void structures, which serves as evidence of the Kirkendall effect. ${ }^{[35]}$ The rate of core consumption and gap broadening between Fe and $\mathrm{Fe}_{3} \mathrm{O}_{4}$ is significantly enhanced at higher reaction temperatures. The core diameter shrunk to $\sim 5 \mathrm{~nm}$ and the gap between $\mathrm{Fe}$ and $\mathrm{Fe}_{3} \mathrm{O}_{4}$ increased to $2.5 \mathrm{~nm}$ after heating at $210^{\circ} \mathrm{C}$ for $40 \mathrm{~min}$, whereas the core was almost depleted after heating at $210^{\circ} \mathrm{C}$ for $80 \mathrm{~min} .^{[35]}$ The majority of cores disappeared after heating for $2 \mathrm{~h}$ at $210^{\circ} \mathrm{C}$, resulting in the formation of spherical voids in the center of the nanoparticles (Figure 6). 

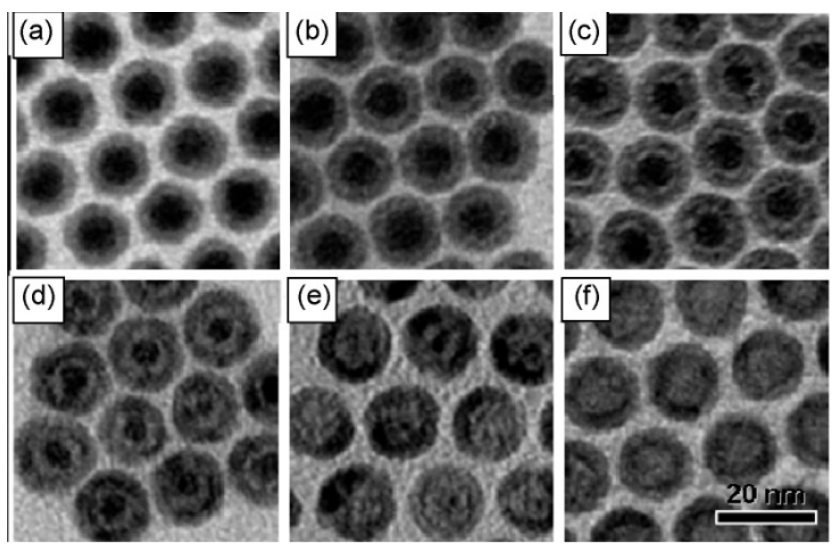

Figure 6. a-f) TEM images showing the shape evolution of $\mathrm{Fe}-\mathrm{Fe}_{3} \mathrm{O}_{4}$ core-shell nanoparticles a) via the Kirkendall effect. Core-shell-void intermediates obtained by the reaction for $1 \mathrm{~h} \mathrm{(b)} \mathrm{and} 2 \mathrm{~h}$ at $130{ }^{\circ} \mathrm{C}$ (c), and $40 \mathrm{~min}$ (d) and $80 \mathrm{~min}$ at $210{ }^{\circ} \mathrm{C}$ (e). Hollow Fe $\mathrm{O}_{4}$ nanoparticles from the reaction for $120 \mathrm{~min}$ at $210^{\circ} \mathrm{C}(\mathrm{f}) .{ }^{[35]}$ Copyright $^{\odot} 2007$ Wiley.

The Kirkendall effect can also be employed for the fabrication of 1-D hollow nanomaterials such as $\mathrm{ZnAl}_{2} \mathrm{O}_{4}$ via solid-solid

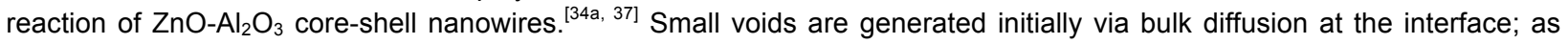
diffusion progresses, the number of voids in contact with the inner surface of the shell increases and, thus, the surface diffusion of atoms of the core material becomes dominant along the skeletal bridges. This observation suggests that surface diffusion processes might be the dominant mass flow mechanism for the growth of the interior pores after their initial nucleation and formation due to the Kirkendall effect. ${ }^{[34 a, 38]}$

\subsection{Galvanic Replacement Reaction}

The galvanic replacement reaction provides a simple and versatile route for the synthesis of hollow metal nanoparticles. ${ }^{[33 \mathrm{~b},}$ ${ }^{39]}$ The electrochemical potential difference between two metals drives the reaction, with one metal serving as the cathode and the other one as the anode. ${ }^{[39 b, 40]} \mathrm{A}$ common example is the zinc $(\mathrm{Zn}) /$ copper $(\mathrm{Cu})$ couple; the $\mathrm{Zn}{ }^{2+} / \mathrm{Zn}$ reduction potential $\left(-0.76 \mathrm{~V}\right.$ vs. SHE) is more negative than the $\mathrm{Cu}^{2+} / \mathrm{Cu}$ potential $(0.34 \mathrm{~V}$ vs. SHE), resulting in the oxidation of $\mathrm{Zn}$ to $\mathrm{Zn}^{2+}$ and the reduction of $\mathrm{Cu}^{2+}$ to $\mathrm{Cu}^{[39 \mathrm{~b}, 41]}$

Hollow metal $\mathrm{Au}, \mathrm{Pt}$ and $\mathrm{Pd}$ nanocubes are synthesized via galvanic replacement using $\mathrm{Ag}$ as the sacrificial template for the formation of metal nanostructures. ${ }^{[33 \mathrm{~b}, 39 \mathrm{a}, 39 \mathrm{~b}, 39 \mathrm{~d}-\mathrm{g}]}$ The standard reduction potential of $\mathrm{AgCl} / \mathrm{Ag}$ is $0.22 \mathrm{~V}$ (vs. SHE), which is low compared to the standard potential of $\mathrm{AuCl}_{4}{ }^{-} / \mathrm{Au}$ (0.99 V vs. SHE), $\mathrm{PdCl}_{4}{ }^{2-} / \mathrm{Pd}\left(0.59 \mathrm{~V}\right.$ vs. SHE) and $\mathrm{PtCl}_{4}{ }^{2-} / \mathrm{Pt}(0.76 \mathrm{~V} \mathrm{vs}$. $\mathrm{SHE}$ ). Hence, when silver nanoparticles co-exist with $\mathrm{AuCl}_{4}{ }^{-}$ions in the solution, $\mathrm{Ag}$ nanocubes are oxidized by $\mathrm{HAuCl}_{4}$ according to the following reaction:

$$
3 \mathrm{Ag}+\mathrm{HAuCl}_{4} \rightarrow \mathrm{Au}+3 \mathrm{AgCl}+\mathrm{HCl}
$$

The produced $\mathrm{Au}$ is confined to the nanocube surface, growing on the cube and adopting its morphology, as interior Ag is oxidized to produce a hollow structure. ${ }^{[33 \mathrm{~b}]}$ The morphological changes at the Ag surface at various stages of the galvanic replacement reaction can be observed by scanning electron microscopy (SEM) and transmission electron microscopy (TEM). Once Ag nanocubes react with $\mathrm{HAuCl}_{4}$, a pinhole is created on one of the six facets of each cube (Figure 7) revealing that the reaction is initiated at a high energy site. ${ }^{[33 b]}$ As the galvanic replacement reaction proceeds, the pinhole serves as the anode where $\mathrm{Ag}$ is oxidized ${ }^{[33 \mathrm{~b}]}$; the released electrons migrate to the facets of the cube and are captured by $\mathrm{AuCl}_{4}{ }_{4}$, generating Au atoms that epitaxially grow on the nanocube. ${ }^{[33 \mathrm{~b}]}$ 

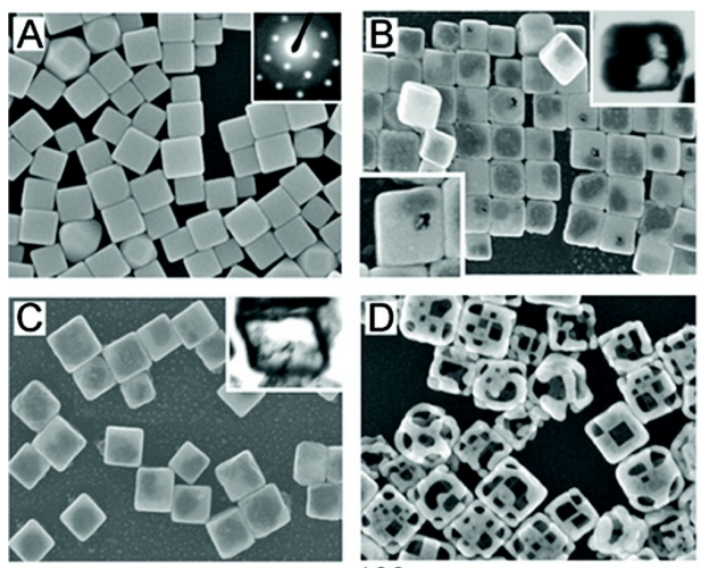

$-100 \mathrm{~nm}$

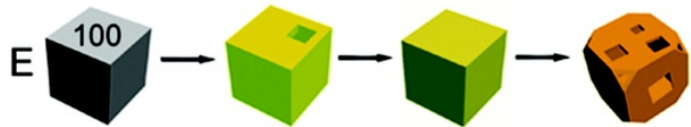

Figure 7. a) SEM of Ag nanocubes; b) SEM of product after addition of $0.30 \mathrm{~mL}$ of $1 \mathrm{mM} \mathrm{HAuCl}$ solution to a 5 -mL $0.8 \mathrm{mM}$ Ag nanocube suspension; a pinhole (lower inset) is observed on the exposed face of $\sim 1$ in 6 nanocubes and TEM (upper inset) of a microtomed sample reveals early hollowing out; c) SEM of product after addition of $0.50 \mathrm{~mL}$ of $\mathrm{HAuCl}_{4}$ solution; TEM (inset) of a microtomed sample reveals the hollow interior of the nanobox; d) SEM of product after addition of $2.25 \mathrm{~mL}$ of $\mathrm{HAuCl}_{4}$ solution; porous nanocages are produced; e) illustration summarizing morphological changes. ${ }^{\text {[33b] }}$ Copyright $^{\odot} 2008$ American Chemical Society.

The same experimental procedure can be used to produce $\mathrm{Pt}$ and $\mathrm{Pd}$ nanoboxes where $\mathrm{Na}_{2} \mathrm{PtCl}_{4}$ and $\mathrm{Na}_{2} \mathrm{PdCl}_{4}$ are used as the starting solutions. However, the observed morphological changes are different from those with the Au/Ag couple. In the case of Pt nanocubes, the structure consists of rough walls, due to the lack of solid-solid inter-diffusion between $\mathrm{Pt}$ and $\mathrm{Ag}$ (Figure S1, Supplementary Information). ${ }^{[3 \mathrm{~b}]}$ On the contrary, solid-solid inter-diffusion does take place in the Pd/Ag system, even though pore formation on the structure is blocked by creating a $\mathrm{Pd} / \mathrm{Ag}$ alloy. ${ }^{[33 \mathrm{~b}]}$

\subsection{Selective Leaching}

Hierarchical metal oxides can be synthesized by selective leaching of the sacrificial phase of the precursor used ${ }^{[42]}$ For the synthesis of $\mathrm{Ni}_{1-\mathrm{x}} \mathrm{Zn}_{\mathrm{x}} \mathrm{O}$ metal oxides ${ }^{[42 \mathrm{e}]}$, a composite with two immiscible phases ( $\mathrm{NiO}$ and $\mathrm{ZnO}$ ) is obtained from $\mathrm{Ni}^{\prime \prime}$ and $\mathrm{Zn}^{\prime \prime}$ nitrates in solution with urea by evaporation and combustion (Figure 8a and b). Combustion followed by sintering leads to a monolith consisting of $\mathrm{NiO}$ and $\mathrm{ZnO}$ particles (Figure $8 \mathrm{c}$ ). The $\mathrm{ZnO}$ particles are leached in alkali to form macroporous $\mathrm{NiO}$ (Figure $8 \mathrm{~d}$ ), which is reduced in $\mathrm{H}_{2} / \mathrm{Ar}$ to yield macroporous $\mathrm{Ni}$ metal (Figure 8e). During NiO reduction, $\mathrm{ZnO}$ is removed from the $\mathrm{Ni}$ matrix, resulting in additional porosity of the $\mathrm{Ni}_{1-\mathrm{x}} \mathrm{Zn}_{\mathrm{x}} \mathrm{O}$ (Figure $8 \mathrm{e}$ ). ${ }^{[42 \mathrm{~b}, 42 \mathrm{e}, 43]}$ 


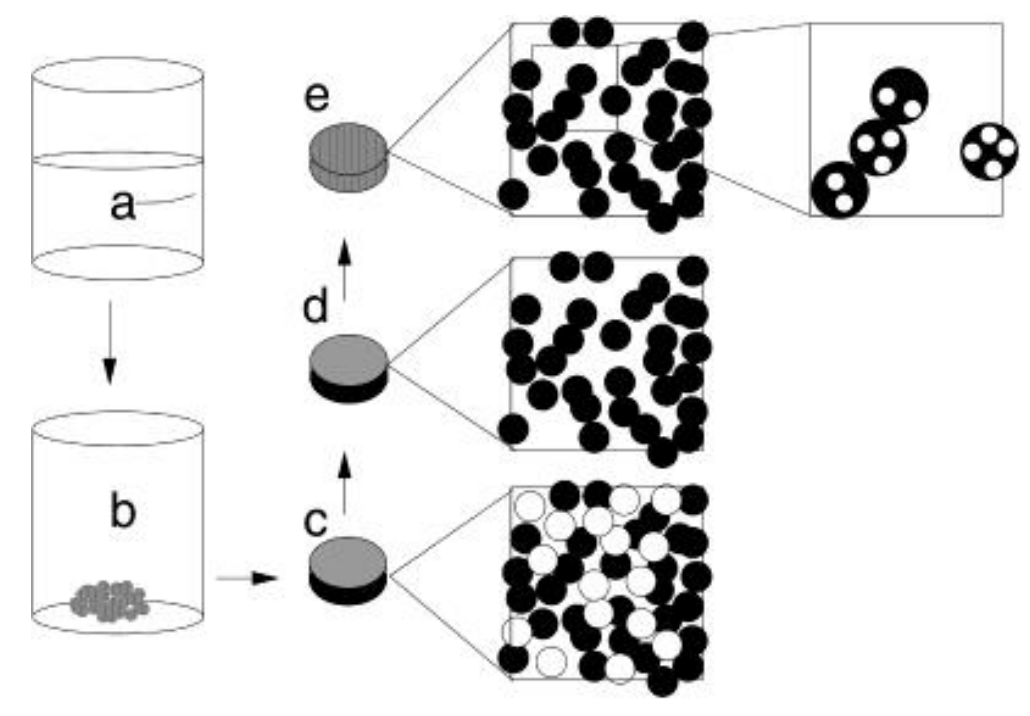

Figure 8. Scheme for the generation of macroporous materials starting with the combustion synthetic preparation of an intimate mixture of two metal oxides. Starting from $\mathrm{Ni}^{\prime \prime}$ and $\mathrm{Zn}$ " nitrates in solution with urea as the fuel "a", combustion synthesis yields an intimate mixture of the oxides "b", which is sintered to form the monolith "c". The $\mathrm{ZnO}$ in monolith is leached by alkali to yield a macroporous oxide "d". Reduction of "d" should yield macroporous $\mathrm{Ni}$ metal "e", but closer examination reveals that, in addition, $\mathrm{ZnO}$ is removed from "d" on reduction, giving rise to another level of porosity. ${ }^{[42 \mathrm{e}]}$ Copyright $^{\oplus} 2002$ American Chemical Society.

Hierarchically porous $\mathrm{MnO}$ is synthesized via reduction of sintered $\mathrm{Mn}_{3} \mathrm{O}_{4}$ pellets, with the concurrent loss of volume being accommodated through the formation of mesopores. ${ }^{[4]}$ Mesopore formation is regenerative, as mesoporosity is lost and regained through oxidation and reduction of $\mathrm{Mn}_{3} \mathrm{O}_{4}$. Oxidation of the final $\mathrm{MnO}$ material results in closing the mesopores without the macropore morphology being altered, whereas reduction of $\mathrm{Mn}_{3} \mathrm{O}_{4}$ to $\mathrm{MnO}$ retains the mesopore network and pore connectivity (Figure $9 \mathrm{~b}$ and $\mathrm{c}){ }^{[44 \mathrm{c}]}$
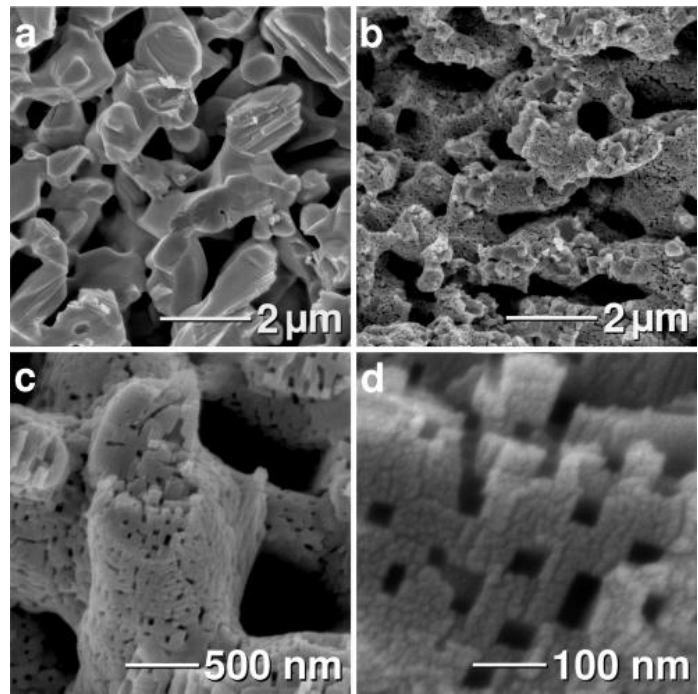

Figure 9. a) SEM images of a $\mathrm{Mn}_{3} \mathrm{O}_{4}$ pellet formed under conditions that produce porosity; b) reduction of the $\mathrm{Mn}_{3} \mathrm{O}_{4}$ monolith to $\mathrm{MnO}$ retains the macroporosity and induces large mesopores in the macropore walls, seen clearly at higher magnification in c); d) on close inspection, the mesopores are found to be $50 \mathrm{~nm}$ on edge and square in shape ${ }^{[44]}$ Copyright ${ }^{\odot} 2006$ American Chemical Society. 


\subsection{Aerogels and Porogens}

Recently, research has focused on the synthesis and utilization of support-less hybrid aerogels of metal nanoparticles (such as $\mathrm{Pd}, \mathrm{Pt}, \mathrm{Au}$ and $\mathrm{Ag}$ ) as catalysts for ethanol and oxygen reduction reactions. ${ }^{[45]}$ These novel materials combine the highly porous structure of aerogels with the catalytic properties of metal nanoparticles and are formed via two different routes. ${ }^{[45 a-c]}$

In the first route (Figure 10 - strategy I), metallic nanoparticles are formed via reduction of the metal precursor (such as $\mathrm{HAuCl}_{4}, \mathrm{AgNO}_{3}, \mathrm{H}_{2} \mathrm{PtCl}_{6}$, or $\mathrm{PdCl}_{2}$ ) followed by gelation of the preformed metal nanoparticles, while in the second route (Figure 10 - strategy II), the hydrogels are spontaneously formed from the in-situ reduction of noble metal precursors with sodium borohydride $\left(\mathrm{NaBH}_{4}\right)$ in a single step (without the preformation of metallic nanoparticles). ${ }^{[45]}$ The final step involves the supercritical drying of the hydrogel to obtain the hybrid metallic aerogel. However, this sol-gel procedure for the synthesis of composite metallic aerogels is difficult, expensive and toxic.

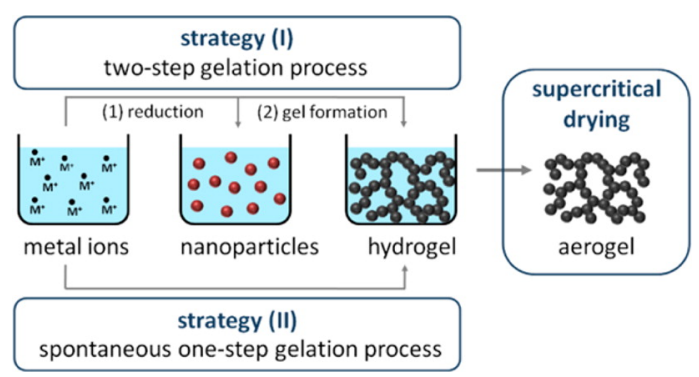

Figure 10. Synthesis of hybrid metallic aerogels via gelation of preformed nanoparticles (strategy I) or spontaneous gelation (strategy II). ${ }^{[45 a]}$ Copyright ${ }^{\odot}$ 2015 Wiley.

Alternatively, the use of gas bubbles (generated in a liquid phase chemical reaction) as a porogen for the synthesis of hollow nanoparticles offers a novel, simple and effective approach avoiding the introduction of impurities, such as surfactants. ${ }^{[1,46]}$ The gas bubbles create numerous gas-liquid interfaces inside the continuous solution phase and act as the nucleation and agglomeration centers for the nanocrystals. ${ }^{[46 l]}$ The nucleation and agglomeration process is thermodynamically favorable; the forces on the solvent molecules at the gas bubbles / bulk liquid interface are asymmetric and in need of nanocrystals to stabilize, while the nanocrystals are characterized by high surface tension that has to be released in order to reach a stable state. As a result, the nanocrystals move into the gas bubbles / bulk liquid interface and once their concentration is sufficiently high, the nanocrystals interact with each other to form hollow microspheres using the gas bubbles as porogens. ${ }^{[461]}$

ZnSe hollow microspheres were synthesized based on this method. ${ }^{[1]}$ After the initial nucleation, ZnSe monomers grow into nanocrystals (Figure 11a) that aggregate on the surface of $\mathrm{N}_{2}$ micro-bubbles produced during the reaction between salts of $\mathrm{ZnO}_{2}{ }^{2-}$ and $\mathrm{SeO}_{3}{ }^{2-}$ ions and hydrazine $\left(\mathrm{N}_{2} \mathrm{H}_{4}\right)$ (Figure $11 \mathrm{~b}$ ), resulting in the formation of hollow ZnSe microspheres (Figure 11c). ${ }^{[1]}$

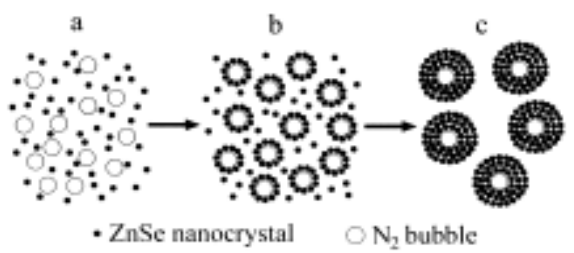

Figure 11. Formation mechanism of ZnSe microspheres via gas bubbles. ${ }^{[1]}$ Copyright $^{(0)} 2003$ Wiley.

\subsection{Synthesis Methods: Summary and Outlook}

To summarize this section, one of the key goals of research on nanoporous materials over the past two decades has been the development of methods to precisely control the structure at different length scales (macro-, meso- and nanoscale). ${ }^{[4]}$ The most common route to achieve this goal is the use of templates that determine the shape and size of the final hierarchical structure. Hard templating is the dominant synthesis technique used thus far, despite its complexity and high 
cost; we firmly believe that the development of new and versatile synthesis methods based on porogens and aerogels (such as gas bubbles, composite aerogels with metal oxides, etc.) will provide a facile, environmentally friendly and more costeffective route to easily tunable hierarchical structures and lead to research breakthroughs. Table 1 summarizes the advantages and disadvantages of the various techniques utilized today for the synthesis of hierarchical nanostructures, inspired by the comparison table by Chal et al. ${ }^{[4]}$, which was used to assess different synthesis strategies towards zeolites with mesopores. The differently grouped synthesis methods have been judged concerning their manufacturing costs, HealthSafety-Environmental (HSE) issues, synthesis procedure, production yield, the predetermined mesoporosity and the foreseen chance on a future breakthrough development.

Hard templates such as polystyrene spheres, colloidal silica and metal oxides are extensively used to get hierarchical structures with well-defined shapes. ${ }^{[49]}$ The control over the structure at the various length scales as well as the ease of synthesis and commercial availability of the templates make this method ideal for the synthesis of hierarchical structures; however, the major drawback is the post-processing to remove the template that adds complexity to the whole synthetic process and increases the chance of structural deformation and introduction of impurities. ${ }^{[50]}$ Chemical etching or calcination at high temperatures are frequently used for this purpose, leading to particle size growth of the oxide formed that destroys the pore solid architecture and the interconnected porosity of the material. ${ }^{[47,51]}$

To mitigate these problems, simpler synthetic approaches have been adopted. Templating against soft (liquid or gaseous) templates such as surfactant micelles, emulsion droplets or gas bubbles has attracted the greatest attention and significant progress has been made during the past decades. ${ }^{[46 f, 49,52]}$ The liquid character of the emulsion droplets allows the fast and efficient removal of these liquid templates by evaporation or dissolution in common solvents, like ethanol. ${ }^{[53]}$ Moreover, the high deformability of the emulsion droplets allows them to accommodate a larger level of shrinkage reducing the risk of structure deformation (cracking) during drying or calcination post-treatment. ${ }^{[46]}$ Despite the attractive advantages of soft templating, the control of the shape, size and uniformity of the synthesized hierarchical material is difficult in comparison to hard templating, as it is sensitive to many parameters such as $\mathrm{pH}$, reaction conditions, solvent and ionic strength. ${ }^{[46 f, 49]}$

Apart from the use of polymeric and inorganic non-metal templates for the synthesis of hierarchical materials, metal templates can also be used. The metal templates have a dual role: they act as the reactant during the synthesis procedure and as the initial template, which dictates the architecture in the nanostructure, the void space and the wall thickness of the formed hollow nanoparticles. Generally, two formation mechanisms, the Kirkendall effect and galvanic replacement, have been used to understand the fundamentals of hollow spheres synthesized by metallic templates. ${ }^{[35,36 f, 54]}$

The galvanic replacement reaction provides a facile, high-quality and reproducible process for synthesizing hollow nanoparticles without post-treatment. ${ }^{[54 a]}$ Galvanic replacement occurs spontaneously when the atoms of one metal react with ions of another metal having a higher electrochemical potential in a solution phase. The atoms of the first metal are oxidized and dissolved into the solution, while the ions of the second metal are reduced and plated on the surface of the first metal. ${ }^{[5]}$ Reactions take place in water at medium temperatures and a very limited amount of reagents is used other than the initial template. ${ }^{[5]}$ Despite the simplicity of this method, galvanic replacement is used to synthesize a wide variety of nanostructures of controlled composition and porosity, such as hollow / alloyed nanoparticles with tunable optical properties. $^{[32 a, 33 b, 54 a, 54 e, 54 k, 55]}$ However, as the galvanic replacement reaction itself involves dissolution of the template structures accompanied by simultaneous deposition on the surface of templates, it is difficult to precisely control the ridge thickness of the final nanostructure. ${ }^{[54 \mathrm{e}, 56]}$ Furthermore, this method is susceptible to surfactant impurities, resulting in selective reaction on specific facets and segregation of alloy components. ${ }^{[5]}$

The Kirkendall effect can also be successfully used for the synthesis of hollow and tubular nanostructures. ${ }^{[32 a, 54 e]}$ It is a vacancy mediated mechanism based on the mutual diffusion process through the interface of two metals of different diffusivities where vacancy diffusion occurs to compensate for the inequality of the material flow. ${ }^{[32 a, 36 n, 49,54 \text { e] }}$ It is a simple, cost-efficient and rapid one-pot synthesis method with nearly $100 \%$ selectivity. ${ }^{[32 a]}$ There is a need, though, to better understand the mechanism of the Kirkendall effect during anion exchange or partial anion / partial cation exchange; anions diffuse more slowly than cations due to their larger size and, hence, longer reaction times and calcination temperatures are required. ${ }^{[54 a]}$ The slow reaction kinetics can be advantageous for obtaining control over reaction intermediates that will result in improved morphological control and, thus, lead to heterostructured or hybrid nanoparticles with tunable structure and properties. $^{[54 a, 57]}$

Based on the preceding discussion, it is clear that the templating methods are very effective and versatile in terms of synthesizing hierarchical structures, but their high cost and tedious synthetic procedure have prohibited their usage in large scale applications. Ideally, a single-step template-free method for the synthesis of hierarchical structures of different sizes 
would be preferred. Ostwald ripening has recently been proposed as an effective template-free method for the synthesis of such structures. It combines the advantages of hard and soft templating while avoiding their pitfalls ${ }^{[54 \mathrm{k}]}$; uniform meso- and nanostructures of controlled size have been prepared. ${ }^{[49,54 k, 58]}$ However, further research is needed to provide fundamental information about the formation mechanism of these hierarchical materials.

Table 1. Summary of the various advantages and disadvantages of the synthesis techniques of hierarchical nanoparticles.

\begin{tabular}{|c|c|c|c|c|c|c|c|}
\hline & $\begin{array}{l}\text { Formation } \\
\text { Route }\end{array}$ & Production cost & $\begin{array}{l}\text { HSE (Health } \\
\text { safety } \\
\text { environment) } \\
\text { issues }\end{array}$ & $\begin{array}{l}\text { Synthesis } \\
\text { procedure }\end{array}$ & Yield & $\begin{array}{l}\text { Predestined } \\
\text { mesoporous } \\
\text { architecture }\end{array}$ & $\begin{array}{l}\text { Breakthrough } \\
\text { development } \\
\text { expected }\end{array}$ \\
\hline \multirow{2}{*}{ 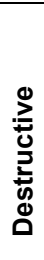 } & $\begin{array}{l}\text { Galvanic } \\
\text { Replacement } \\
\text { Reaction }\end{array}$ & Low & No (non-toxic) & Simple & High & Yes & No \\
\hline & $\begin{array}{l}\text { Kirkendall } \\
\text { Effect }\end{array}$ & Low & No (non-toxic) & Simple & High & Yes & No \\
\hline \multirow{3}{*}{ 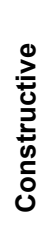 } & \multirow[t]{2}{*}{$\begin{array}{l}\text { Aerogels \& } \\
\text { Porogens }\end{array}$} & $\begin{array}{l}\text { Medium } \\
\text { (aerogels) }\end{array}$ & Yes (aerogels) & Simple & High & No & Yes \\
\hline & & $\begin{array}{l}\text { Low } \\
\text { bubbles) }\end{array}$ & $\begin{array}{l}\text { No } \\
\text { bubbles) }\end{array}$ & & & & \\
\hline & $\begin{array}{l}\text { Hard } \\
\text { Templating }\end{array}$ & High & Yes & Difficult & Low & Yes & No \\
\hline
\end{tabular}

\section{Applications}

\subsection{Lithium Ion Batteries}

Hierarchical 3DOM carbon materials are mainly used as active electrodes in lithium batteries due to their high surface area, high effective ionic conductivity of the electrolyte within the 3DOM matrix and their interconnected wall structure that provides a continuous pathway for Li-ions to reach the porous surface, resulting in good electrical conductivity. ${ }^{\text {[9a, 26a, 59] }}$

3DOM carbon materials are prepared via the colloidal crystal templating introduced in Section 1.1. ${ }^{[26]}$ Polymethyl methacrylate (PMMA) colloidal crystals $(\sim 433 \mathrm{~nm})$ are used as the starting template; after infiltration with silicate/poly(oxyethylene) surfactant solution, followed by calcination to remove $\mathrm{PMMA}, 3 \mathrm{DOM} / \mathrm{m} \mathrm{SiO} \mathrm{monoliths}_{2}$ are obtained with macropores of $\sim 300 \mathrm{~nm}$ diameter and pore windows of $\sim 100 \mathrm{~nm}$ (Figure 12a-d). ${ }^{[26 a]} 3 \mathrm{DOM} / \mathrm{m} \mathrm{SiO} 2$ is used as the hard template to prepare its carbon replica $3 \mathrm{DOM} / \mathrm{m} \mathrm{C}$ by gas-phase polymerization, carbonization and hydrofluoric acid etching to remove the silica. Nitrogen doped graphite is then incorporated into $3 \mathrm{DOM} / \mathrm{m} \mathrm{C}$ via CVD using acetonitrile as a precursor leading to the final product, namely $3 \mathrm{DOM} / \mathrm{m}$ amorphous carbon/graphitic carbon nanocomposite $(3 \mathrm{DOM} / \mathrm{mC} / \mathrm{C}){ }^{[26 \mathrm{a}]}$ The deposition time affects the growth of the macropore walls, the diameter of which is $\sim 58 \mathrm{~nm}$ after $2 \mathrm{~h}$ CVD and increases to $\sim 90 \mathrm{~nm}$ after $5 \mathrm{~h}$ deposition (Figure 12e-f). ${ }^{[26 a]}$ The addition of the graphitic phase increases the electronic conductivity of porous carbon and the lithium capacity at high charge and discharge rates (Figure S2, Supplementary Information), indicating that hierarchical porosity can be used to tune the properties of the material. ${ }^{[26 a]}$ 


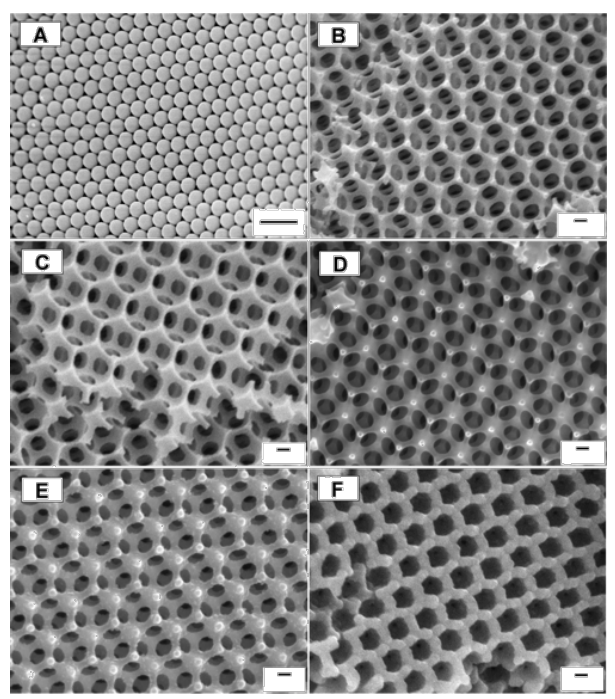

Figure 12. SEM images at different processing stages of 3DOM carbon: a) PMMA colloidal crystal template (scale bar: $1 \mu \mathrm{m}$ ); b) $3 \mathrm{DOM} / \mathrm{m} \mathrm{SiO}{ }_{2}$ monolith synthesized with PMMA as template (scale bar: $100 \mathrm{~nm}$ ); c) $3 \mathrm{DOM} / \mathrm{m} \mathrm{Al}-\mathrm{SiO}_{2}$ monolith, obtained from aluminum impregnation of the $3 \mathrm{DOM} / \mathrm{m}$ $\mathrm{SiO}_{2}$ monolith (scale bar: $100 \mathrm{~nm}$ ); d) $3 \mathrm{DOM} / \mathrm{mC}$, after introduction of polymer, carbonization, and removal of silica with $\mathrm{HF}$ (scale bar: $100 \mathrm{~nm}$ ); e) Carbon/carbon nanocomposites-2h and f) Carbon/carbon nanocomposites-5h carbon/graphite composite monoliths after CVD reaction times of 2 and $5 \mathrm{~h}$, respectively (scale bar: $100 \mathrm{~nm}$ ). ${ }^{[26 a]}$ Copyright $^{\odot} 2006$ American Chemical Society.

PMMA templates are frequently used to synthesize porous lithium iron phosphate $\left(\mathrm{LiFePO}_{4}\right)$. Even though non-porous $\mathrm{LiFePO}_{4}$ is commonly used as a cathode material in lithium ion batteries due to its high capacity $\left(\sim 170 \mathrm{mAhg}^{-1}\right)$, low cost and toxicity. ${ }^{[60]}$, the low intrinsic conductivity of $\mathrm{LiFePO}_{4}{ }^{[60 \mathrm{a}, 60 \mathrm{c}, 61]}$ limits its application at high power. ${ }^{[60-62]}$ To circumvent this issue, porous $\mathrm{LiFePO}_{4}$ (Figure 13) is used to increase the available interfacial area and decrease the lithium-ion diffusion distance, which increases the charge transport and power capability. ${ }^{[60 \mathrm{a}, 60 \mathrm{~b}, 63]}$ For example, ${ }^{6 i F e P O_{4}}$ prepared with $270 \mathrm{~nm}$ PMMA templates offers high surface area and improved access to the active $\mathrm{LiFePO}_{4}$, resulting in a discharge capacity of

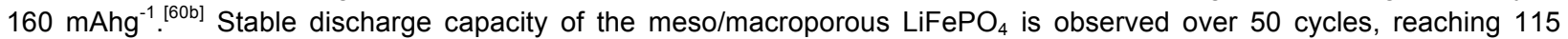
$\mathrm{mAhg}^{-1}$ and $93 \mathrm{mAhg}^{-1}$ at $75 \mathrm{~min}$ and $150 \mathrm{~min}$ discharge, respectively, indicating the high stability of this material under cycling at high discharge rates (Figure S3, Supplementary Information). ${ }^{[60 b]}$
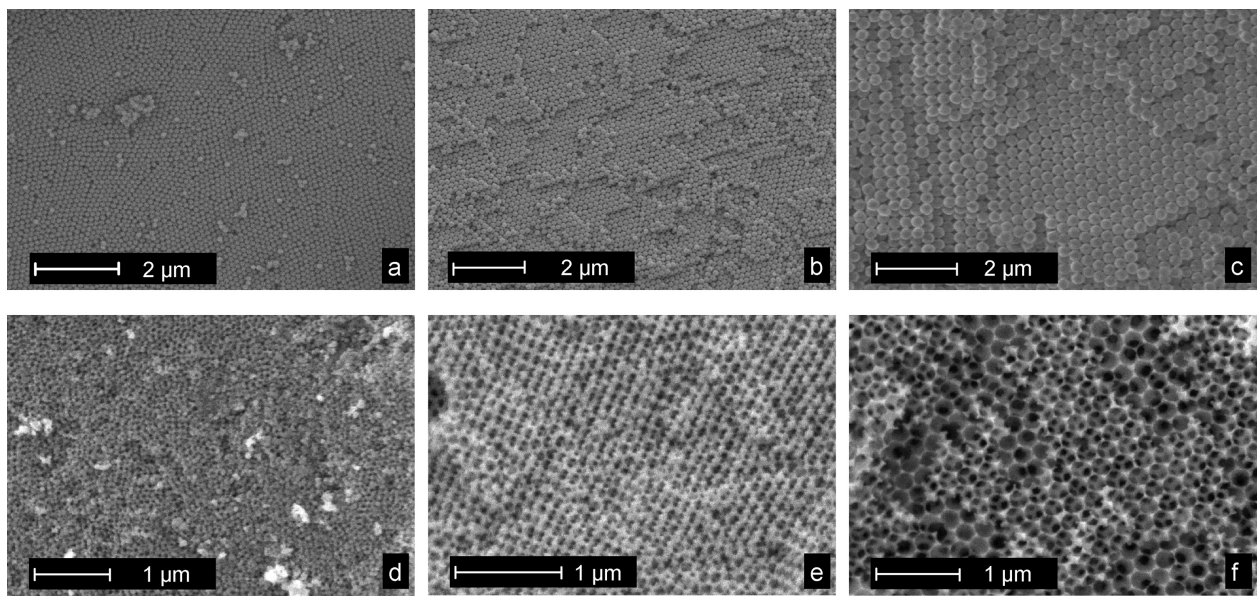

Figure 13. SEM images of the colloidal crystal templates (top) and associated $\mathrm{LiFePO}_{4}$ templated samples calcined at $500{ }^{\circ} \mathrm{C}$ (bottom) formed using PMMA beads of diameter (a, d) 100, (b, e) 140, and (c, f) $270 \mathrm{~nm}$, respectively. ${ }^{[60 \mathrm{~b}]}$ Copyright ${ }^{\odot} 2009$ American Chemical Society.

However, the porous $\mathrm{LiFePO}_{4}$ materials synthesized by PMMA templates are not spherical, which reduces their packing density and power capability. ${ }^{[63]} \mathrm{A} 3 \mathrm{D}$ nanoporous sphere is the optimal structure for $\mathrm{LiFePO}_{4}$ in order to obtain high power output without compromising density. Spray pyrolysis can be used for the synthesis of such 3D nanoporous, spherical 
nanomaterials with well interconnected pores, providing full access of the electrolyte into the inner part of the $\mathrm{LiFePO}_{4}$ sphere (Figure 14). ${ }^{[63]}$ The $\mathrm{LiFePO}_{4} / \mathrm{C}$ spheres consist of interconnected hierarchically organized pores, creating 3D electronic and ionic pathways that enhance lithium ion diffusion and electron migration in the liquid and solid phases, respectively. ${ }^{[63]}$
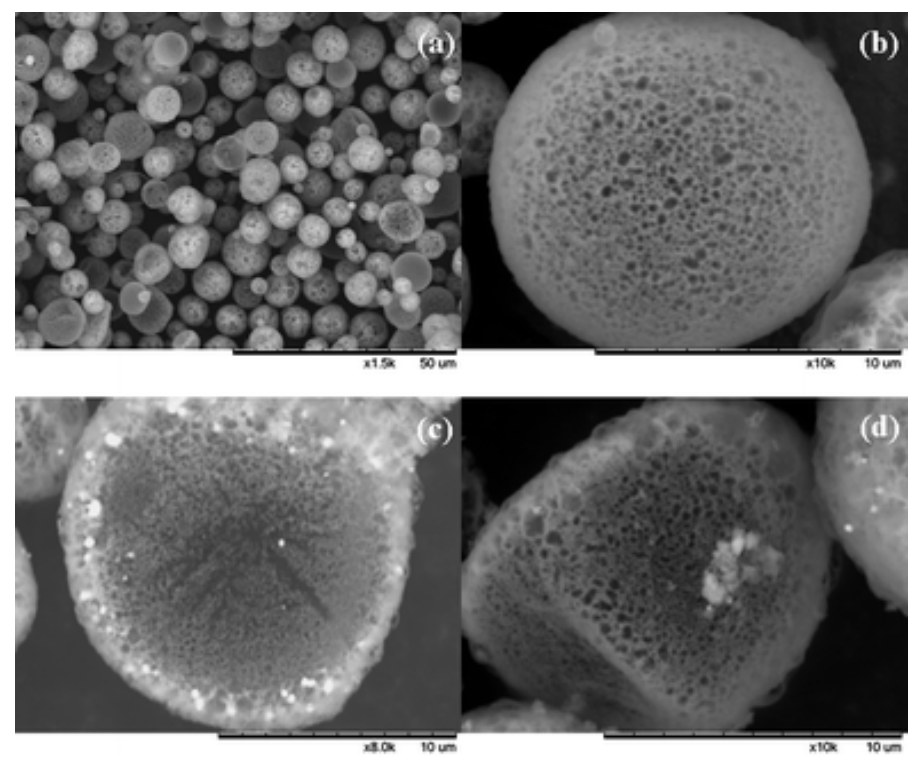

Figure 14. SEM images of a) 3D nanoporous $\mathrm{LiFePO}_{4} / \mathrm{C}$ spheres; b) the surface of a single sphere; $\mathrm{c}$ and d) cross-sections of spheres, showing the interconnected pores ${ }^{[63]}$ Copyright $^{\oplus} 20011$ Royal Society of Chemistry.

At low rates $\left(\sim 20 \mathrm{mAg}^{-1}\right)$, the capacity of $3 \mathrm{D} \mathrm{LiFePO}_{4} / \mathrm{C}$ is $165 \mathrm{mAhg}^{-1}$ - close to the theoretical value of $170 \mathrm{mAhg}{ }^{-1}-$ with $100 \%$ retention over 100 cycles (Figure S4a, Supplementary Information). At high rates $\left(\sim 1700 \mathrm{mAg}^{-1}\right)$, the capacity retention over 100 cycles is $98 \%$ and the average Coulombic efficiency is 99\%, indicating the suitability of the material for high power applications. ${ }^{[63]}$ Furthermore, $\mathrm{LiFePO}_{4} / \mathrm{C}$ demonstrates superior rate capability, reaching specific capacities of $\sim 123 \mathrm{mAhg}^{-1}$ and $\sim 106 \mathrm{mAhg}^{-1}$ at $10 \mathrm{C}$ and $20 \mathrm{C}$ respectively (Figure S4b, Supplementary Information). ${ }^{[63]}$

Another widely used metal oxide is lithium manganese oxide $\left(\mathrm{LiMn}_{2} \mathrm{O}_{4}\right)$, due to its high theoretical capacity $\left(\sim 150 \mathrm{mAhg}{ }^{-1}\right)$, which is similar to the capacity of the commercially used $\mathrm{LiCoO}_{2}{ }^{[64]} 3 \mathrm{DOM} \mathrm{LiMn}_{2} \mathrm{O}_{4}$ is synthesized via the colloidal templating method ${ }^{[65]}$; the ordered hollow spheres consist of a $\{1,1,1\}$ and $\{1,0,0\}$ lattice with $\sim 355 \mathrm{~nm}$ macropores and $\sim 8$ $12 \mathrm{~nm}$ wall thickness with a surface area of $24 \mathrm{~m}^{2} \mathrm{~g}^{-1}$ (Figure S5, Supplementary Information). Capacity stabilizes at $\sim 90 \%$ of the initial value, indicating the good cyclic stability of the material, while the original capacity of the material is fully regained at low rates. ${ }^{[65]}$

Apart from the above mentioned hierarchical porous materials, several other ordered macro/mesoporous metal oxides are used in lithium batteries, including $\mathrm{SnO}_{2}{ }^{[66]}, \mathrm{V}_{2} \mathrm{O}_{5}{ }^{[67]}, \mathrm{Co}_{3} \mathrm{O}_{4}{ }^{[68]}, \mathrm{NiO}^{[69]}, \mathrm{TiO}_{2}{ }^{[70]}, \mathrm{LiCoO}_{2}{ }^{[71]}$ and $\mathrm{LiNiO}_{2} .^{[72]}$

To sum up, the utilization of hierarchically ordered nanoporous metal oxides as cathode materials in lithium batteries enhances the rate performance of batteries, since the well interconnected wall structures provide continuous electrical pathways, increasing the conductivity of these materials.

\subsection{Photocatalysis}

Another application of hierarchical materials is in photocatalysis, which involves the absorption of photons by a molecule or substrate to produce highly reactive electronically excited states. ${ }^{[73]}$ Photo-induced molecular reactions occur at the surface of the catalyst ${ }^{[73 \mathrm{~b}]}$ and can be divided into catalyzed or sensitized photoreactions, depending on the location where the initial excitation occurs. ${ }^{[73]}$ In a catalyzed photoreaction, the initial photo-excitation takes place in an adsorbate molecule that interacts with the ground state catalyst substrate; whereas, in a sensitized photoreaction, the initial photo-excitation occurs in the catalyst substrate, which, in turn, transfers electrons into a ground state molecule. ${ }^{[73]}$ 
The initial excitation is followed by subsequent electron transfer from the valence to the conduction band if the energy of the photons exceeds the band width of the semiconductor. ${ }^{[73-74]}$ When an electron is promoted to the conduction band, this creates an unoccupied state in the valence band $\left(\mathrm{h}^{+}\right) \cdot{ }^{[74 a, 74 \mathrm{e}]}$ The excited electrons that migrate to the surface are used to start the photocatalytic cycle (Eqn. 2) (Figure 15) ${ }^{[73-74]}$, while the rest recombine with unoccupied states producing heat. The semiconductor-sensitized reaction (Eqn. 2)

$$
A+D \underset{\text { light } \geq E_{g}}{\longrightarrow} A^{-}+D^{+}
$$

(where $E_{g}$ is the band gap of the semiconductor, and $A$ and $D$ represent acceptor and donor, respectively) can either represent photocatalysis (negative change in Gibbs free energy) or photosynthesis (positive change in Gibbs free energy). ${ }^{[64}$ 75]

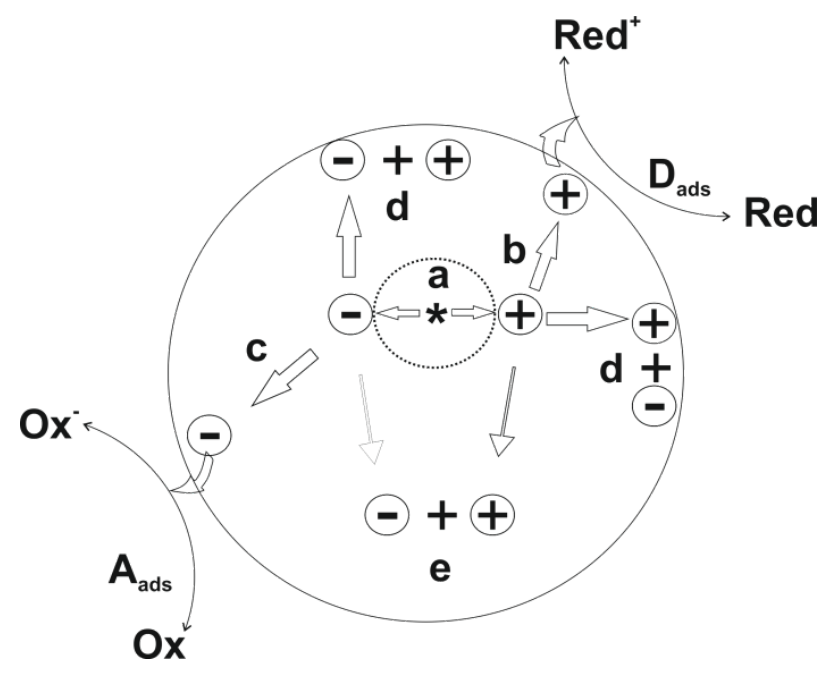

Figure 15. Main processes occurring on a semiconductor particle: a) electron-hole generation; b) oxidation of donor (D); c) reduction of acceptor (A); d) and e) electron-hole recombination at surface and in bulk, respectively.

Most photocatalysts are semiconductors, due to the relatively high stability and mobility of charge carriers in these materials, which facilitates the transport of electrons to the surface ${ }^{[73-74,76]}$ Among various metal oxide semiconductor photocatalysts, titanium dioxide $\left(\mathrm{TiO}_{2}\right)$ is currently recognized as the most suitable material for environmental applications, due to its high chemical inertness and photo-stability as well as strong oxidizing power and low cost. ${ }^{[7]}$

$\mathrm{TiO}_{2}$ is an n-type semiconductor due to the low amount of oxygen vacancies on the surface that is compensated by the presence of $\mathrm{Ti}^{3+}$ centers. ${ }^{[73 \mathrm{a}]}$ The conduction band of $\mathrm{TiO}_{2}$ is formed by the $3 \mathrm{~d}$ orbitals of $\mathrm{Ti}^{4+}$ cations, whereas the valence band of this material is due to the overlap of oxygen $2 p$ orbitals. ${ }^{[74 b]}$ The photonic efficiency of $\mathrm{TiO}_{2}$ is affected by the crystallite size or the presence of dopants ${ }^{[78]}$, transforming $\mathrm{TiO}_{2}$ into an ideal photocatalytic material, since a low amount of photocatalyst is needed to achieve high photonic efficiency. ${ }^{\text {[3a] }}$

Remarkable among semiconductors, the electronic structure of $\mathrm{TiO}_{2}$ allows both the oxidation of water (1.2 eV vs. $\left.\mathrm{NHE}\right)$ and reduction of protons $\left(0 \mathrm{eV}\right.$ vs. NHE) to occur simultaneously. ${ }^{[73 b, 74 a, 74 d, 79]}$ Surface $\mathrm{OH}^{-}$groups react with the valence band holes to yield hydroxyl radicals $\left(\mathrm{OH}^{*}\right)$, which are the main intermediate in the photo-oxidation reactions with $\mathrm{TiO}_{2}{ }^{[73 b, 74]}$

Both anatase and rutile crystal structures of $\mathrm{TiO}_{2}$ are used as photocatalysts, with anatase demonstrating the highest photocatalytic activity in most photoreactions. ${ }^{[73 \mathrm{~b}, 74,80]}$ The enhanced photoactivity of this material is attributed to the higher Fermi level of the anatase form than the rutile form, the lower capacity to adsorb oxygen and the higher concentration of hydroxyl groups on the surface ${ }^{[80-81]}$ On the contrary, the rutile form has a lower surface area than the anatase form due to its larger crystalline size, resulting in lower photoactivity per geometric area. ${ }^{[33 a]}$ A photocatalyst consisting of anatase/rutile mixture is also a viable option; commercial Degussa P25 photocatalyst for the degradation of organic pollutants is more active than both $\mathrm{TiO}_{2}$ crystalline structures separately. ${ }^{[81 \mathrm{a},}{ }^{82]}$ This behavior is attributed to the increased efficiency of electron-hole separation due to the formation of $n-p$ junctions from the contact of crystals of both phases. ${ }^{\text {[81a, 81b, 82a] }}$ 
The high catalytic activity of the $\mathrm{TiO}_{2}$ anatase phase places meso/macroporous $\mathrm{TiO}_{2}$ as well as mesoporous $\mathrm{TiO}$ with

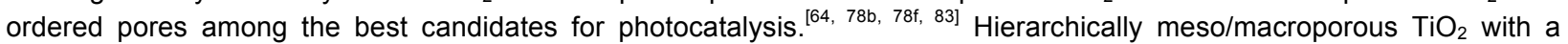
crystalline anatase phase is characterized by a high surface area, resulting in a high number of active adsorption sites and photocatalytic reaction centers. ${ }^{[83 e]}$ Additionally, macroporous channels act as light transfer pathways for introducing the photon flux to the inner surface of mesoporous $\mathrm{TiO}_{2}{ }^{[83 \mathrm{a}, 84]}$, increasing the mass transfer and light utilization efficiency and transforming meso/macroporous $\mathrm{TiO}_{2}$ into an efficient light harvester. ${ }^{[83 \mathrm{~d}]}$

However, the calcination temperature influences the photoactivity of meso/macroporous $\mathrm{TiO}_{2}{ }^{[83 \mathrm{~d}]}$ The hierarchical structure of $\mathrm{TiO}_{2}$ is stable at $350^{\circ} \mathrm{C}$, exhibiting a macroscopic network structure consisting of homogeneous macropores (2-4 $\left.\mu \mathrm{m}\right)$; the macroscopic channels are parallel to each other and perpendicular to the tangent of the surface of the particle (Figure 16a, b). ${ }^{[85]}$ At higher calcination temperatures $\left(\sim 500^{\circ} \mathrm{C}\right)$, however, the mesoporous structure of $\mathrm{TiO}_{2}$ is partially destroyed and the size of macropores is decreased to $1-2 \mu \mathrm{m}$ (Figure $16 \mathrm{c}, \mathrm{d})^{[83 \mathrm{~d}, 86]}$; further calcination above $600^{\circ} \mathrm{C}$ leads to the destruction of the meso/macroporous structure (Figure 16e, f). Photodegradation of ethylene in gas-phase medium has been employed to evaluate the activity of meso/macroporous $\mathrm{TiO}_{2}$. This $\mathrm{TiO}_{2}$ photocatalyst, calcined at $350^{\circ} \mathrm{C}$, demonstrates $\sim 60 \%$ higher photoactivity than commercial $\mathrm{P} 25 \mathrm{TiO}_{2}{ }^{[83 \mathrm{~d}]}$, while further heating above $600^{\circ} \mathrm{C}$ results in a dramatic loss in photoactivity. ${ }^{[83 \mathrm{~d}]}$

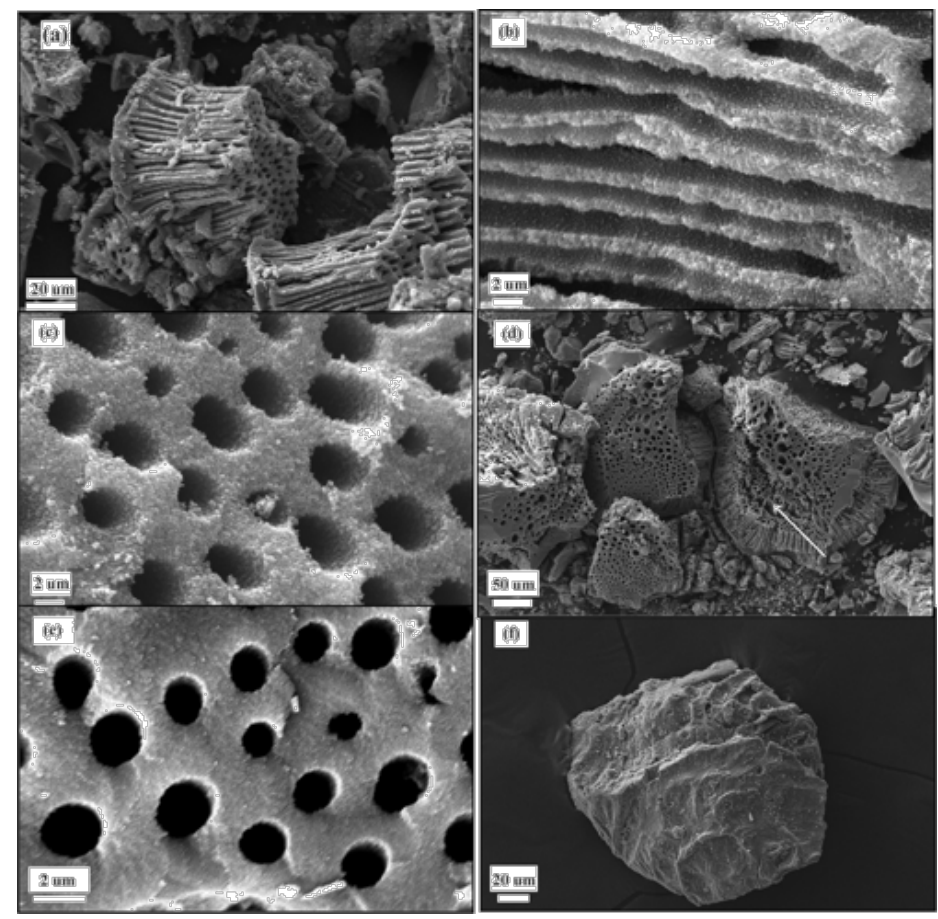

Figure 16. SEM images of the $\mathrm{TiO}_{2}$ monolithic particles calcined at $350^{\circ} \mathrm{C}(\mathrm{a}, \mathrm{b}, \mathrm{C}), 500^{\circ} \mathrm{C}(\mathrm{d}, \mathrm{e})$, and $650^{\circ} \mathrm{C}(\mathrm{f}) .{ }^{[83 \mathrm{~d}]}$ Copyright@ 2005 American Chemical Society.

Another form of hierarchical $\mathrm{TiO}_{2}$ is mesoporous $\mathrm{TiO}_{2}$ film with ordered pores, which is an ideal host matrix for embedding metal nanoparticles, due to its tunable pores and large surface area. ${ }^{[78 b, 78 f, 78 g, 83 f-h, ~}{ }^{87]}$ The small size of the mesopores (nanometers), though, hinders the effective diffusion of organic molecules through the pores, as a large fraction of the internal surface is excluded. ${ }^{[7]}$ To circumvent this issue, a hierarchically porous structure containing large pore channels is built within the mesoporous film, leading to increased diffusivity of reactants and products within the film, as well as utilization of a larger internal surface area. ${ }^{[67 b, 88]}$ It still remains a challenge to independently control the porosity at each length scale to minimize the loss of surface area, and quantitative information in these studies is largely absent, precluding truly rational design. ${ }^{[88 a, 89]}$

Composites of hierarchically ordered meso/macroporous $\mathrm{TiO}_{2}$ films over graphene with 2D hexagonal mesostructures and well interconnected macropores have been synthesized. ${ }^{[7]}$ The latter improve mass transport through the $\mathrm{TiO}_{2}$ film, reduce the length of the mesopore channels and increase the accessible surface area of the thin film, improving the photocatalytic activity of the material. ${ }^{[77]}$ Additionally, graphene is incorporated into the $\mathrm{TiO}_{2}$ structure to suppress charge recombination in 
the film. As a result, an 11-fold increase in the photoactivity of composite graphene- $\mathrm{TiO}_{2}$ films is achieved, compared to pristine, mesoporous $\mathrm{TiO}_{2}$ films. ${ }^{[77]}$
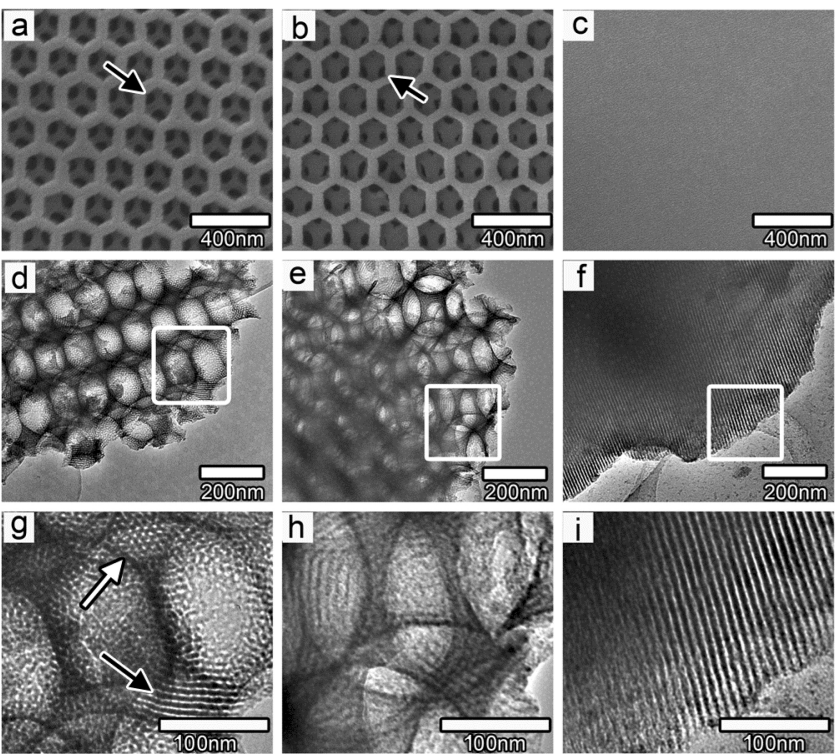

Figure 17. SEM / TEM micrographs of macro-mesoporous $\mathrm{TiO}_{2}$ films without $(a, d, g)$ and with $(b, e, h)$ graphene and purely mesoporous $\mathrm{TiO}_{2}$ film $(c, f, i)$. The black arrows in $(a, b)$ indicate the interconnected channels between macropores in the films, whereas the white and black arrows in (g) suggest the mesopores in the macroporous walls. ${ }^{[77]}$ Copyright $^{\oplus} 2010$ American Chemical Society.

SEM and TEM micrographs of macro-mesoporous $\mathrm{TiO}_{2}$ films demonstrate the formation of hexagonal macropores $(\sim 200$ $\mathrm{nm}$ ) (Figure 17a, b). Each macropore wall comprises smaller mesopores $(\sim 3 \mathrm{~nm})$ with hexagonal and striped patterns (Figure $17 \mathrm{~g}, \mathrm{~h}$ ) confirming the mesoporosity of the material. ${ }^{[77]}$

Furthermore, 3D macroporous materials or inverse opal $\mathrm{TiO}_{2}$ are also used in photocatalysis, due to their highly interconnected porosity, uniform size and high surface area. ${ }^{[33-\mathrm{m}, 83 \mathrm{r}]}$ Colloidal crystal templating is the most common method for the synthesis of inverse opals in the visible region ${ }^{[20 c, 90]}$ while CVD is used for the synthesis of silicon and germanium

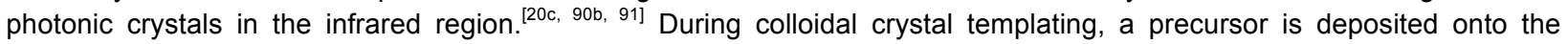
interstices of the template and then it is selectively removed, forming an inverse porous structure. ${ }^{[20 \mathrm{c}, 90 \mathrm{~b}]} \mathrm{However}$, the $\mathrm{TiO}_{2}$ precursor hydrolyzes when exposed to atmosphere ${ }^{[20 \mathrm{c}]}$ resulting in anisotropic distribution of $\mathrm{TiO}_{2}$ within the opal structure, as well as formation of surface heterogeneities, decreasing the optical sensitivity of $\mathrm{TiO}_{2} .^{\text {[91a, 92] }}$

To circumvent this issue, a hydrophobic and air/moisture stable $\mathrm{TiO}_{2}$ precursor is used ${ }^{[91 \mathrm{a}]}$ to infiltrate the interstitial spaces of the template. Planar $\mathrm{TiO}_{2}$ inverse opals with flat surfaces are produced after calcination, even though the formation of overlayers cannot be completely avoided. ${ }^{[12 a, 92 a]}$ Overlayer formation is resolved by the introduction of the sandwich-vacuum method ${ }^{[83]]}$ resulting in $\mathrm{TiO}_{2}$ binary inverse opals without overlayers. Briefly, a moisture-stable $\mathrm{TiO}_{2}$ precursor is backfilled into the interstitial spaces of the template (polystyrene binary colloidal crystals), under vacuum, and the sample is calcined at $500^{\circ} \mathrm{C}$ to remove the template, resulting in the formation of $\mathrm{TiO}_{2}$ binary inverse opals without overlayers in large domains (Figure 18). ${ }^{[83]]} 3 \mathrm{DOM} \mathrm{TiO}_{2}$ demonstrates significantly higher photocatalytic activity than pristine $\mathrm{TiO}_{2}$ nanoparticles $(50 \%$ increase in the decomposition rate of benzoic acid), due to its high specific surface area $\left(57 \mathrm{~m}^{2} \mathrm{~g}^{-1}\right.$ compared to $39 \mathrm{~m}^{2} \mathrm{~g}^{-1}$ for pristine $\mathrm{TiO}_{2}$ ) and 3DOM structure that allows increased adsorption of benzoic acid on the surface of $\mathrm{TiO}_{2}$ and, thus, enhanced photoactivity. ${ }^{[33]}$ 

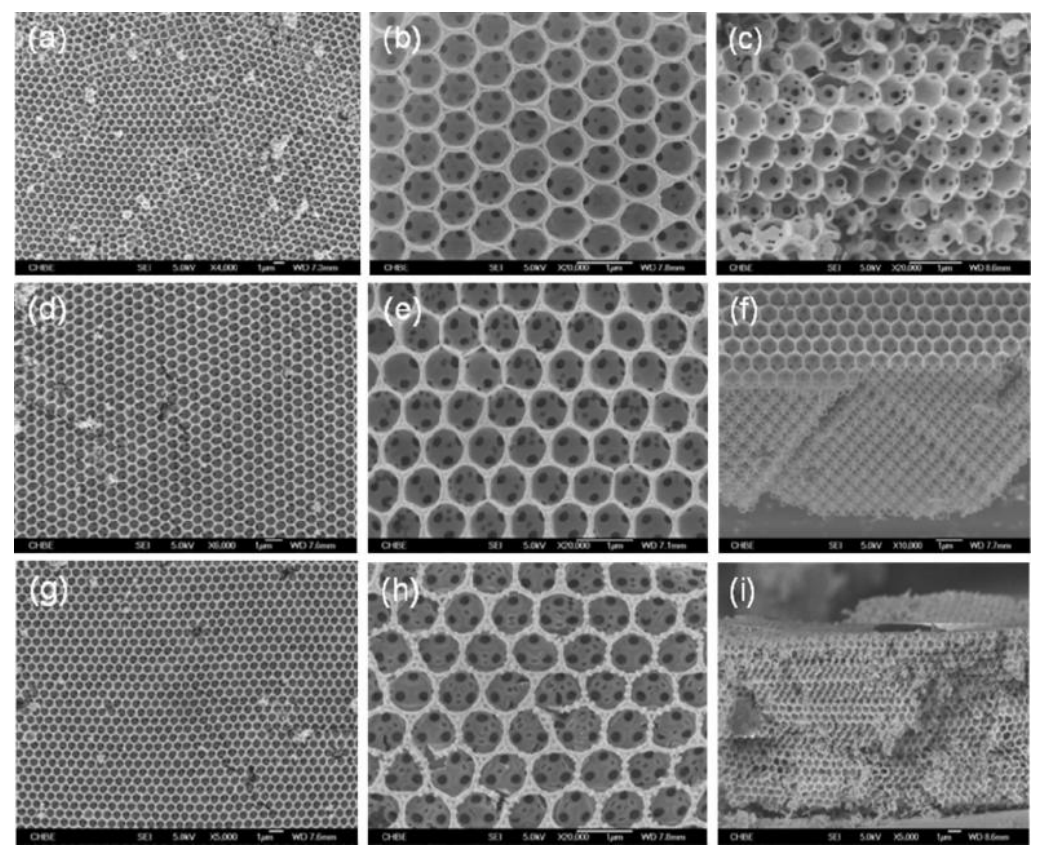

Figure 18. Top and cross-sectional views of $\mathrm{TiO}_{2}$ binary inverse opals fabricated using the sandwich-vacuum infiltration technique. The number ratios of small to large microspheres are $2(\mathrm{a}-\mathrm{c}), 4(\mathrm{~d}-\mathrm{f})$, and $8(\mathrm{~g}-\mathrm{i}) .{ }^{\left[{ }^{[3 j]}\right.}$ Copyright ${ }^{\odot} 2011$ American Chemical Society.

Finally, $\mathrm{TiO}_{2}$ meso/macroporous photocatalysts can be synthesized based on hierarchically structured materials existing in nature. Hierarchically porous structures such as leaves are highly efficient in light harvesting and, as a result, natural materials have been used as biotemplates to synthesize materials with enhanced photoactivity. The latter are called biogenic materials since they are synthesized through the use of living organisms as biotemplates in order to replicate their hierarchical structure. ${ }^{[64,75 b, 86-87,93]}$

Kelp is a water plant that can maximize sunlight absorption due to the presence of chromatophores on its epidermis. ${ }^{\text {[93] }}$ Its porous structure increases light scattering and thus enhances solar energy conversion. ${ }^{[93]}$ The increased photoactivity of iodine doped $\mathrm{TiO}_{2}$ is attributed to the pure anatase phase and small mean diameter ${ }^{[94]}$ that favors fast diffusion of photogenerated carriers from the inner region to the catalyst surface. ${ }^{[94]}$

The photocatalytic activity of biogenic $\mathrm{TiO}_{2}$ has been measured for the degradation of methylene blue under solar irradiation. The mean decomposition rates of biogenic $\mathrm{TiO}_{2}$ are twice those for nitrogen-doped $\mathrm{TiO}_{2}$, suggesting that hierarchical structures enhance the photoactivity of the catalyst. ${ }^{[93]}$

To summarize, $\mathrm{TiO}_{2}$ is among the best photocatalysts due to its high photoactivity and chemical stability. ${ }^{[93,95]}$ Using a hierarchical porous structure further enhances the photocatalytic activity of the material due to increased mass transport through the pores and accessible surface area. However, $\mathrm{TiO}_{2}$ can only be activated under ultraviolet (UV) light at energies greater than $3.2 \mathrm{eV}^{[95]}$ Ultraviolet radiation represents a small fraction $(\sim 5 \%)$ of the solar spectrum ${ }^{[96]}$ and hence research is focused on the development of modified $\mathrm{TiO}_{2}$ photocatalysts with high photoactivity using visible light. The composition of $\mathrm{TiO}_{2}$ can be improved by substituting metal ions ${ }^{[97]}$ at Ti sites or doping $\mathrm{TiO}_{2}$ with non-metallic elements (such as carbon ${ }^{[77}$, ${ }^{78 \mathrm{e}, 78 \mathrm{~g}, 98]}$, sulfur ${ }^{[77,92 \mathrm{c}, 95,98-99]}$, nitrogen ${ }^{[75,77,92 \mathrm{c}, 93,95,98,99 \mathrm{~b}, 100]}$ and semiconductors $\left(\mathrm{SiO}_{2}, \mathrm{ZrO}_{2}\right) \cdot{ }^{[73 b, 74 a, 74 d, 83 a, 101]}$ Apart from $\mathrm{TiO}_{2}$ based photocatalysts, alkaline earth titanate materials as well as non- $\mathrm{TiO}_{2}$ hierarchically structured photocatalysts $\left(\mathrm{WO}_{3}, \mathrm{CeO}_{2}, \ln _{2} \mathrm{O}_{3}\right.$, and $\left.\ln _{2} \mathrm{~S}_{3}\right)$ could be used. ${ }^{[75 \mathrm{~b}, 102]}$

\subsection{Fuel Cells}

\subsubsection{Pt based Nanostructures}

Polymer electrolyte fuel cells (PEFCs) are environmentally friendly electrochemical energy conversion devices with applications in the transportation, stationary power, portable electronics and military sectors. The principal catalysts used are 
based on Pt. Electrochemical reactions (hydrogen oxidation (HOR), alcohol oxidation (AOR) and oxygen reduction reaction $(\mathrm{ORR})$ ) take place on the surface of the Pt or Pt-alloy catalyst. ${ }^{[103]}$ However, the kinetics and corrosion stability of Pt as well as its tolerance to $\mathrm{CO}$ poisoning have to be improved significantly to transform PEFCs into cost-competitive technology. This can be achieved by the utilization of hollow Pt/Pt-alloys as electrocatalysts due to their higher surface area and utilization efficiency over pristine $\mathrm{Pt}^{\left[{ }^{[33 c}, 104\right]}$ as well as increased catalytic activity over monometallic Pt, due to compositional effects. ${ }^{[105]}$ Another issue to be considered is electrocatalyst support corrosion, especially under automotive drive cycles. ${ }^{[106]}$ This can be mitigated by the synthesis and use of corrosion-resistant metal-oxide supports and derivative electrocatalysts. ${ }^{[107]}$

Pure hollow Pt nanoparticles synthesized via a galvanic replacement reaction (using different sacrificial templates) exhibited significantly higher activity than pristine Pt towards the ORR and MOR reactions. ${ }^{[104 d, 108]}$ The pronounced difference in activity is directly related to the available surface area; both the inner and outer surface of Pt hollow nanoparticles participate in the catalytic reaction, whereas only the outer surface of Pt nanoparticles is used in the reaction resulting in a $\sim 2$ fold increase in available surface area of hollow Pt nanoparticles. ${ }^{[104 d, 109]}$ Additionally, the enhanced Pt mass activity is stable during extended potential cycling $\left(10,000 \text { cycles between } 0.65 \text { and } 1.05 \mathrm{~V} \text { vs. RHE at } 50 \mathrm{mVs}^{-1}\right)^{[36 \mathrm{n}]}$; no ECA and ORR/MOR losses were observed and the mass activity of hollow Pt nanoparticles was 6 fold higher than Pt nanoparticles after 100h of

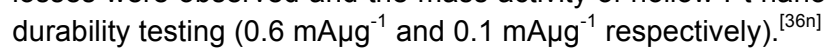

Apart from hollow Pt nanoparticles, hollow Pt-alloys (PtM, M=Au, Ag, Co, Ni, $\mathrm{Ru}, \mathrm{Pd}, \mathrm{Cu}$ ) are also used as electrocatalysts in

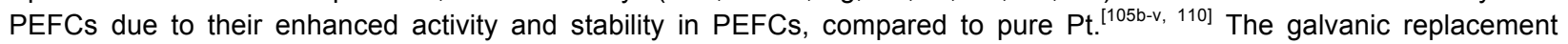
reaction is the most common method to synthesize these hollow nanoparticles, since it allows easy control of the shape and size of the product by varying shape of the sacrificial template and the ratio of surfactant/reductant as discussed in section $1.4 .^{[39 f, 110 \mathrm{~b}, 110 \mathrm{ll}]}$

Raspberry-like hierarchical Au/Pt hollow spheres (RHAHS) exhibit higher oxygen reduction peak potential $(0.46 \mathrm{~V}$ compared to $0.1 \mathrm{~V}$ vs. $\mathrm{Ag} / \mathrm{AgCl}$ ) than pristine Au nanoparticles ${ }^{[111]}$ and probe the 4-electron reduction of water; their mass activity was 8 and 4 times higher than $\mathrm{Pt} / \mathrm{C}$ at 0.595 and $0.465 \mathrm{~V}$ (vs. SHE), respectively (Figure 19). ${ }^{[103 a]}$ Hollow Pt/Au spheres are also used in direct formic acid fuel cells, increasing the catalytic activity and the tolerance to CO poisoning through ensemble effects. ${ }^{[105 a, 112]}$
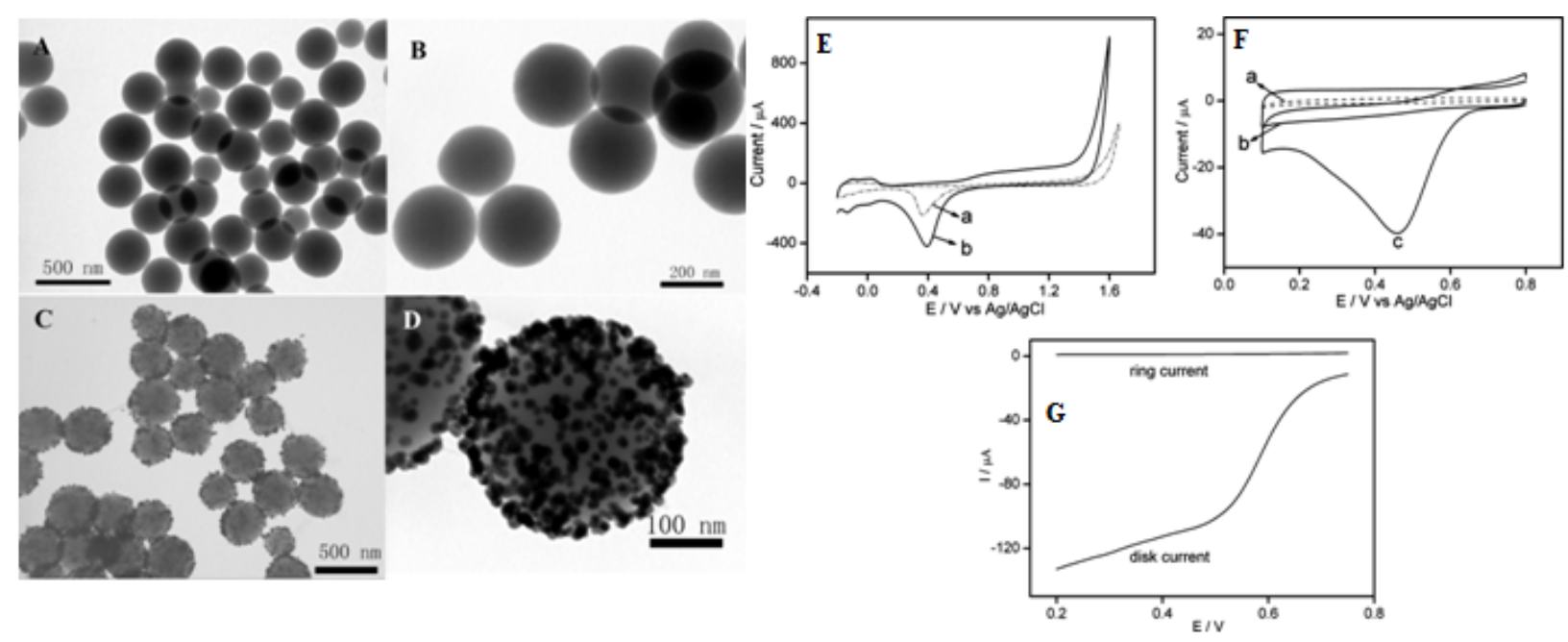

Figure 19. TEM image (A, B) of $\mathrm{TiO}_{2}$ precursor spheres at different magnifications; TEM images (C and D) of $\mathrm{TiO}_{2}(\mathrm{precursor}$ sphere)/Au hybrid

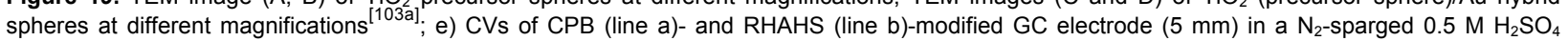
solution; f) $\mathrm{CVs}$ of $\mathrm{O}_{2}$ reduction at RHAHS-modified gold electrode (lines b and c) and bare gold electrode (line a) in air-saturated (lines a and c) and $\mathrm{N}_{2}$-saturated (line b) $0.5 \mathrm{M} \mathrm{H}_{2} \mathrm{SO}_{4}$ solution; g) Current-potential curves for the reduction of $\mathrm{O}_{2}$ at a rotating platinum ring-GC (5 mm) disk electrode with RHAHS adsorbed on the disk electrode in the presence of air (experimental conditions: $1 \mathrm{~V}$ constant ring potential, $500 \mathrm{rpm}$ rotation rate, $50 \mathrm{mVs}{ }^{-1}$ scan rate, $0.5 \mathrm{M} \mathrm{H}_{2} \mathrm{SO}_{4}$ solution). ${ }^{[103 a]}$ Copyright $^{\odot} 2009$ American Chemical Society.

Hollow $\mathrm{Ni}_{1-x} \mathrm{Pt}_{\mathrm{x}}$ nanospheres exhibit higher catalytic activity towards methanol oxidation than commercial $\mathrm{Pt} / \mathrm{C}$ and solid $\mathrm{PtNi}$ nanoparticles. ${ }^{[36 n, 110 \mathrm{~g}, 113]}$ Chronoamperometry measurements at constant potential $(0.45 \mathrm{~V}$ vs. SCE) reveal the high activity of hollow PtNi nanospheres towards MOR, since their oxidation current density is significantly higher than Pt/C ( 200 
$\mathrm{mAmg}^{-1}$ and $50 \mathrm{mAmg}^{-1}$, respectively) due to the high surface area of the hollow structure and the change in Pt electronic structure after the addition of $\mathrm{Ni}^{\left[{ }^{[113 a]}\right.} \mathrm{Ni}(0)$ occupies the $\mathrm{Pt}$ lattice and the metallic grains are intermixed with amorphous $\mathrm{Ni}$ hydroxides such as $\mathrm{Ni}(\mathrm{OH})_{2}$ and $\mathrm{NiOOH}^{[113 \mathrm{a}]}$ The presence of these $\mathrm{Ni}$ oxides results in the increase of $\mathrm{Pt}(0)$ and decrease of $\mathrm{Pt}(\mathrm{IV})$ content, due to the electronic effect of $\mathrm{Ni}$ on $\mathrm{Pt}$ and, thus, a higher catalytic activity of PtNi. ${ }^{[113 a]} \mathrm{Moreover}, \mathrm{Ni}$ hydroxides can offer $\mathrm{OH}$ species to remove the intermediate $\mathrm{CO}$ that strongly adsorbs on the $\mathrm{Pt}$ surface, regenerate the $\mathrm{Pt}$ active sites for methanol adsorption ${ }^{[114]}$, and thus improve the catalytic activity of the nanospheres.

\subsubsection{Nanostructures based on Other Noble Metals}

Hollow non-Pt alloys have been mainly used for the electrochemical oxidation of formic acid. ${ }^{[15]}$ In particular, Pd catalysts possess higher activity in formic acid oxidation than Pt based catalysts. ${ }^{[115-116]}$ Small Pd particles $(\sim 9-11 \mathrm{~nm})$ exhibit the highest binding energy shift and valence band center downshift with respect to the Fermi level, resulting in a decrease in the bond strength of the adsorbents ${ }^{[117]}$ and, thus, higher formic acid reactivity. ${ }^{[16]}$ The low d-band center of small $\mathrm{Pd}$ nanoparticles allows them to bind less strongly with the $\mathrm{COOH}$ intermediate than larger Pd nanoparticles, thus reducing the surface $(\mathrm{COOH})_{\text {ads }}$ coverage (Eqn. $\left.7 \& 8\right) .{ }^{[16]}$ As a result, the rate determining step (Eqn. 8) can be avoided and a higher rate of $\mathrm{HCOOH}$ decomposition to $\mathrm{CO}_{2}$ is achieved (Eqn. 6). ${ }^{[16]}$

$$
\begin{aligned}
& \mathrm{HCOOH}_{\text {bulk }} \rightarrow 2 \mathrm{H}^{+}+2 \mathrm{e}^{-}+\mathrm{CO}_{2} \\
& \mathrm{HCOOH}_{\text {ads }} \rightarrow(\mathrm{COOH})_{a d s}+\mathrm{H}^{+}+\mathrm{e}^{-} \\
& (\mathrm{COOH})_{a d s} \stackrel{\text { rds }}{\rightarrow} \mathrm{CO}_{2}+\mathrm{H}^{+}+\mathrm{e}^{-}
\end{aligned}
$$

To further improve the catalytic activity of $\mathrm{Pd}, \mathrm{Pd}-\mathrm{M}$ alloys $(\mathrm{M}=\mathrm{Au}, \mathrm{Rh}, \mathrm{Cu}, \mathrm{Ag})$ with hollow/core-shell structure are used due to their high surface area and the modulated electron structure. ${ }^{[110 s, 118]}$

For example, hollow Pd/Au nanospheres demonstrate higher activity towards formic acid oxidation than pristine Pd and Au nanoparticles due to their increased surface to volume ratio ${ }^{[118 \mathrm{c}]}$; the raspberry surface of Au nanospheres contains irregular $\mathrm{Pd}$ grains, which increase the surface-to-volume ratio and surface activity of the $\mathrm{Pd} / \mathrm{Au}$ catalyst. ${ }^{[118 c]}$ Similar results are observed in the case of hollow $\mathrm{Pd} / \mathrm{Cu}$ and $\mathrm{Pd} / \mathrm{Ag}$ nanospheres. ${ }^{[118 \mathrm{a}, 119]}$ Hollow $\mathrm{Pd} / \mathrm{Ag}$ nanotubes have a single-layer crystalline structure comprised of $\mathrm{Ag}\{1,1,1\}$ and $\mathrm{Pd}\{1,1,1\}$ planes with six-fold rotational symmetry resulting in a 2-fold increase of catalytic activity compared to pristine $\mathrm{Pd}$ and a high tolerance to $\mathrm{CO}$ poisoning, as evidenced by the shift of the onset potential for formic acid oxidation towards more positive values. ${ }^{[18 \mathrm{~b}]}$

\subsubsection{Hierarchical Catalyst Supports}

The activity and stability of electrocatalysts is closely related to the catalysts support. ${ }^{[120]}$ Carbon black (Vulcan XC-72) is the most common support used in fuel cells, due to its large surface area, high electrical conductivity and porous structure. ${ }^{[120 b]}$ However, carbon is susceptible to the corrosive environment of PEMFCs, leading to the oxidation of carbon supports and to the detachment and agglomeration of Pt nanoparticles and, thus, to fuel cell performance and ECA losses. ${ }^{[120 \mathrm{~b}]}$ Specifically, carbon is readily (and irreversibly) oxidized to carbon dioxide at the high overpotentials encountered at the cathode (during the fuel-air transients that occur during automobile start-up and shut down) and at the anode (during fuel starvation). ${ }^{[06]}$

As a result, different forms of nanoporous carbon materials (carbon nanotubes, nanofibers and mesoporous carbon) as well as non-carbon electrocatalyst supports have been investigated. ${ }^{[46 c, 120 a, 121]}$ They have to meet the following criteria in order to be considered as viable options: i) high surface area; ii) porosity; iii) high electrical conductivity and iv) stability under fuel cell conditions (especially potential transients).

A promising catalyst support is well-aligned carbon nanotubes (WCNTs), providing high catalyst dispersion between nanotubes. ${ }^{[46 c, 121 e]}$ The energy required for ORR activation is smaller for Pt/WCNTs compared to Pt supported on Vulcan XC-72 Carbon; thus, Pt/WCNTs exhibit improved ORR kinetics. ${ }^{[121 e]}$ Similar results are obtained for the energy required for MOR activation ${ }^{[46 c]}$, indicating that Pt/WCNTs have enhanced MOR kinetics over Pt/C.

Carbon nanofibers (CNFs) are also used as catalyst supports in PEFCs ${ }^{[120 a, 121 a-d]}$ in three different structures: fishbone, deck of cards, and parallel. ${ }^{[122]}$ The CNFs with fishbone morphology (f-CNF) have graphene layers with a $45^{\circ}$ angle to the growth axis, while CNFs with deck of cards morphology (platelet, p-CNF) have graphene layers perpendicular to the growth axis 
(Figure 20). CNFs with parallel morphology (tubular, t-CNF) have graphene layers parallel to the growth axis, with a multiwall ensemble. ${ }^{[122 b]}$
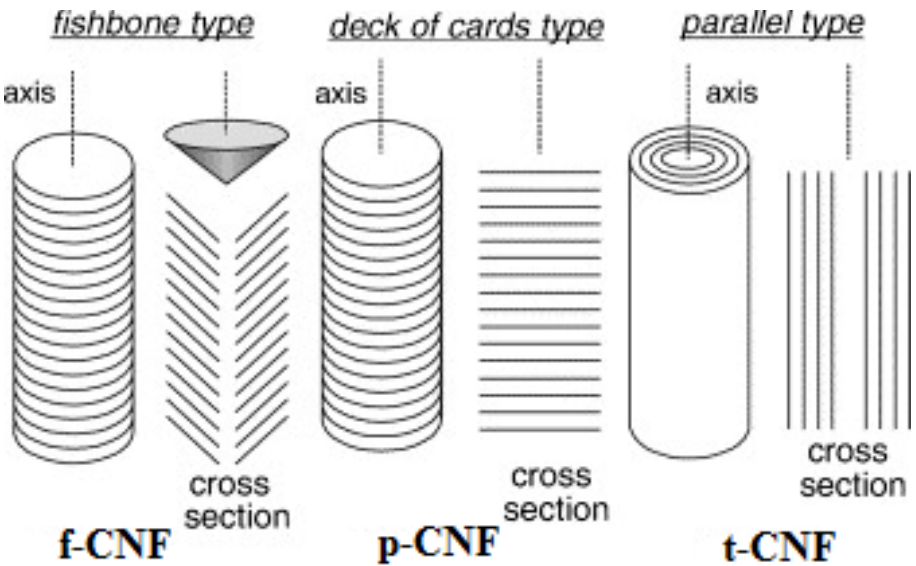

Figure 20. Schematic representation of three types of CNFs. ${ }^{[122 b]}$ Based on ${ }^{[122 b]}$ with permission from Elsevier.

CVs in oxygen saturated $\mathrm{HClO}_{4}(0.5 \mathrm{M})$ reveal that $\mathrm{p}-\mathrm{CNF}$ has the most positive ORR peak potential and, hence, the highest ORR activity (Table 2), due to the higher ratio of edge to basal atoms in p-CNFs. ${ }^{[123]}$ With regard to peak current, $p$-CNFs have a lower ORR current than f-CNFs, due to the smaller particle size of f-CNFs $(\sim 60 \mathrm{~nm}$ compared to $\sim 100 \mathrm{~nm}$ for $\mathrm{p}$ CNFs) and, thus, a higher active site density. ${ }^{[123]}$

Table 2. ORR peak potential and current of different CNF electrodes $\left(0.5 \mathrm{M} \mathrm{HClO}_{4}, 100 \mathrm{mVs}^{-1}\right) .{ }^{[123]}$

\begin{tabular}{lll}
\hline Sample & Peak potential (V) & Peak current (mA) \\
\hline f-CNF & -0.27 & -0.128 \\
p-CNF & -0.25 & -0.064 \\
t-CNF & -0.38 & -0.048 \\
Graphite & -0.48 & -0.038 \\
\hline
\end{tabular}

These different CNF structures are also used as supports for PtRu catalysts in DMFCs. ${ }^{[124]}$ Platelet CNFs exhibit the highest catalytic activity towards methanol oxidation, followed by tubular and herringbone CNFs $\left(\sim 90,60\right.$, and $50 \mathrm{mWcm}^{-2}$ respectively). ${ }^{[124]}$ These values are 2-3 times higher than the measured PtRu/carbon black $\left(\sim 30 \mathrm{mWcm}^{-2}\right) .{ }^{[124]}$

The difference in CNF nanostructure causes preferential localization of metal nanoparticles. ${ }^{[125]}$ Metal nanoparticles are dispersed on the edge of the graphite layers (Figure 21a) in the case of p-CNFs, in the tubes and on the surface for t-CNFs (Figure 22c), and between the layers and on the edge for h-CNFs (Figure 21b). Thus, the nanostructure of CNFs influences the dispersion and reactivity of supported nanoparticles, as well as the stability, since a good interaction with the surface limits nanoparticle mobility and sintering. 
A

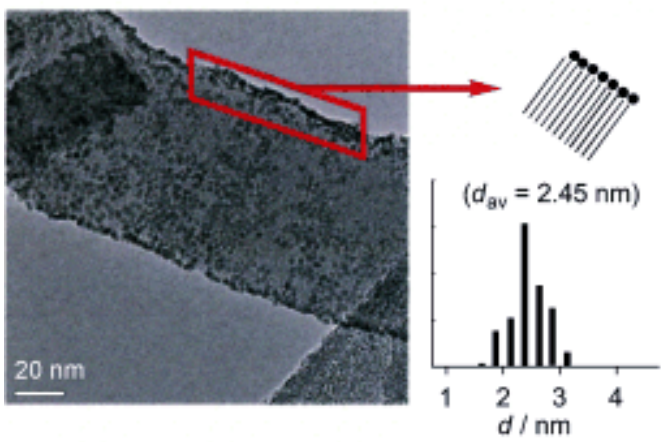

$\mathrm{C}$

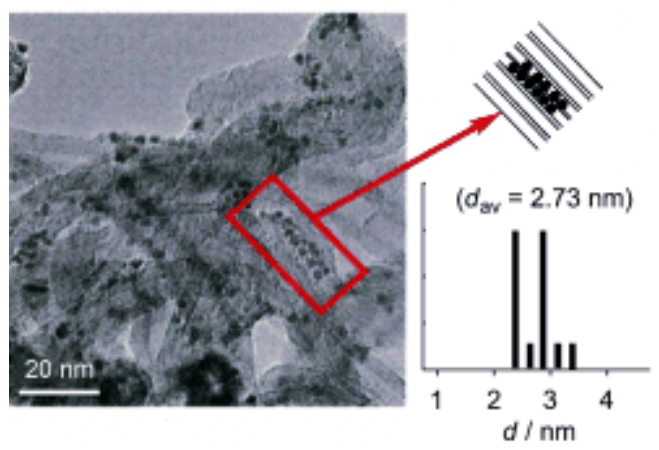

B

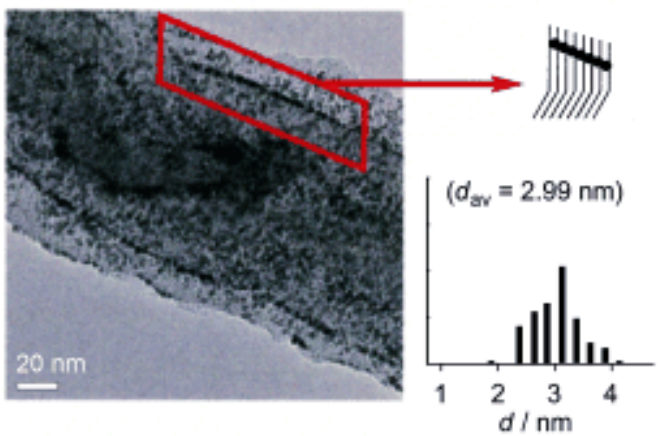

D

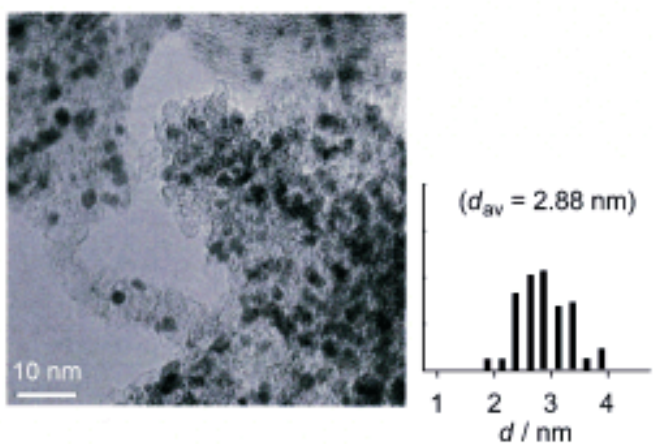

Figure 21. TEM images and histograms of the Ru particles: a) Ru/CNF-P; b) Ru/CNF-H; c) Ru/CNF-T; and d) Ru/AC. ${ }^{[125]}$ Copyright $^{\oplus} 2007$ Wiley. $^{2}$

Mesoporous carbon is another alternative for catalyst supports. It is classified into ordered (OMC) and disordered (DOMC), based on its structure and morphology. ${ }^{[120 b]}$ OMCs are usually prepared using a mesoporous silica template ${ }^{[26 b \text {, 28a, 126] }}$, while block copolymers are used for the preparation of DOFCs. ${ }^{[121 b, 127]}$ However, DOMC has low conductivity, due to the wide pore size distribution and irregular interconnections between mesopores; hence, OMC is generally preferred as the catalyst support in PEFCs and DMFCs ${ }^{[128]}$, since it provides a high surface area with mono-dispersed 3D interconnected mesopores. ${ }^{[121 c, 128 c]}$

Pt supported on OMCs exhibits a doubling in specific activity towards MOR compared to Pt/C $\left(\sim 1.4\right.$ and $1.3 \mathrm{mAcm}^{-2}$ for $\mathrm{Pt} / \mathrm{OMCs}$ and $\sim 0.6 \mathrm{mAcm}^{-2}$ for $\mathrm{Pt} / \mathrm{C}$ ), due to the facile transport of methanol and oxidation products through the ordered mesopores. ${ }^{[129]}$ Similar results are observed when OMCs are employed as supports in PEFCs. ${ }^{[128 c]}$ The mass-based activity of $\mathrm{Pt} / \mathrm{OMCs}$ is $\sim 4$ times higher than that of $\mathrm{Pt} / \mathrm{DMCs}\left(\sim 230\right.$ and $63 \mathrm{Ag}_{\mathrm{Pt}}{ }^{-1}$ respectively), due to the highly ordered structure and good 3D interconnectivity. ${ }^{[128 c]}$

Furthermore, hollow graphitic spheres (HGS) with high surface area (> $\left.1000 \mathrm{~m}^{2} \mathrm{~g}^{-1}\right)$ and controlled pore structure are used as $\mathrm{Pt}$ support. ${ }^{[130]} \mathrm{HGS}$ were synthesized using silica as exotemplate and impregnated with hexachloroplatinic acid $\left(\mathrm{H}_{2} \mathrm{PtCl}_{6} \cdot \mathrm{xH}_{2} \mathrm{O}\right)$ under ultrasonication. ${ }^{[130 \mathrm{a}]}$ Annealing the sample at high temperature $\left(900^{\circ} \mathrm{C}\right)$ results in growth and confinement of $\mathrm{Pt}$ nanoparticles $(\sim$ 3-4 $\mathrm{nm})$ in the mesoporous structure of HGS. ${ }^{[130 \mathrm{a}]}$

The stability of Pt/HGS is significantly higher than that of commercial $\mathrm{Pt} / \mathrm{C}$, due to the suppression of agglomeration and detachment of Pt nanoparticles by the HGS structure (Figure 22). The high initial Pt density is retained to a high extent upon completion of accelerated degradation tests: the number of Pt particles in Pt/HGS is decreased by $14 \%$, while there is an approximately $50 \%$ reduction in the $\mathrm{Pt}$ particle density in the case of commercial $\mathrm{Pt} / \mathrm{C}$, due to Ostwald ripening. ${ }^{[130 a]}$ 

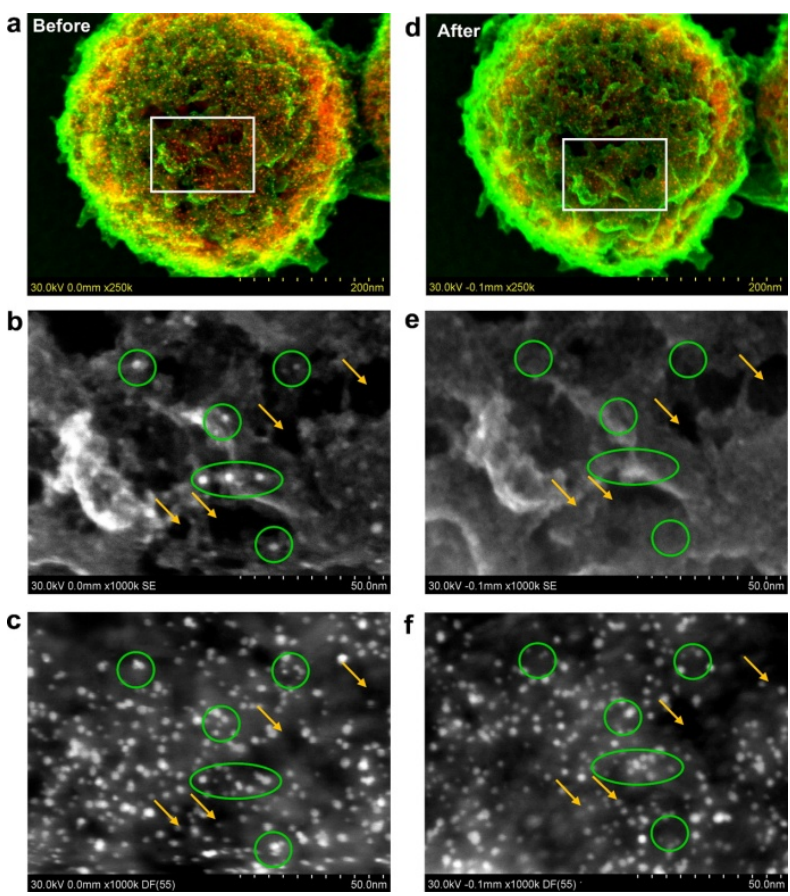

Figure 22. Identical location-SEM/STEM micrographs of Pt/HGS after 0 and after 3600 electrochemical degradation cycles: a) overlap of high resolution SEM (green) and dark field STEM (red) of a representative Pt/HGS particle; b) high resolution SEM of a region in the middle of the Pt/HGS particle highlighted with a white square; c) simultaneously taken dark field STEM micrograph; d-f) correspond to identical locations after electrochemical degradation. Yellow arrows point at pores and green circles at Pt nanoparticles placed at the external surface of the HGS support. ${ }^{[130]}$ Copyright $^{\oplus} 2012$ American Chemical Society.

Enhanced fuel cell performance after 1000 start-stop cycles at $1.4 \mathrm{~V}$ is observed for Pt/HGS. ${ }^{\text {[130a] }}$ Commercial Pt/C suffers an approximately $50 \mathrm{mV}$ voltage loss at the end of 1000 cycles, whereas the cell voltage of Pt/HGS is constant throughout the potential cycling. ${ }^{[130 a]}$

Since carbon is thermodynamically unstable at the cathode even under regular fuel cell operating conditions, and kinetically unstable under transients seen during automotive start-stop cycles, the supports described above will not be suitable for the highly challenging automotive application beyond a few 100 cycles. Therefore, for this demanding application, it is expedient to identify corrosion-resistant electrocatalyst supports. Recently, Ramani and co-workers have demonstrated exceptionally stable mixed metal oxide ${ }^{[107 \mathrm{c}-\mathrm{f}]}$ and doped metal oxide ${ }^{[107 \mathrm{a}, 107 \mathrm{~b}]}$ electrocatalyst supports that show superb corrosion resistance even under the harshest drive cycle conditions. These supports can be prepared with very high surface areas, allowing for good $\mathrm{Pt}$ dispersion and mass transport. Moreover, it has been demonstrated that one can deposit $\mathrm{Pt}$ nanoparticles on these non-carbon supports and derive fuel cell performances equivalent to state-of-the-art $\mathrm{Pt} / \mathrm{C}$ electrocatalysts, while retaining the exceptional stability of the non-carbon support. ${ }^{[107 f]}$ Finally, they have shown clear evidence (via X-ray absorption spectroscopy experiments) of electron back-donation from the doped titanium oxide support to the platinum nanoparticles, thereby confirming strong-metal-support-interactions in this system. Such interactions provide an additional handle to tune and further enhance the electrocatalytic activity of platinum. ${ }^{[107 b]}$

In summary, the instability of carbon black under transient fuel cell conditions, as well as the presence of micropores that hinder reactant flow and thus fuel cell performance, has led to the investigation of alternative carbon-based catalyst supports, namely mesoporous carbon, well-aligned carbon nanotubes, carbon nanofibers and hollow graphitic spheres. The high surface area and mesoporosity of these materials allows for high catalyst dispersion and reactant flow, leading to increased catalytic activity towards MOR and ORR. However, even these supports will not be adequately stable for automotive applications. For this application, a series of non-carbon metal-oxide based supports have been synthesized, and the resultant catalysts were demonstrated to possess exceptional stability and tunable activity. Further improvements to the structure of these alternative carbon supports can be achieved by implementing hierarchical macro/mesoporous structures inspired by those present in nature, as discussed in Section 3. 


\subsubsection{Support-less Hybrid Metallic Aerogels}

Recently, research has been focused on the synthesis and utilization of support-less hybrid aerogels of metal nanoparticles (such as $\mathrm{Pd}, \mathrm{Pt}, \mathrm{Au}$ and $\mathrm{Ag}$ ) as catalysts for the ethanol and oxygen reduction reaction. ${ }^{[45]}$ Hybrid Pd aerogels demonstrated superior catalytic activity towards ethanol and oxygen reduction and high durability. The current density of the forward oxidation of ethanol was approximately twice the density of $\mathrm{Pd} / \mathrm{C}$ due to the high porosity of the hybrid aerogel favoring the exposure of catalytic active sites, ${ }^{[45 b]}$ whereas the stability of hybrid Pd aerogels was approximately 6 times higher than Pd/C after a 4 h durability testing. ${ }^{[45 b]}$

Similar results were obtained when hybrid bimetallic PtPd aerogels were used as catalysts towards ORR. ${ }^{[45]} \mathrm{PtPd}$ aerogels with higher than $40 \mathrm{wt} \% \mathrm{Pt}$ content meet or exceed the performance target for ORR fuel cell catalysts $\left(0.44 \mathrm{Amg}_{\mathrm{P}}^{\mathrm{t}-1} \mathrm{Pt}\right.$ at 0.9 $\mathrm{V}$ vs RHE, $80^{\circ} \mathrm{C}$ ) set by the U.S. Department of Energy. The enhanced catalytic activity is attributed to the high porosity and the existence of mesopores wider than $25 \mathrm{~nm}$ in PtPd aerogels, which avoids Knudsen diffusion limitations and thus decreases the diffusion resistance in the catalyst layer. ${ }^{[45 c]}$ In terms of stability (mass activity measurement after 10000 potential cycles between 0.5 and $1 \mathrm{~V}$ vs. SHE), $\mathrm{Pt}_{80} \mathrm{Pd}_{20}\left(12 \%\right.$ loss) and $\mathrm{Pt}_{40} \mathrm{Pd}_{60}(36 \%$ increase) hybrid aerogels exhibit significantly higher durability than $\mathrm{Pt}$ aerogel and commercial $\mathrm{Pt} / \mathrm{C}$ (54\% and $56 \%$ loss respectively), indicating that the existence of $\mathrm{Pd}$ stabilizes the catalyst (Figure 23). The observed increase in mass activity in the case of $\mathrm{Pd}$ rich aerogel $\left(\mathrm{Pt}_{40} \mathrm{Pd}_{60}\right)$ is due to the de-alloying of $\mathrm{Pd}$ upon potential cycling such that it slowly approaches the behavior of the $\mathrm{Pt}$-rich aerogel alloys. ${ }^{[45 c]}$

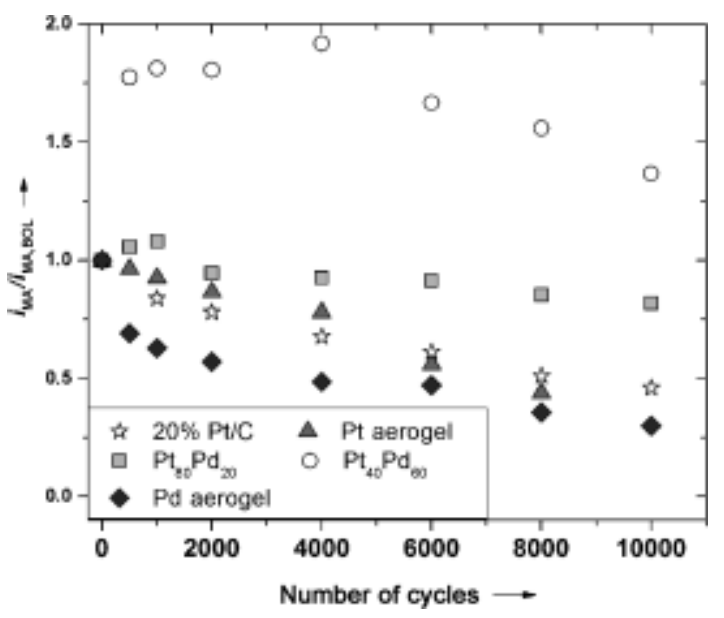

Figure 23. Relative ORR mass activity of $\mathrm{Pt}_{x} \mathrm{Pd}_{\mathrm{y}}$ catalysts of different compositions as a function of the number of potential cycles $(0.5 \mathrm{~V}$ to $1.0 \mathrm{~V})$. The mass activity was obtained from the cathodic scan of ORR polarization curves (corrected for electrolyte resistances) at $10 \mathrm{mVs}^{-1}$ and $1600 \mathrm{rpm} \cdot{ }^{[45 c]}$ Copyright $^{\oplus} 2013$ Wiley.

Hence, support-less hybrid metallic aerogels constitute a new class of fuel cell electrocatalysts combining high catalytic activity with high stability. Even though the preliminary results are very promising, extensive research is needed to broaden the range of metal nanoparticles that can be used in aerogels, and to investigate the mechanism of gel formation and thus be able to accurately control the porosity and surface area of the hybrid aerogels. Also, simple, cost-effective synthesis methods need to be developed in order to make hybrid aerogel synthesis scalable.

\section{From Biomimetics to Rational Design and Nature-Inspired Engineering}

Hierarchical structures are omnipresent in biology, from protein-complexes at the nanoscale, to the inherently scalable structure of organs and biological transport networks, and up to the macroscopic scale of entire organisms and biological

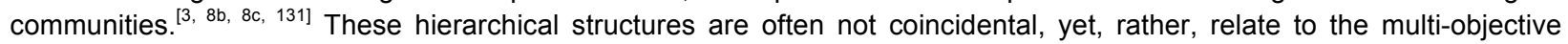
optimization of different biological functions, and adaptability under growth as well as under perturbations, for example, to cope with changing environmental conditions. ${ }^{[8 \mathrm{~b}, 8 \mathrm{c}]}$ 
Manmade designs that copy features of biological structures to achieve similar properties are often referred to as 'biomimetic' (derived from the Greek word mimesis). While spurring innovation, many such biomimetic designs neglect the issue that the constraints in technological applications are not necessarily the same as in biological systems, or that a natural structure is not optimal under all conditions. Relevant timescales are different, available material resources differ, the objectives could be different, and thermodynamics might tell us that the best temperature or pressure is not the physiological one of the model biological system.

We therefore advocate a broader, nature-inspired chemical engineering (NICE) approach, as one that takes guidance from nature for design. The NICE approach translates fundamental mechanisms behind desirable properties in natural systems (such as scalability, efficiency or robustness) to technological applications, within the context and under the constraints of these applications. Rather than superficial analogies, fundamental physics are taken as a basis for rational design. ${ }^{\text {[8, } 8 \mathrm{8c}, 132]}$

After discussing some biomimetic approaches to fuel cell design, we discuss rational design principles and early applications and opportunities of the nature-inspired engineering approach, developed by Coppens and co-workers.

\subsection{Biomimetics}

Several biomimetic approaches have been used so far to design PEFC flow fields based on the structure of leaves and lungs. ${ }^{[133]}$ These biomimetic designs combine serpentine and interdigitated patterns to avoid water flooding and increase the power density of the fuel cell (Figure 24). ${ }^{[133 b, 133 c]}$ Simulation studies using a thick gas diffusion layer (GDL $\left.\sim 1.02 \mathrm{~mm}\right)$ with high permeability show that the incorporation of biomimetic flow field designs result in a lower pressure drop from the inlet to the outlet than the commercial serpentine/interdigitated design ( 26 and $\sim 40 \mathrm{~Pa}$ pressure loss, respectively) and more uniform pressure distribution. ${ }^{[133 b]}$ Experimental validation of the theoretical results at various operating conditions show that the biomimetic flow fields increase the peak power density and overall fuel cell performance by $30 \%$. ${ }^{[133 b, 133 c]}$

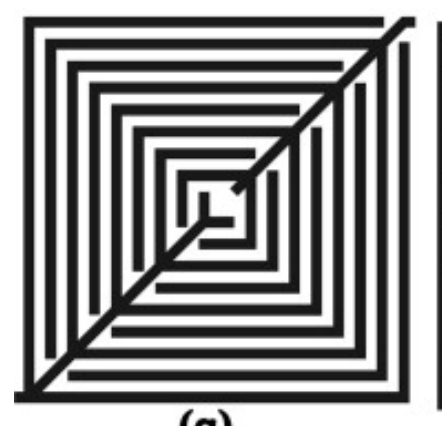

(a)

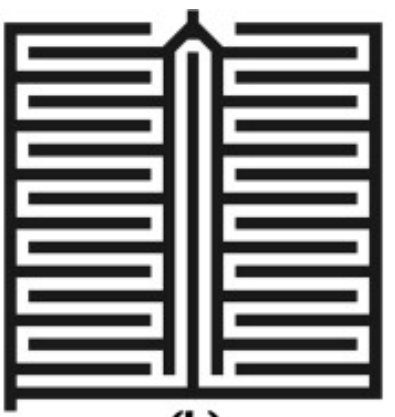

(b)

Figure 24. a) Leaf- and b) lung-inspired, biomimetic flow field designs. The inlet is at the top and the outlet is at the bottom. ${ }^{[133 b]}$ Reprinted from ${ }^{[133 b]}$ with permission from Elsevier.

However, additional experimental evaluation of these designs is necessary in order to validate fuel cell performance and scalability of the system under extensive fuel cell operation. An essential shortcoming of these biomimetic designs is the lack of a rigorous theoretical motivation to support them. Even though the inspirational source is clear, the absence of an underlying theory makes it difficult to test alternative designs, as there is no theoretical basis to compare against. Interesting fundamental properties of the pulmonary architecture, such as the fractal structure of the bronchial tree, which is tied to its scalability and efficiency ${ }^{[8 i, 134]}$, are not utilized.

\subsection{Modeling}

Computational modeling has been extensively employed to study the effect of operational parameters as well as cell components on fuel-cell performance ${ }^{[58 \mathrm{~s}, 135]}$, without accounting for the structure of the material. Many numerical models have been developed with increasingly less restrictive assumptions and more physical complexities to provide solutions for the equations that incorporate the electrochemical kinetics and thermodynamics, as well as heat, mass, charge and momentum transport. ${ }^{[58 s, 135-136]}$ A brief and by no means comprehensive overview is provided in Supplementary Information; it is clear that further development of multi-scale modeling approaches is required to account for not only the steady state, but also the dynamics of the complex, multi-phase phenomena occurring in electrocatalysts and fuel cells. This is especially 
so in view of the tremendous progress in capabilities to synthesize hierarchically structured nanomaterials; these experimental synthetic capabilities can only be truly taken advantage of if they are complemented by simulations that allow to interpret experiments, and guide the engineering of better electrochemical devices.

\subsection{Rational Design Guided by Nature-Inspired Engineering}

Even though Pt is a highly efficient electrocatalyst for PEFCs, the high cost of this material dictates the use of low Pt loading or novel nanostructured $\mathrm{Pt}$ or Pt alloy-based catalysts. A nature-inspired chemical engineering (NICE) approach can aid towards achieving the low Pt loading target by modifying the PEFC design, guided by the hierarchical structure of the lung. ${ }^{[8 c]}$ Nature-inspired engineering researches the fundamental mechanism underlying a desired property or function in nature and applies this mechanism in a technological context. ${ }^{[8 c]}$

The respiratory tract of a mammalian lung has a self-similar, fractal structure consisting of many generations of branches (14-16 for the adult human lung), from the trachea to the bronchioles, in which flow dominates transport, followed by generations of space-filling acini lined by alveoli in which diffusion dominates transport. ${ }^{[137]}$ Entropy production while breathing is uniformly distributed and globally minimized in both regimes ${ }^{[8 i, 134,137]}$, a very desirable property from the point of view of thermodynamic efficiency. ${ }^{[138]}$ The fractal architecture of the upper part of the lung, which is similar to a tree ${ }^{[139]}$, connects multiple microscopic elements to a single macroscopic element via equal hydraulic path lengths providing equal transport rates to or from the cells. ${ }^{[8]} \mathrm{A}$ great advantage of this fractal structure is its scalability. The fractal network can be broadened by adding a generation, while keeping the structure of the microscopic building units the same (Figure 25). ${ }^{[8 b]}$
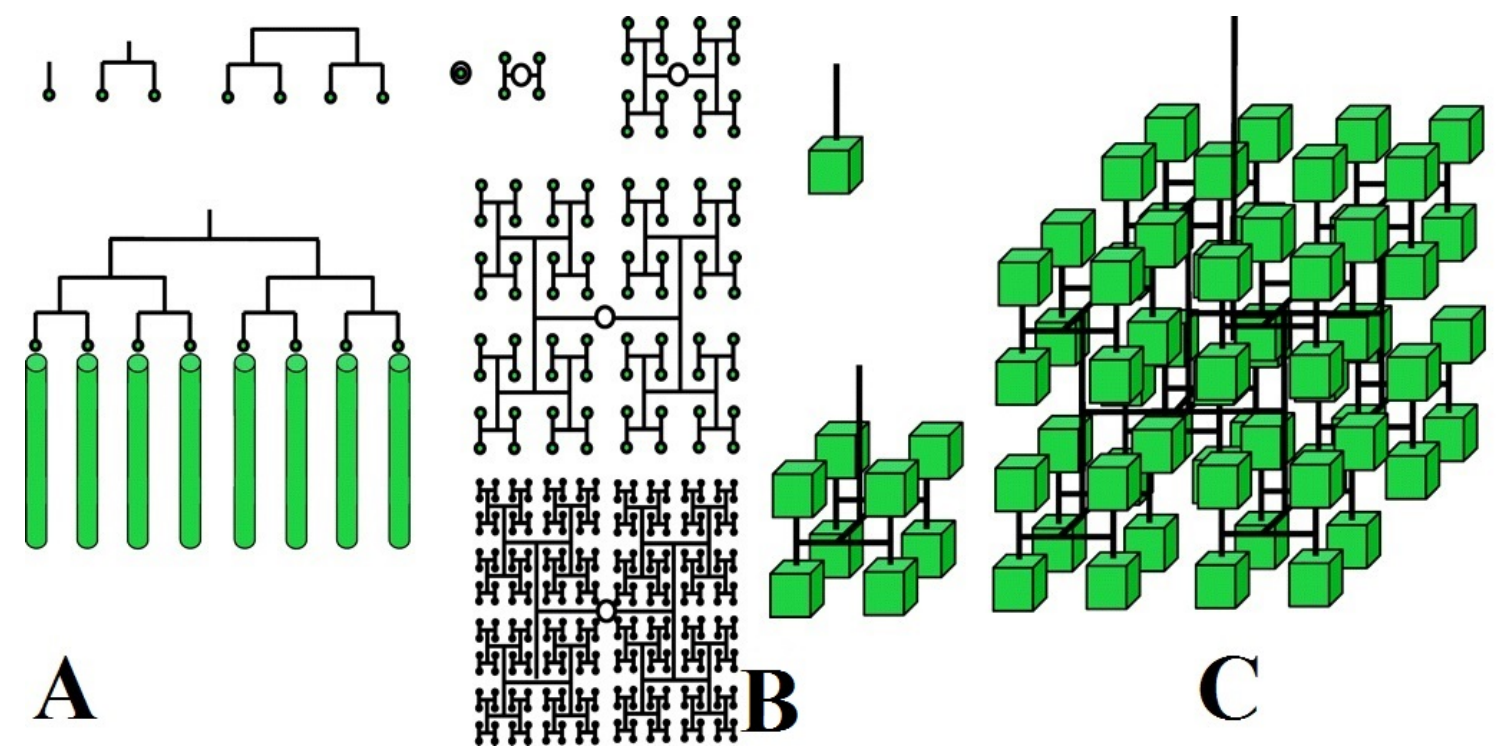

Figure 25. A set of 1D distributors feeding progressively larger 1D arrays (vectors); b-c) extension of the scalable, fractal distributor concept to 2D and $3 \mathrm{D}$, respectively.

These observations, already successfully applied to fractal injectors in multiphase reactors, such as fluidized beds ${ }^{[8 \mathrm{~b}, 140]}$, can be used as a building principle for fuel-cell design as well. Figure 26 shows a two-dimensional fractal distributor built inhouse, by rapid prototyping or stereo-lithography. Air or oxygen enters the distributor through a single inlet; it flows through the branching channels and eventually exits the distributor through a square array of outlets, which have the same hydraulic distance from the inlet. As a result, this fractal distributor uniformly feeds reactants $\left(\mathrm{O}_{2} /\right.$ air $)$ to the catalyst layer, while produced water is removed via an embedded collector, circumventing the non-uniformity issues of other flow-field geometries. Fuel cell performance measurements are currently under way. 


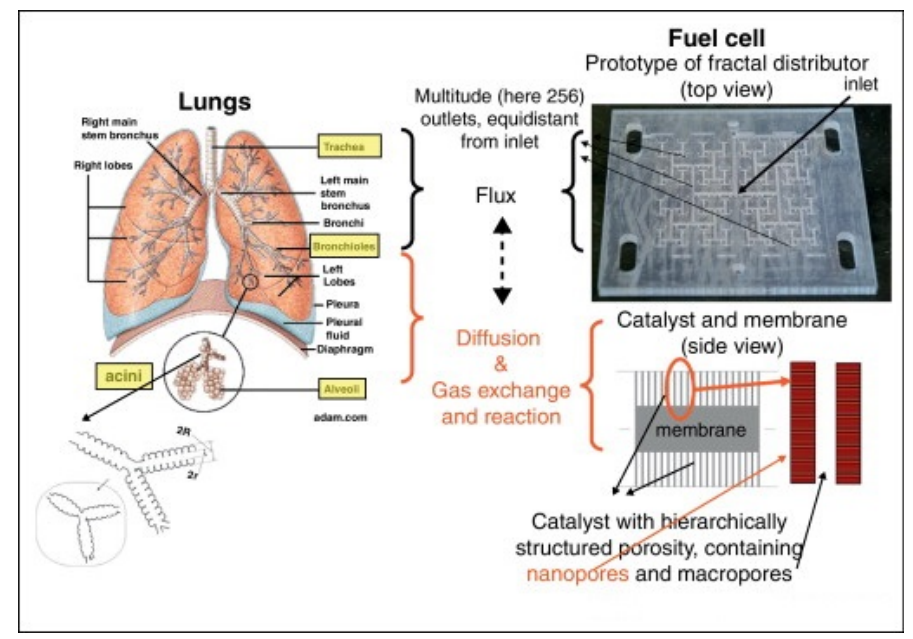

Figure 26. Fuel cell design guided by the architecture of the lung and the associated physical mechanisms. ${ }^{[8 c]}$ Reprinted from ${ }^{[8 c]}$ with permission from Elsevier.

Murray's law can be used to design fractal distributors. ${ }^{[141]}$ Murray found, for vascular networks, that the flow of blood past any section should bear the same relation to the cube of the radius of the vessel at that point. By derivation, the cube of the radius of the parent vessel must be equal to the sum of the cubes of the radii of the daughter vessels. An extended Murray's law (Eqn. 9) is obeyed in the vascular and pulmonary systems of animals, as well as in the xylem structures of plants ${ }^{[133 a}$, 142].

$$
r_{p}^{\Delta}=r_{d 1}^{\Delta}+r_{d 2}^{\Delta}+\cdots+r_{d n}^{\Delta}
$$

where $r_{p}$ is the radius of the parent vessel, $r_{d 1}, \ldots, r_{d n}$ are the radii of the daughter vessels and $\Delta$ the diameter exponent (for example, $\Delta=2$ for many botanical trees, $\Delta=2.7$ for the arteries and $\Delta=3$ for the lung). ${ }^{[143]}$

Murray's law has been used to develop non-fractal flow field designs as well (Figure 27), to address the issue of nonuniform current density distribution across a fuel cell. ${ }^{[142 a]}$ The side branches are connected directly to a side channel that is gradually increasing in width as more branches are attached according to Murray's law. ${ }^{[142 a]}$

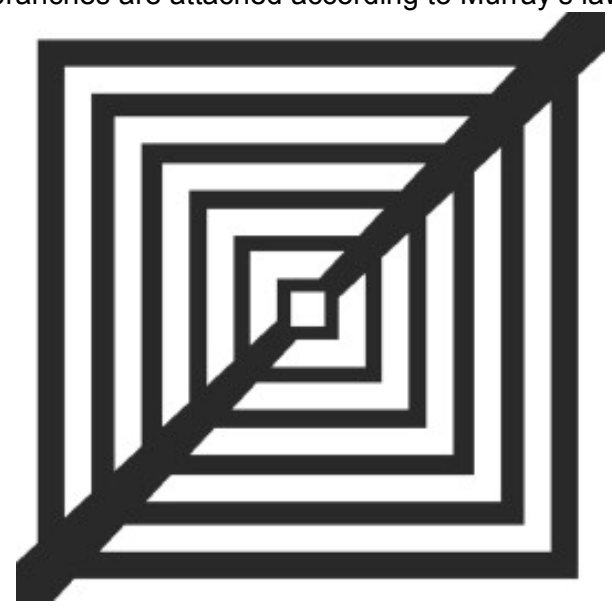

Figure 27. Parallel channel flow field design incorporating Murray's branching law design. ${ }^{[142 a]}$ Copyright ${ }^{\circledR} 2010$ Wiley.

The depicted flow field exhibits lower pressure drop than serpentine designs and, hence, reduces the parasitic load required to pump fuel/oxidant gas. ${ }^{[142 a]}$ However, this flow field does not display inherent fractal scalability and was observed to be prone to flooding during fuel-cell operation at a low temperature $\left(70^{\circ} \mathrm{C}, 100 \% \mathrm{RH}\right)$. This issue could be resolved if the fuel cell 
was operated at high temperatures $\left(>100^{\circ} \mathrm{C}\right)$ and low relative humidities where the water is always in the vapor phase, and the improved mass transfer and reduced pressure drop characteristics of the Murray's-law-based flow field could be fully utilized.

Combined with a fractal design, Murray's law provides a formal theoretical foundation to optimize flow field design. Nevertheless, while Murray's law provides a relation between parent and daughter channel dimensions at a branch, it does not provide a criterion for the number of branches. Further research is needed to identify the optimal channel dimensions, the optimal number of branches, as well as the design limitations of these flow fields. The structure of the lung suggests that the final generation of the fractal distributor contains uniformly spaced outlets just close enough to allow for a seamless interface via diffusion to and in the hierarchically structured catalytic layer, as illustrated in Figure 27.

These preliminary results show that nature-inspired flow field designs have tremendous potential to become the new standard for fuel cell performance and reliability, thanks to their inherent scalability and efficiency. Extensive research is needed, though, to optimize the mathematical foundation of the design, carry out experimental studies of the flow field designs for extended periods and under various transient loads, and evaluate the practical scalability of the system by taking into account the cost of materials and manufacturing complexity. The latter issues should be increasingly addressed by progress in micromachining and additive manufacturing methods.

\section{Conclusions and Outlook}

The utilization of hierarchical nanomaterials in electrochemical energy conversion to optimize the electronic and ionic mobility and kinetics at multiphase boundaries is an area of growing interest. Controlling the architecture of these materials at multiple length scales, and not only at the nano-scale, is critical to improve their properties. The nanopores of these materials lead to a large surface area, providing short diffusion lengths and excellent multiphase contact, while the macropores improve the overall transport properties and maximize effective performance.

Several experimental methods are used for the synthesis of hierarchical nanomaterials, including templating, self-formation and galvanic replacement. Hollow Pt or Pt alloys synthesized by galvanic replacement exhibit enhanced catalytic properties towards ORR and MOR and high tolerance to $\mathrm{CO}$ poisoning. Similar results are observed when hierarchical metal oxides are used as electrodes in batteries: the interconnected wall structure provides a continuous electron pathway, increasing their conductivity. Additionally, meso/macroporous carbon, hollow graphitic spheres, and mixed-metal oxides can be used as alternative catalyst supports; the high surface area and mesoporosity of these materials allows high catalyst dispersion and reactant flow, leading to increased catalytic activity towards MOR and ORR. Furthermore, mixed-metal oxide supports offer excellent corrosion resistance under automotive drive cycles.

To further improve the design of these hierarchical nanomaterials, in-depth research on the effect of their architecture on reaction and transport kinetics is necessary. This requires multi-scale models that properly account for the physical and chemical phenomena at all scales. Nature can be an excellent guide to rational design, as it is full of hierarchical structures that are intrinsically scaling, efficient and robust. This, however, should not reduce to mindless imitation: the biological example needs to be properly chosen, and the different context of technological applications should be accounted for. Thus far, the majority of "biomimetic" research is focused on imitating isolated features of biological structures to synthesize new supports, catalysts or flow fields for PEFCs with sub-optimal results. In most cases, the actual physical processes that govern the system are neglected. Biological systems include different optimal architectures at different scales, and the equipartition of entropy production is a guiding principle to maximize energy efficiency. A plethora of computational models are now available to examine the effect of fuel cell operating conditions, flow field design and catalysts structure on fuel cell performance. In combination with experiments and building on progress in synthesis and manufacturing methods, these models can serve to create highly performing, scalable fuel cells and other electrochemical systems.

Hence, we suggest focusing research on the fundamental understanding of hierarchical structure/function relationships in biological systems, and to use this understanding in guiding the computationally assisted development of novel, natureinspired hierarchical catalytic nanomaterials and electrochemical devices. Initial results on the development of biologically inspired flow field designs based on Murray's law that governs the vascular systems of animals and the xylem structures of plants suggest that nature-inspired flow field designs have tremendous potential to become the new standard for fuel-cell performance. 
Acknowledgments. MOC and PT gratefully acknowledge the EPSRC for funding via a "Frontier Engineering" Award, EP/K038656/1. PS and PT would like to acknowledge German DFG for funding through STR 596/4-1. 
Nomenclature

\begin{tabular}{|c|c|}
\hline 3DOM & 3D ordered macroporous nanomaterials \\
\hline AOR & Alcohol oxidation reaction \\
\hline CNC & Cubic nanocages \\
\hline CV & Cyclic voltammogram \\
\hline $\mathrm{CDH}$ & Cubic dendritic hollow nanocrystals \\
\hline CNF & Carbon nanofiber \\
\hline CVD & Chemical vapor deposition \\
\hline DMFC & Direct methanol fuel cell \\
\hline DOMC & Disordered mesoporous carbon \\
\hline ECA & Electrochemically active surface area \\
\hline fcc & Face centered cubic \\
\hline GDL & Gas diffusion layer \\
\hline HER & Hydrogen evolution reaction \\
\hline HGS & Hollow graphitic spheres \\
\hline HOR & Hydrogen oxidation reaction \\
\hline ITO & Indium tin oxide \\
\hline LB & Lattice Boltzmann model \\
\hline LSV & Linear sweep voltammetry \\
\hline MOR & Methanol oxidation reaction \\
\hline MWCNTs & Multi-walled carbon nanotubes \\
\hline NHE & Normal hydrogen electrode $\left(E_{o}=0 \mathrm{~V}\right)$ \\
\hline NICE & Nature-inspired chemical engineering \\
\hline $\mathrm{OH}^{*}$ & Hydroxyl radicals \\
\hline $\mathrm{ODH}$ & Octahedral dendritic hollow nanocrystals \\
\hline OMC & Ordered mesoporous carbon \\
\hline ONC & Octahedral nanocages \\
\hline ORR & Oxygen reduction reaction \\
\hline PEO & Polyethylene oxide \\
\hline PEFC & Polymer electrolyte fuel cell \\
\hline PM & Pore morphology model \\
\hline PN & Pore network model \\
\hline PMMA & Polymethyl methacrylate \\
\hline PVP & Polyvinylpyrrolidone \\
\hline RHAHS & Raspberry hierarchical Au/Pt hollow spheres \\
\hline RHE & Reversible hydrogen electrode $\left(E_{0}=0 \mathrm{~V}\right)$ \\
\hline RRDE & Rotating ring-disk electrode \\
\hline SCE & Saturated calomel electrode $\left(E_{0}=+0.243 \vee\right.$ vs. $\left.S H E\right)$ \\
\hline SEM & Scanning electron microscopy \\
\hline STEM & Scanning transmission electron microscopy \\
\hline TEM & Transmission electron microscopy \\
\hline TMA & Trimethylaluminum \\
\hline
\end{tabular}


Keywords: Hierarchical materials $\cdot$ Hollow bimetallic nanoparticles $\cdot$ Hierarchical supports $•$ Electrochemical energy devices - Kirkendall effect • Galvanic replacement Nature inspired engineering 
[1] Q. Peng, Y. Dong, Y. Li, Angew. Chem. Int. Ed. 2003, 42, 3027-3030.

[2] a) H. Gao, B. Ji, I. L. Jäger, E. Arzt, P. Fratzl, PNAS 2003, 100, 5597-5600; b) D. Sen, M. J. Buehler, Sci. Rep. 2011, 1; c) H. Yao, H. Gao, Int. J. Solids Struct. 2007, 44, 8177-8193.

[3] B. Bhushan, Philosoph. Trans. Royal Soc. A: Mathem. Phys. Eng. Sc. 2009, 367, 1445-1486.

[4] M. J. Buehler, S. Keten, T. Ackbarow, Progr. Mater. Sc. 2008, 53, 1101-1241.

[5] a) J. Aizenberg, J. C. Weaver, M. S. Thanawala, V. C. Sundar, D. E. Morse, P. Fratzl, Science 2005, 309, 275-278; b) J. D. Currey, Proceedings of the Royal Society of London. Series B. Biological Sciences 1977, 196, 443-463; c) P. Fratzl, R. Weinkamer, Progr. Mater. Sc. 2007, 52, 1263-1334; d) A. P. Jackson, J. F. V. Vincent, R. M. Turner, Proceedings of the Royal Society of London. Series B. Biological Sciences 1988, 234, 415-440; e) S. Kamat, X. Su, R. Ballarini, A. H. Heuer, Nature 2000, 405, 1036-1040; f) S. Keten, Z. Xu, B. Ihle, M. J. Buehler, Nat. Mater. 2010, 9, 359-367; g) R. Menig, M. H. Meyers, M. A. Meyers, K. S. Vecchio, Mater. Sc. Eng.: A 2001, 297, 203-211; h) J.Y. Rho, L. Kuhn-Spearing, P. Zioupos, Med. Eng. Phys.cs, 20, 92-102; i) M. Sarikaya, Microsc. Res. Techniq. 1994, 27, 360-375; j) S. Weiner, H. D. Wagner, Annu. Rev. Mater. Sc. 1998, 28, 271-298.

[6] a) W. J. Landis, Bone, 16, 533-544; b) W. J. Landis, K. J. Hodgens, M. J. Song, J. Arena, S. Kiyonaga, M. Marko, C. Owen, B. F. McEwen, J. Struct. Biology 1996, 117, 24-35.

[7] B. Zhao, M. M. Collinson, Chem. Mater. 2010, 22, 4312-4319.

[8] a) M.-O. Coppens, Catal. Today 1999, 53, 225-243; b) M.-O. Coppens, Ind. Eng. Chem. Res. 2005, 44, 5011-5019; c) M.-O. Coppens, Curr. Opin. Chem. Eng. 2012, 1, 281-289; d) M. O. Coppens, ChemInform 2011, 42; e) M. O. Coppens, G. Wang, Design of Heterogeneous Catalysts: New Approaches based on Synthesis, Characterization and Modeling 2009, 25-58; f) M.-O. Coppens, G. F. Froment, Fractals 1997, 5, 493-505; g) M.-O. Coppens, S. Gheorghiu, P. Pfeifer, Studies in Surface Science and Catalysis 2005, 156, 371-378; h) S. Gheorghiu, M. O. Coppens, AlChE J. 2004, 50, 812-820; i) C. Hou, S. Gheorghiu, M.-O. Coppens, V. H. Huxley, P. Pfeifer, in Fractals in Biology and Medicine, Springer, 2005, pp. 17-30; j) E. Johannessen, G. Wang, M.-O. Coppens, Ind. Eng. Chem. Res. 2007, 46, 4245-4256; k) G. Wang, E. Johannessen, C. R. Kleijn, S. W. de Leeuw, M.-O. Coppens, Chem. Eng. Sc. 2007, 62, 5110-5116.

[9] a) N. Liu, W. Li, M. Pasta, Y. Cui, Front. Phys. 2014, 9, 323-350; b) Z.-Y. Yuan, B.-L. Su, J. Mater. Chem. 2006, 16, 663-677.

[10] a) D. M. Antonelli, J. Y. Ying, Angew. Chem. Int. Ed. 1996, 35, 426-430; b) A. Sayari, Y. Yang, The J. Phys. Chem. B 2000, 104, 4835-4839.

[11] a) F. Jiao, P. G. Bruce, Angew. Chem. Int. Ed. 2004, 43, 5958-5961; b) J. Lee, S. Yoon, T. Hyeon, S. M. Oh, K. Bum Kim, Chem. Comm. 1999, 2177-2178; c) W.-C. Li, A.-H. Lu, C. Weidenthaler, F. Schüth, Chem. Mater. 2004, 16, 5676-5681.

[12] a) C. Perego, R. Millini, Chem. Soc. Rev. 2013, 42, 3956-3976; b) Y. Ye, C. Jo, I. Jeong, J. Lee, Nanoscale 2013, 5, 4584-4605; c) S. Meoto, M.-O. Coppens, J. Mater. Chem. A 2014, 2, 56405654; d) R. Pitchumani, J. J. Heiszwolf, A. Schmidt-Ott, M. O. Coppens, Micropor. Mesopor. Mater. 2009, 120, 39-46; eJ.-K. Sun, Q. Xu, Energ. Env. Sc. 2014, 7, 2071-2100.

[13] a) A. Fischer, Y.-S. Jun, A. Thomas, M. Antonietti, Chem. Mater. 2008, 20, 7383-7389; b) N. D. Petkovich, A. Stein, Chem. Soc. Rev. 2013, 42, 3721-3739; c) A. Stein, S. G. Rudisill, N. D. Petkovich, Chem. Mater. 2013, 26, 259-276.

[14] a) J. Lee, J. Kim, T. Hyeon, Adv. Mater. 2006, 18, 2073-2094; b) C. Liang, Z. Li, S. Dai, Angew. Chem. Int. Ed. 2008, 47, 3696-3717; c) R. Ryoo, S. H. Joo, S. Jun, J. Phys. Chem. B 1999, 103, 7743-7746.

[15] a) A. Fischer, M. Antonietti, A. Thomas, Adv. Mater. 2007, 19, 264-267; b) A. Fischer, J. O. Müller, M. Antonietti, A. Thomas, ACS Nano 2008, 2, 2489-2496.

[16] a) A. Fischer, P. Makowski, J.-O. Müller, M. Antonietti, A. Thomas, F. Goettmann, ChemSusChem 2008, 1, 444-449; b) S. Kaskel, K. Schlichte, G. Chaplais, M. Khanna, J. Mater. Chem. 2003, 13, 
1496-1499; c) S. Kaskel, K. Schlichte, T. Kratzke, J. Mol. Catal. A: Chemical 2004, 208, 291-298; d) O. T. M. Musthafa, S. Sampath, Chem. Comm. 2008, 67-69.

[17] M. Kawaguchi, K. Nozaki, Chem. Mater. 1995, 7, 257-264.

[18] A. Stein, R. C. Schroden, Curr. Opin. Solid State Mater. Sc. 2001, 5, 553-564.

[19] a) A. Blanco, E. Chomski, S. Grabtchak, M. Ibisate, S. John, S. W. Leonard, C. Lopez, F. Meseguer, H. Miguez, J. P. Mondia, G. A. Ozin, O. Toader, H. M. van Driel, Nature 2000, 405, 437-440; b) H. Kajii, Y. Kawagishi, H. Take, K. Yoshino, A. A. Zakhidov, R. H. Baughman, J. Appl. Phys. 2000, 88, 758-763; c) A. A. Zakhidov, R. H. Baughman, Z. Iqbal, C. Cui, I. Khayrullin, S. O. Dantas, J. Marti, V. G. Ralchenko, Science 1998, 282, 897-901.

[20] a) B. T. Holland, L. Abrams, A. Stein, J. Am. Chem.Soc. 1999, 121, 4308-4309; b) B. T. Holland, C. F. Blanford, T. Do, A. Stein, Chem. Mater. 1999, 11, 795-805; c) B. T. Holland, C. F. Blanford, A. Stein, Science 1998, 281, 538-540; d) B. Lebeau, C. E. Fowler, S. Mann, C. Farcet, B. Charleux, C. Sanchez, J. Mat. Chem. 2000, 10, 2105-2108; e) O. D. Velev, T. A. Jede, R. F. Lobo, A. M. Lenhoff, Nature 1997, 389, 447-448; f) O. D. Velev, T. A. Jede, R. F. Lobo, A. M. Lenhoff, Chem. Mater. 1998, 10, 3597-3602; g) J. E. G. J. Wijnhoven, W. L. Vos, Science 1998, 281, 802-804; h) H. Yan, C. F. Blanford, B. T. Holland, W. H. Smyrl, A. Stein, Chem. Mater. 2000, 12, 1134-1141; i) J. S. Yin, Z. L. Wang, Appl. Phys. Lett. 1999, 74, 2629-2631.

[21] a) Y. Chen, W. T. Ford, N. F. Materer, D. Teeters, J. Am. Chem. Soc. 2000, 122, 10472-10473; b) B. Gates, Y. Yin, Y. Xia, Chem. Mater. 1999, 11, 2827-2836; c) P. Jiang, K. S. Hwang, D. M. Mittleman, J. F. Bertone, V. L. Colvin, J. Am. Chem. Soc. 1999, 121, 11630-11637; d) S. A. Johnson, P. J. Ollivier, T. E. Mallouk, Science 1999, 283, 963-965; e) S. H. Park, Y. Xia, Chem. Mater. 1998, 10, 1745-1747; f) M. Srinivasarao, D. Collings, A. Philips, S. Patel, Science 2001, 292, 79-83; g) T.-B. Xu, Z.-Y. Cheng, Q. M. Zhang, R. H. Baughman, C. Cui, A. A. Zakhidov, J. Su, J. Appl. Phys. 2000, 88, 405-409.

[22] a) P. N. Bartlett, P. R. Birkin, M. A. Ghanem, C.-S. Toh, J. Mater. Chem. 2001, 11, 849-853; b) P. V. Braun, P. Wiltzius, Nature 1999, 402, 603-604; cP. V. Braun, P. Wiltzius, Adv. Mater. 2001, 13, 482-485.

[23] A. Stein, B. E. Wilson, S. G. Rudisill, Chem. Soc. Rev. 2013, 42, 2763-2803.

[24] Z. Sun, Y. Deng, J. Wei, D. Gu, B. Tu, D. Zhao, Chem. Mater. 2011, 23, 2176-2184.

[25] F. Li, M. B. Wilker, A. Stein, Langmuir 2012, 28, 7484-7491.

[26] a) Z. Wang, F. Li, N. S. Ergang, A. Stein, Chem. Mater. 2006, 18, 5543-5553; b) Y. Xia, Z. Yang, R. Mokaya, J. Phys. Chem. B 2004, 108, 19293-19298; c) Z. Yan, Z. Peng, J. M. Tour, Acc. Chem. Res. 2014, 47, 1327-1337.

[27] T. Kyotani, T. Nagai, S. Inoue, A. Tomita, Chem. Mater. 1997, 9, 609-615.

[28] a) Y. Xia, R. Mokaya, Adv. Mater. 2004, 16, 1553-1558; b) Y. Xia, R. Mokaya, Chem. Mater. 2005, 17, 1553-1560; c) Y. Xia, Z. Yang, R. Mokaya, Chem. Mater. 2005, 18, 140-148; d) Y. Zhang, L. Zhang, C. Zhou, Acc. Chem. Res. 2013, 46, 2329-2339.

[29] K. L. Choy, Progr. Mater. Sc. 2003, 48, 57-170.

[30] P. Marchand, I. A. Hassan, I. P. Parkin, C. J. Carmalt, Dalton Trans. 2013, 42, 9406-9422.

[31] a) K. An, T. Hyeon, Nano Today 2009, 4, 359-373; b) F. Caruso, R. A. Caruso, H. Möhwald, Science 1998, 282, 1111-1114.

[32] a) H. J. Fan, U. Gösele, M. Zacharias, Small 2007, 3, 1660-1671; b) Y. Yin, R. M. Rioux, C. K. Erdonmez, S. Hughes, G. A. Somorjai, A. P. Alivisatos, Science 2004, 304, 711-714.

[33] a) J. Chen, H. Lu, S. Wang, Y. Shang, J. Asian Earth Sc. 2005, 25, 473-480; b) S. E. Skrabalak, J. Chen, Y. Sun, X. Lu, L. Au, C. M. Cobley, Y. Xia, Acc. Chem. Res. 2008, 41, 1587-1595.

[34] a) H. J. Fan, M. Knez, R. Scholz, D. Hesse, K. Nielsch, M. Zacharias, U. Gösele, Nano Letters 2007, 7, 993-997; b) H. Nakajima, JOM 1997, 49, 15-19.

[35] S. Peng, S. Sun, Angew. Chem. Int. Ed. 2007, 46, 4155-4158. 
[36] a) A. Cabot, R. K. Smith, Y. Yin, H. Zheng, B. M. Reinhard, H. Liu, A. P. Alivisatos, ACS Nano 2008, 2, 1452-1458; b) H. Cao, X. Qian, J. Zai, J. Yin, Z. Zhu, Chem. Comm. 2006, 4548-4550; c) Y. Chang, M. L. Lye, H. C. Zeng, Langmuir 2005, 21, 3746-3748; d) X. Chen, Z. Zhang, Z. Qiu, C. Shi, X. Li, J. Colloid Interf. Sc. 2007, 308, 271-275; e) R.-K. Chiang, R.-T. Chiang, Inorg. Chem. 2006, 46, 369371; f) A. E. Henkes, Y. Vasquez, R. E. Schaak, J. Am. Chem. Soc. 2007, 129, 1896-1897; g) X. Liang, X. Wang, Y. Zhuang, B. Xu, S. Kuang, Y. Li, J. Am. Chem. Soc. 2008, 130, 2736-2737; h) R. Nakamura, J. G. Lee, D. Tokozakura, H. Mori, H. Nakajima, Materi. Lett. 2007, 61, 1060-1063; i) H.-F. Shao, X.-F. Qian, Z.-K. Zhu, J. Solid State Chem. 2005, 178, 3522-3528; j) E. V. Shevchenko, M. I. Bodnarchuk, M. V. Kovalenko, D. V. Talapin, R. K. Smith, S. Aloni, W. Heiss, A. P. Alivisatos, Adv. Mater. 2008, 20, 4323-4329; k) E. V. Shevchenko, J. Kortright, D. V. Talapin, S. Aloni, A. P. Alivisatos, Adv. Mater. 2007, 19, 4183-4188; I) H. Tan, S. Li, W. Y. Fan, J. Phys. Chem. B 2006, 110, 15812-15816; m) S. Zhou, B. Varughese, B. Eichhorn, G. Jackson, K. Mcllwrath, Angew. Chem. Int. Ed. 2005, 44, 4539-4543; n) J. X. Wang, C. Ma, Y. Choi, D. Su, Y. Zhu, P. Liu, R. Si, M. B. Vukmirovic, Y. Zhang, R. R. Adzic, J. Am. Chem. Soc. 2011, 133, 13551-13557.

[37] H. J. Fan, M. Knez, R. Scholz, K. Nielsch, E. Pippel, D. Hesse, M. Zacharias, U. Gösele, Nat. Mater. 2006, 5, 627-631.

[38] a) M. Heggen, M. Oezaslan, L. Houben, P. Strasser, J. Phys. Chem. C 2012, 116, 19073-19083; b) M. Oezaslan, F. Hasché, P. Strasser, J. Phys. Chem. Lett. 2013, 4, 3273-3291.

[39] a) M. Chen, L. Gao, Inorg. Chem. 2006, 45, 5145-5149; b) S. Guo, Y. Fang, S. Dong, E. Wang, J. Phys. Chem. C 2007, 111, 17104-17109; c) H. P. Liang, Y. G. Guo, H. M. Zhang, J. S. Hu, L. J. Wan, C. L. Bai, Chem. Comm. 2004, 10, 1496-1497; d) H. P. Liang, H. M. Zhang, J. S. Hu, Y. G. Guo, L. J. Wan, C. L. Bai, Angew. Chem. Int. Ed. 2004, 43, 1540-1543; e) H.-P. Liang, L.-J. Wan, C.-L. Bai, L. Jiang, J. Phys. Chem. B 2005, 109, 7795-7800; f) Y. Vasquez, A. K. Sra, R. E. Schaak, J. Am. Chem. Soc. 2005, 127, 12504-12505; g) J. Zeng, J. Huang, W. Lu, X. Wang, B. Wang, S. Zhang, J. Hou, Adv. Mater. 2007, 19, 2172-2176.

[40] a) S. R. Brankovic, J. X. Wang, R. R. Adžić, Surf. Sc. 2001, 474, L173-L179; b) L. Yang, M. B. Vukmirovic, D. Su, K. Sasaki, J. A. Herron, M. Mavrikakis, S. Liao, R. R. Adzic, J. Phys. Chem. C 2012, 117, 1748-1753; c) J. Zhang, F. H. B. Lima, M. H. Shao, K. Sasaki, J. X. Wang, J. Hanson, R. R. Adzic, J. Phys. Chem. B 2005, 109, 22701-22704; d) J. Zhang, Y. Mo, M. B. Vukmirovic, R. Klie, K. Sasaki, R. R. Adzic, J. Phys. Chem. B 2004, 108, 10955-10964; e) Y. Zhang, C. Ma, Y. Zhu, R. Si, Y. Cai, J. X. Wang, R. R. Adzic, Catal. Today 2013, 202, 50-54.

[41] R. Loukrakpam, Q. Yuan, V. Petkov, L. Gan, S. Rudi, R. Yang, Y. Huang, S. R. Brankovic, P. Strasser, Phys. Chem. Chem. Phys. 2014, 16, 18866-18876.

[42] a) E. S. Toberer, J. D. Epping, B. F. Chmelka, R. Seshadri, Chem. Mater. 2006, 18, 6345-6351; b) J. Erlebacher, M. J. Aziz, A. Karma, N. Dimitrov, K. Sieradzki, Nature 2001, 410, 450-453; c) P. Levitz, G. Ehret, S. K. Sinha, J. M. Drake, J. Chem. Phys. 1991, 95, 6151-6161; d) X. Li, M. Sun, J. C. Rooke, L. Chen, B.-L. Su, Chinese J. Catal. 2013, 34, 22-47; e) M. Panda, M. Rajamathi, R. Seshadri, Chem. Mater. 2002, 14, 4762-4767; f) Y. Suzuki, N. Kondo, T. Ohji, J. Am. Ceramic Soc. 2003, 86, 1128-1131; g) E. S. Toberer, A. Joshi, R. Seshadri, Chem. Mater. 2005, 17, 2142-2147; h) E. S. Toberer, J. C. Weaver, K. Ramesha, R. Seshadri, Chem. Mater. 2004, 16, 2194-2200.

[43] a) Y. Ding, J. Erlebacher, J. Am. Chem. Soc. 2003, 125, 7772-7773; b) Y. Ding, A. Mathur, M. Chen, J. Erlebacher, Angew. Chem. Int. Ed. 2005, 44, 4002-4006; c) T. Fujita, P. Guan, K. McKenna, X. Lang, A. Hirata, L. Zhang, T. Tokunaga, S. Arai, Y. Yamamoto, N. Tanaka, Y. Ishikawa, N. Asao, Y. Yamamoto, J. Erlebacher, M. Chen, Nat. Mater. 2012, 11, 775-780; d) J. Rugolo, J. Erlebacher, K. Sieradzki, Nat. Mater. 2006, 5, 946-949; eJ. Snyder, T. Fujita, M. W. Chen, J. Erlebacher, Nat. Mater. 2010, 9, 904-907; f) J. Snyder, I. McCue, K. Livi, J. Erlebacher, J. Am. Chem. Soc. 2012, 134, 8633-8645. 
[44] a) Y. F. Shen, R. P. Zerger, R. N. DeGuzman, S. L. Suib, L. McCurdy, D. I. Potter, C. L. O'Young, Science 1993, 260, 511-515; b) Z.-R. Tian, W. Tong, J.-Y. Wang, N.-G. Duan, V. V. Krishnan, S. L. Suib, Science 1997, 276, 926-930; c) E. S. Toberer, T. D. Schladt, R. Seshadri, J. Am. Chem. Soc. 2006, 128, 1462-1463.

[45] a) W. Liu, A.-K. Herrmann, N. C. Bigall, P. Rodriguez, D. Wen, M. Oezaslan, T. J. Schmidt, N. Gaponik, A. Eychmüller, Acc. Chem. Res. 2015, 48, 154-162; b) W. Liu, A.-K. Herrmann, D. Geiger, L. Borchardt, F. Simon, S. Kaskel, N. Gaponik, A. Eychmüller, Angew. Chem. Int. Ed. 2012, 51, 5743-5747; c) W. Liu, P. Rodriguez, L. Borchardt, A. Foelske, J. Yuan, A.-K. Herrmann, D. Geiger, Z. Zheng, S. Kaskel, N. Gaponik, R. Kötz, T. J. Schmidt, A. Eychmüller, Angew. Chem. Int. Ed. 2013, 52, 9849-9852; d) H. Chen, G. Wei, A. Ispas, S. G. Hickey, A. Eychmüller, J. Phys. Chem. C 2010, 114, 21976-21981; e) N. Gaponik, A.-K. Herrmann, A. Eychmüller, J. Phys. Chem. Lett. 2012, 3, 817; f) A.-K. Herrmann, P. Formanek, L. Borchardt, M. Klose, L. Giebeler, J. Eckert, S. Kaskel, N. Gaponik, A. Eychmüller, Chem. Mater. 2014, 26, 1074-1083; g) L. Lu, A. Eychmüller, Acc. Chem. Res. 2008, 41, 244-253.

[46] a) J. Changlong, Z. Wangqun, Z. Guifu, Y. Weicao, Q. Yitai, Nanotechnology 2005, 16, 551; b) X. Fan, Z. Zhang, G. Li, N. A. Rowson, Chem. Eng. Sc. 2004, 59, 2639-2645; c) H. Tang, J. Chen, S. Yao, L. Nie, Y. Kuang, Z. Huang, D. Wang, Z. Ren, Mater. Chem. Phys. 2005, 92, 548-553; d) Z. Hua, Z. Shuyuan, P. Shuan, L. Gongpu, H. Jianguo, Nanotechnology 2004, 15, 945; e) X. Li, Y. Xiong, Z. Li, Y. Xie, Inorg. Chem. 2006, 45, 3493-3495; f) X. W. Lou, L. A. Archer, Z. Yang, Adv. Mater. 2008, 20, 3987-4019; g) Y. Ma, L. Qi, J. Colloid Interf. Sc. 2009, 335, 1-10; h) Y. Ma, R. Wang, H. Wang, J. Key, S. Ji, RSC Adv. 2015, 5, 9837-9842; i) Q. Peng, Y. Dong, Y. Li, Inorg. Chem. 2003, 42, 2174-2175; j) E. Prouzet, F. Cot, C. Boissiere, P. J. Kooyman, A. Larbot, J. Mater. Chem. 2002, 12, 1553-1556; k) D. G. Shchukin, K. Köhler, H. Möhwald, G. B. Sukhorukov, Angew. Chem. Int. Ed. 2005, 44, 3310-3314; I) X. Wang, Q. Peng, Y. Li, Acc. Chem. Res. 2007, 40, 635-643; m) J. J. Zhu, S. Xu, H. Wang, J. M. Zhu, H. Y. Chen, Adv. Mater. 2003, 15, 156-159.

[47] I. E. Rauda, R. Buonsanti, L. C. Saldarriaga-Lopez, K. Benjauthrit, L. T. Schelhas, M. Stefik, V. Augustyn, J. Ko, B. Dunn, U. Wiesner, D. J. Milliron, S. H. Tolbert, ACS Nano 2012, 6, 6386-6399.

[48] R. Chal, C. Gérardin, M. Bulut, S. van Donk, ChemCatChem 2011, 3, 67-81.

[49] A. K. Srivastava, Oxide Nanostructures: Growth, Microstructures, and Properties, 1st ed., Pan Stanford Publishing, 2014.

[50] A. Öchsner, A. Shokuhfar, New Frontiers of Nanoparticles and Nanocomposite Materials, Vol. 4, Springer Berlin Heidelberg, 2013.

[51] a) E. L. Crepaldi, G. J. d. A. A. Soler-Illia, D. Grosso, F. Cagnol, F. Ribot, C. Sanchez, J. Am. Chem. Soc. 2003, 125, 9770-9786; b) E. L. Crepaldi, G. J. d. A. A. Soler-Illia, D. Grosso, C. Sanchez, New J. Chem. 2003, 27, 9-13.

[52] S. Cheng, D. Yan, J. T. Chen, R. F. Zhuo, J. J. Feng, H. J. Li, H. T. Feng, P. X. Yan, J. Phys. Chem. C 2009, 113, 13630-13635.

[53] a) D. H. M. Buchold, C. Feldmann, Nano Lett. 2007, 7, 3489-3492; b) C. E. Fowler, D. Khushalani, S. Mann, J. Mater. Chem. 2001, 11, 1968-1971; c) A. V. Jovanovic, R. S. Underhill, T. L. Bucholz, R. S. Duran, Chem. Mater. 2005, 17, 3375-3383; d) T. Miyao, K. Minoshima, S. Naito, J. Mater. Chem. 2005, 15, 2268-2270.

[54] a) B. D. Anderson, J. B. Tracy, Nanoscale 2014, 6, 12195-12216; b) A. Cabot, A. P. Alivisatos, V. F. Puntes, L. Balcells, Ò. Iglesias, A. Labarta, Phys. Rev. B 2009, 79, 094419; c) A. Cabot, M. Ibáñez, P. Guardia, A. P. Alivisatos, J. Am. Chem. Soc. 2009, 131, 11326-11328; d) R.-K. Chiang, R.-T. Chiang, Inorg. Chem. 2007, 46, 369-371; e) Z. Fang, Y. Wang, C. Liu, S. Chen, W. Sang, C. Wang, J. Zeng, Small 2015, 11, 2593-2605; f) J. Gao, G. Liang, B. Zhang, Y. Kuang, X. Zhang, B. Xu, J. Am. Chem. Soc. 2007, 129, 1428-1433; g) J. Gao, B. Zhang, X. Zhang, B. Xu, Angew. Chem. Int. Ed. 2006, 45, 1220-1223; h) E. González, J. Arbiol, V. F. Puntes, Science 2011, 334, 1377-1380; i) S. 
Guo, S. Dong, E. Wang, Chem. Eur. J. 2008, 14, 4689-4695; j) L. Han, H. Liu, P. Cui, Z. Peng, S. Zhang, J. Yang, Sci. Rep. 2014, 4; k) J. Hu, M. Chen, X. Fang, L. Wu, Chem. Soc. Rev. 2011, 40, 5472-5491; I) Z. W. Shan, G. Adesso, A. Cabot, M. P. Sherburne, S. A. Syed Asif, O. L. Warren, D. C. Chrzan, A. M. Minor, A. P. Alivisatos, Nat. Mater. 2008, 7, 947-952; m) Y. Sun, B. T. Mayers, Y. Xia, Nano Lett. 2002, 2, 481-485; n) Y. Yin, C. K. Erdonmez, A. Cabot, S. Hughes, A. P. Alivisatos, Adv. Funct. Mater. 2006, 16, 1389-1399.

[55] C. M. Cobley, Y. Xia, Mater. Sc. Eng.: R: Reports 2010, 70, 44-62.

[56] X. Lu, L. Au, J. McLellan, Z.-Y. Li, M. Marquez, Y. Xia, Nano Lett. 2007, 7, 1764-1769.

[57] a) P. H. C. Camargo, Y. H. Lee, U. Jeong, Z. Zou, Y. Xia, Langmuir 2007, 23, 2985-2992; b) H. Cheng, B. Huang, X. Qin, X. Zhang, Y. Dai, Chem. Comm. 2012, 48, 97-99; c) Y. Gao, M. Fan, Q. Fang, W. Han, New J. Chem. 2013, 37, 670-678; dT. Grzyb, A. Gruszeczka, R. J. Wiglusz, Z. Sniadecki, B. Idzikowski, S. Lis, J. Mater. Chem. 2012, 22, 22989-22997; e) X. Huang, M. Wang, M.-G. Willinger, L. Shao, D. S. Su, X.-M. Meng, ACS Nano 2012, 6, 7333-7339; f) X. Kang, D. Yang, Y. Dai, M. Shang, Z. Cheng, X. Zhang, H. Lian, P. a. Ma, J. Lin, Nanoscale 2013, 5, 253-261; g) X. Kang, D. Yang, P. a. Ma, Y. Dai, M. Shang, D. Geng, Z. Cheng, J. Lin, Langmuir 2013, 29, 12861294; h) H. Li, M. Zanella, A. Genovese, M. Povia, A. Falqui, C. Giannini, L. Manna, Nano Lett. 2011, 11, 4964-4970; i) R. Lv, S. Gai, Y. Dai, F. He, N. Niu, P. Yang, Inorg. Chem. 2014, 53, 9981008; j) I. T. Sines, R. E. Schaak, J. Am. Chem. Soc. 2011, 133, 1294-1297; k) I. T. Sines, D. D. Vaughn, A. J. Biacchi, C. E. Kingsley, E. J. Popczun, R. E. Schaak, Chem. Mater. 2012, 24, 30883093; I) T. Teranishi, M. Sakamoto, J. Phys. Chem. Lett. 2013, 4, 2867-2873; m) X. Xia, C. Zhu, J. Luo, Z. Zeng, C. Guan, C. F. Ng, H. Zhang, H. J. Fan, Small 2014, 10, 766-773; n) S. Xiong, H. C. Zeng, Angew. Chem. Int. Ed. 2012, 51, 949-952; o) Y. Xu, R. Wu, J. Zhang, Y. Shi, B. Zhang, Chem. Comm. 2013, 49, 6656-6658; p) Z. Xu, Y. Cao, C. Li, P. a. Ma, X. Zhai, S. Huang, X. Kang, M. Shang, D. Yang, Y. Dai, J. Lin, J. Mater. Chem. 2011, 21, 3686-3694; q) Z. Xu, P. a. Ma, C. Li, Z. Hou, X. Zhai, S. Huang, J. Lin, Biomaterials 2011, 32, 4161-4173; r) H. Zhang, L. V. Solomon, D.-H. Ha, S. Honrao, R. G. Hennig, R. D. Robinson, Dalton Trans. 2013, 42, 12596-12599; s) S. Zhuo, Y. Xu, W. Zhao, J. Zhang, B. Zhang, Angew. Chem. Int. Ed. 2013, 52, 8602-8606.

[58] a) Z. An, S. Pan, J. Zhang, G. Song, Dalton Trans. 2008, 5155-5158; b) Z. An, J. Zhang, S. Pan, Dalton Trans. 2009, 3664-3667; c) C.-Y. Cao, Z.-M. Cui, C.-Q. Chen, W.-G. Song, W. Cai, J. Phys. Chem. C 2010, 114, 9865-9870; d) X. B. Cao, L. Gu, L. J. Zhuge, W. J. Gao, W. C. Wang, S. F. Wu, Adv. Funct. Mater. 2006, 16, 896-902; e) Y. Chang, J. J. Teo, H. C. Zeng, Langmuir 2005, 21, 10741079; f) W. Cheng, K. Tang, Y. Qi, J. Sheng, Z. Liu, J. Mater. Chem. 2010, 20, 1799-1805; g) X.-J. Dai, Y.-S. Luo, W.-D. Zhang, S.-Y. Fu, Dalton Trans. 2010, 39, 3426-3432; h) C.-W. Guo, Y. Cao, S.H. Xie, W.-L. Dai, K.-N. Fan, Chem. Comm. 2003, 700-701; i) H. Li, Z. Bian, J. Zhu, D. Zhang, G. Li, Y. Huo, H. Li, Y. Lu, J. Am. Chem. Soc. 2007, 129, 8406-8407; j) J. Li, H. C. Zeng, Angew. Chem. Int. Ed. 2005, 44, 4342-4345; k) J. Li, H. C. Zeng, J. Am. Chem. Soc. 2007, 129, 15839-15847; I) B. Liu, H. C. Zeng, Small 2005, 1, 566-571; m) Z.-R. Shen, J.-G. Wang, P.-C. Sun, D.-T. Ding, T.-H. Chen, Chem. Comm. 2009, 1742-1744; n) G. Tian, Y. Chen, W. Zhou, K. Pan, Y. Dong, C. Tian, H. Fu, J. Mater. Chem. 2011, 21, 887-892; o) X. Tian, J. Li, K. Chen, J. Han, S. Pan, Y. Wang, X. Fan, F. Li, Z. Zhou, Cryst. Growth Des. 2010, 10, 3990-3995; p) Y. Wang, Q. Zhu, H. Zhang, Chem. Comm. 2005, 5231-5233; q) Y. Wang, Q. Zhu, H. Zhang, J. Mater. Chem. 2006, 16, 1212-1214; r) Z. Wang, L. Wu, M. Chen, S. Zhou, J. Am. Chem. Soc. 2009, 131, 11276-11277; s) C.-Y. Wang, Chem. Rev. 2004, 104, 4727-4766; t) H. G. Yang, H. C. Zeng, J. Phys. Chem. B 2004, 108, 3492-3495; u) X. M. Yin, C. C. Li, M. Zhang, Q. Y. Hao, S. Liu, L. B. Chen, T. H. Wang, J. Phys. Chem. C 2010, 114, 8084-8088; v) H. Yu, J. Yu, S. Liu, S. Mann, Chem. Mater. 2007, 19, 4327-4334; w) J. Yu, H. Yu, H. Guo, M. Li, S. Mann, Small 2008, 4, 87-91; x) J. Yu, J. Zhang, Dalton Trans. 2010, 39, 5860-5867; y) J. G. Yu, H. Guo, S. A. Davis, S. Mann, Adv. Funct. Mater. 2006, 16, 2035-2041; z) X. Yu, J. Yu, B. Cheng, B. Huang, Chem. Eur. J. 2009, 15, 6731-6739. 
[59] a) K. T. Lee, J. C. Lytle, N. S. Ergang, S. M. Oh, A. Stein, Adv. Funct. Mat. 2005, 15, 547-556; b) S. Yin, Y. Zhang, J. Kong, C. Zou, C. M. Li, X. Lu, J. Ma, F. Y. C. Boey, X. Chen, ACS Nano 2011, 5, 3831-3838; c) B. L. Ellis, P. Knauth, T. Djenizian, Adv. Mater. 2014, 26, 3368-3397.

[60] a) C. M. Doherty, R. A. Caruso, B. M. Smarsly, P. Adelhelm, C. J. Drummond, Chem. Mater. 2009, 21, 5300-5306; b) C. M. Doherty, R. A. Caruso, B. M. Smarsly, C. J. Drummond, Chem. Mater. 2009, 21, 2895-2903; c) A. K. Padhi, K. S. Nanjundaswamy, J. B. Goodenough, J. Electrochem. Soc. 1997, 144, 1188-1194.

[61] A. K. Padhi, K. S. Nanjundaswamy, C. Masquelier, S. Okada, J. B. Goodenough, J. Electrochem. Soc. 1997, 144, 1609-1613.

[62] J. B. Goodenough, J. Power Sources 2007, 174, 996-1000.

[63] J. Liu, T. E. Conry, X. Song, M. M. Doeff, T. J. Richardson, Energ. Env. Sc. 2011, 4, 885-888.

[64] Y. Li, Z.-Y. Fu, B.-L. Su, Adv. Funct. Mater. 2012, 22, 4634-4667.

[65] D. Tonti, M. J. Torralvo, E. Enciso, I. Sobrados, J. Sanz, Chem. Mater. 2008, 20, 4783-4790.

[66] a) J. C. Lytle, H. Yan, N. S. Ergang, W. H. Smyrl, A. Stein, J. Mater. Chem. 2004, 14, 1616-1622; b) Q. Wang, Z. Wen, J. Li, J. Power Sources 2008, 182, 334-339; c) Z. Wen, Q. Wang, Q. Zhang, J. Li, Adv. Funct. Mater. 2007, 17, 2772-2778.

[67] a) P. Liu, S. H. Lee, C. E. Tracy, Y. Yan, J. A. Turner, Adv. Mater. 2002, 14, 27-30; b) J. S. Sakamoto, B. Dunn, J. Mater. Chem. 2002, 12, 2859-2861; c) S. Wang, S. Li, Y. Sun, X. Feng, C. Chen, Energ. Env. Sc. 2011, 4, 2854-2857.

[68] X. H. Xia, J. P. Tu, J. Y. Xiang, X. H. Huang, X. L. Wang, X. B. Zhao, J. Power Sources 2010, 195, 2014-2022.

[69] a) X. H. Huang, J. P. Tu, X. H. Xia, X. L. Wang, J. Y. Xiang, L. Zhang, J. Power Sources 2010, 195, 1207-1210; b) X. H. Huang, J. P. Tu, X. H. Xia, X. L. Wang, J. Y. Xiang, L. Zhang, Y. Zhou, J. Power Sources 2009, 188, 588-591; c) X. H. Huang, J. P. Tu, Z. Y. Zeng, J. Y. Xiang, X. B. Zhao, J. Electrochem. Soc. 2008, 155, A438-A441; d) Y. F. Yuan, X. H. Xia, J. B. Wu, J. L. Yang, Y. B. Chen, S. Y. Guo, Electrochem. Comm. 2010, 12, 890-893.

[70] a) Y.-G. Guo, Y.-S. Hu, J. Maier, Chem. Comm. 2006, 2783-2785; b) H.-G. Jung, S. W. Oh, J. Ce, N. Jayaprakash, Y.-K. Sun, Electrochem. Comm. 2009, 11, 756-759; c) I. Moriguchi, Y. Shono, H. Yamada, T. Kudo, J. Phys. Chem. B 2008, 112, 14560-14565.

[71] a) N. S. Ergang, J. C. Lytle, H. Yan, A. Stein, J. Electrochem. Soc. 2005, 152, A1989-A1995; b) F. Jiao, K. M. Shaju, P. G. Bruce, Angew. Chem. Int. Ed. 2005, 44, 6550-6553.

[72] H. Yan, S. Sokolov, J. C. Lytle, A. Stein, F. Zhang, W. H. Smyrl, J. Electrochem. Soc. 2003, 150, A1102-A1107.

[73] a) M. D. Hernandez-Alonso, F. Fresno, S. Suarez, J. M. Coronado, En. Env. Sc. 2009, 2, 1231-1257;

b) A. L. Linsebigler, G. Lu, J. T. Yates, Chem. Rev. 1995, 95, 735-758.

[74] a) O. Carp, C. L. Huisman, A. Reller, Prog. Solid State Chem. 2004, 32, 33-177; bA. Fujishima, T. N. Rao, D. A. Tryk, J. Photochem. Photobio. C: Photochem. Rev. 2000, 1, 1-21; c) J.-M. Herrmann, Catal. Today 1999, 53, 115-129; d) M. R. Hoffmann, S. T. Martin, W. Choi, D. W. Bahnemann, Chem. Rev. 1995, 95, 69-96; e) A. Mills, S. Le Hunte, J. Photochem. Photobio. A: Chem. 1997, 108, 1-35.

[75] a) X. Li, T. Fan, H. Zhou, S.-K. Chow, W. Zhang, D. Zhang, Q. Guo, H. Ogawa, Adv. Funct. Mater. 2009, 19, 45-56; b)H. Zhou, X. Li, T. Fan, F. E. Osterloh, J. Ding, E. M. Sabio, D. Zhang, Q. Guo, Adv. Mater. 2010, 22, 951-956.

[76] J. Poppe, S. G. Hickey, A. Eychmüller, J. Phys. Chem. C 2014, 118, 17123-17141.

[77] J. Du, X. Lai, N. Yang, J. Zhai, D. Kisailus, F. Su, D. Wang, L. Jiang, ACS Nano 2010, 5, 590-596.

[78] a) R. Abe, H. Takami, N. Murakami, B. Ohtani, J. Am. Chem. Soc. 2008, 130, 7780-7781; b) I. Bannat, K. Wessels, T. Oekermann, J. Rathousky, D. Bahnemann, M. Wark, Chem. Mater. 2009, 21, 1645-1653; c) G. Liu, Z. Chen, C. Dong, Y. Zhao, F. Li, G. Q. Lu, H.-M. Cheng, J. Phys. Chem. B 
2006, 110, 20823-20828; d) M. Ni, M. K. H. Leung, D. Y. C. Leung, K. Sumathy, Renew. Sust. Energ. Rev. 2007, 11, 401-425; e) S. Wang, Q. Gong, J. Liang, Ultrason. Sonochem. 2009, 16, 205208; f) J. C. Yu, G. Li, X. Wang, X. Hu, C. W. Leung, Z. Zhang, Chem. Comm. 2006, 2717-2719; g) H. Zhang, X. Lv, Y. Li, Y. Wang, J. Li, ACS Nano 2009, 4, 380-386.

[79] X. Chen, S. S. Mao, Chem. Rev. 2007, 107, 2891-2959.

[80] K. Tanaka, M. F. V. Capule, T. Hisanaga, Chem. Phys. Lett. 1991, 187, 73-76.

[81] a) R. I. Bickley, T. Gonzalez-Carreno, J. S. Lees, L. Palmisano, R. J. D. Tilley, J. Solid State Chem. 1991, 92, 178-190; b) H. Gerischer, A. Heller, J. Electrochem. Soc. 1992, 139, 113-118; c) H. P. Maruska, A. K. Ghosh, Solar Energy 1978, 20, 443-458.

[82] a) T. Ohno, K. Sarukawa, K. Tokieda, M. Matsumura, J. Catal. 2001, 203, 82-86; b) Q. Zhang, L. Gao, J. Guo, Appl. Catal. B: Env. 2000, 26, 207-215.

[83] a) X. Chen, X. Wang, X. Fu, Energ. Env. Sc. 2009, 2, 872-877; b) X.-Y. Li, L.-H. Chen, Y. Li, J. C. Rooke, C. Wang, Y. Lu, A. Krief, X.-Y. Yang, B.-L. Su, J. Colloid Interf. Sc. 2012, 368, 128-138; c) D. R. Rolison, Science 2003, 299, 1698-1701; d) X. Wang, J. C. Yu, C. Ho, Y. Hou, X. Fu, Langmuir 2005, 21, 2552-2559; e) J. G. Yu, Y. R. Su, B. Cheng, Adv. Funct. Mater. 2007, 17, 1984-1990; f) H. Choi, M. G. Antoniou, M. Pelaez, A. A. de la Cruz, J. A. Shoemaker, D. D. Dionysiou, Env. Sc. Tech. 2007, 41, 7530-7535; g) J. H. Pan, W. I. Lee, Chem. Mater. 2006, 18, 847-853; h) J. Tang, Y. Wu, E. W. McFarland, G. D. Stucky, Chem. Comm. 2004, 1670-1671; i) F. Bosc, P. Lacroix-Desmazes, A. Ayral, J. Colloid Interf. Sc. 2006, 304, 545-548; j) Z. Cai, J. Teng, Z. Xiong, Y. Li, Q. Li, X. Lu, X. S. Zhao, Langmuir 2011, 27, 5157-5164; k) J. I. L. Chen, E. Loso, N. Ebrahim, G. A. Ozin, J. Am. Chem. Soc. 2008, 130, 5420-5421; I) J. I. L. Chen, G. A. Ozin, J. Mater. Chem. 2009, 19, 26752678; m) J. I. L. Chen, G. von Freymann, V. Kitaev, G. A. Ozin, J. Am. Chem. Soc. 2007, 129, 11961202; n) J. I. L. Chen, G. von Freymann, S. Y. Choi, V. Kitaev, G. A. Ozin, Adv. Mater. 2006, 18, 1915-1919; o) L.-H. Chen, X.-Y. Li, G. Tian, Y. Li, H.-Y. Tan, G. Van Tendeloo, G.-S. Zhu, S.-L. Qiu, X.-Y. Yang, B.-L. Su, ChemSusChem 2011, 4, 1452-1456; p) L.-H. Chen , X.-Y. Li, G. Tian, Y. Li, J. C. Rooke, G.-S. Zhu, S.-L. Qiu, X.-Y. Yang, B.-L. Su Angew. Chem. Int. Ed. 2011, 50, 11156-11161; q) Y. Li, X.-Y. Yang, G. Tian, A. Vantomme, J. Yu, G. Van Tendeloo, B.-L. Su, Chem. Mater. 2010, 22, 3251-3258; r) F. Sordello, C. Duca, V. Maurino, C. Minero, Chem. Comm. 2011, 47, 6147-6149; s) B.-L. Su, A. Vantomme, L. Surahy, R. Pirard, J.-P. Pirard, Chem. Mater. 2007, 19, 3325-3333; t) M. Wu, Y. Li, Z. Deng, B.-L. Su, ChemSusChem 2011, 4, 1481-1488; u) X.-Y. Yang, A. Leonard, A. Lemaire, G. Tian, B.-L. Su, Chem. Comm. 2011, 47, 2763-2786; v) X.-Y. Yang, Y. Li, G. Van Tendeloo, F.-S. Xiao, B.-L. Su, Adv. Mater. 2009, 21, 1368-1372; w) Z.-Y. Yuan, T.-Z. Ren, A. Azioune, J.-J. Pireaux, B.-L. Su, Chem. Mater. 2006, 18, 1753-1767.

[84] a) Q. Dai, L. Y. Shi, Y. G. Luo, J. L. Blin, D. J. Li, C. W. Yuan, B. L. Su, J. Photoch. Photobio. A: Chem. 2002, 148, 295-301; b) J. Yu, J. C. Yu, M. K. P. Leung, W. Ho, B. Cheng, X. Zhao, J. Zhao, J. Catal. 2003, 217, 69-78.

[85] a) W. Deng, M. W. Toepke, B. H. Shanks, Adv. Funct. Mater. 2003, 13, 61-65; b) Z. Y. Yuan, T. Z. Ren, B. L. Su, Adv. Mater. 2003, 15, 1462-1465.

[86] S. Zhu, D. Zhang, Z. Chen, G. Zhou, H. Jiang, J. Li, J. Nanopart. Res. 2010, 12, 2445-2456.

[87] Y. Zhao, X. Zhang, J. Zhai, J. He, L. Jiang, Z. Liu, S. Nishimoto, T. Murakami, A. Fujishima, D. Zhu, Appl. Catal. B: Env. 2008, 83, 24-29.

[88] a) X. Meng, T. Kimura, T. Ohji, K. Kato, J. Mater. Chem. 2009, 19, 1894-1900; b) P. Yang, T. Deng, D. Zhao, P. Feng, D. Pine, B. F. Chmelka, G. M. Whitesides, G. D. Stucky, Science 1998, 282, 22442246.

[89] Y. Fu, Z. Jin, W. Xue, Z. Ge, J. Am. Ceramic Soc. 2008, 91, 2676-2682.

[90] a) A. Stein, F. Li, N. R. Denny, Chem. Mater. 2007, 20, 649-666; b) O. D. Velev, A. M. Lenhoff, Curr. Opin. Colloid Interf. Sc. 2000, 5, 56-63; c) Y. Xia, B. Gates, Y. Yin, Y. Lu, Adv. Mater. 2000, 12, 
693-713; d) X. S. Zhao, F. Su, Q. Yan, W. Guo, X. Y. Bao, L. Lv, Z. Zhou, J. Mater. Chem. 2006, 16, 637-648.

[91] a) J. W. Galusha, C.-K. Tsung, G. D. Stucky, M. H. Bartl, Chem. Mater. 2008, 20, 4925-4930; b) G. Guan, R. Zapf, G. Kolb, V. Hessel, H. Löwe, J. Ye, R. Zentel, Int. J. Hydrogen En. 2008, 33, 797801; c) Y.-J. Lee, S. A. Pruzinsky, P. V. Braun, Langmuir 2004, 20, 3096-3106.

[92] a) X. Chen, Z. Li, J. Ye, Z. Zou, Chem. Mater. 2010, 22, 3583-3585; b) E. Vekris, G. A. Ozin, V. Kitaev, Adv. Mater. 2006, 18, 2481-2485; c) Y. Yang, H. Yan, Z. Fu, B. Yang, L. Xia, Y. Xu, J. Zuo, F. Li, J. Phys. Chem. B 2005, 110, 846-852.

[93] N. Shi, X. Li, T. Fan, H. Zhou, J. Ding, D. Zhang, H. Zhu, En. Env. Sc. 2011, 4, 172-180.

[94] X. Hong, Z. Wang, W. Cai, F. Lu, J. Zhang, Y. Yang, N. Ma, Y. Liu, Chem. Mater. 2005, 17, 15481552.

[95] R. Asahi, T. Morikawa, T. Ohwaki, K. Aoki, Y. Taga, Science 2001, 293, 269-271.

[96] S. Yin, H. Yamaki, M. Komatsu, Q. Zhang, J. Wang, Q. Tang, F. Saito, T. Sato, J. Mater. Chem. 2003, 13, 2996-3001.

[97] a) T. Ikeda, T. Nomoto, K. Eda, Y. Mizutani, H. Kato, A. Kudo, H. Onishi, J. Phys. Chem. C 2008, 112, 1167-1173; b) M. Takeuchi, H. Yamashita, M. Matsuoka, M. Anpo, T. Hirao, N. Itoh, N. Iwamoto, Catal. Lett. 2000, 67, 135-137; c) H. Yamashita, M. Harada, J. Misaka, M. Takeuchi, B. Neppolian, M. Anpo, Catal. Today 2003, 84, 191-196.

[98] S. U. M. Khan, M. Al-Shahry, W. B. Ingler, Science 2002, 297, 2243-2245.

[99] a) T. Ohno, M. Akiyoshi, T. Umebayashi, K. Asai, T. Mitsui, M. Matsumura, Appl. Catal. A: General 2004, 265, 115-121; b) J. Xu, B. Yang, M. Wu, Z. Fu, Y. Lv, Y. Zhao, J. Phys. Chem. C 2010, 114, 15251-15259.

[100] a) H. Irie, Y. Watanabe, K. Hashimoto, J. Phys. Chem. B 2003, 107, 5483-5486; b) M. Miyauchi, A. Ikezawa, H. Tobimatsu, H. Irie, K. Hashimoto, Phys. Chem. Chem. Phys. 2004, 6, 865-870.

[101] S.-Z. Chu, S. Inoue, K. Wada, D. Li, H. Haneda, S. Awatsu, J. Phys. Chem. B 2003, 107, 6586-6589.

[102] a) Y. Huang, Z. Ai, W. Ho, M. Chen, S. Lee, J. Phys. Chem. C 2010, 114, 6342-6349; b) F. Lu, W. Cai, Y. Zhang, Adv. Funct. Mater. 2008, 18, 1047-1056; c) S. Rengaraj, S. Venkataraj, C.-w. Tai, Y. Kim, E. Repo, M. Sillanpää, Langmuir 2011, 27, 5534-5541; d) G. Xi, B. Yue, J. Cao, J. Ye, Chem. Eur. J. 2011, 17, 5145-5154; e) F. Xu, P. Zhang, A. Navrotsky, Z.-Y. Yuan, T.-Z. Ren, M. Halasa, B.L. Su, Chem. Mater. 2007, 19, 5680-5686; f) Y. Zhao, M. Wei, J. Lu, Z. L. Wang, X. Duan, ACS Nano 2009, 3, 4009-4016.

[103] a) S. Guo, S. Dong, E. Wang, J. Phys. Chem. C 2009, 113, 5485-5492; b) A. Rabis, P. Rodriguez, T. J. Schmidt, ACS Catal. 2012, 2, 864-890.

[104] a) A. T. Bell, Science 2003, 299, 1688-1691; b) M. Chen, T. Pica, Y.-B. Jiang, P. Li, K. Yano, J. P. Liu, A. K. Datye, H. Fan, J. Am. Chem. Soc. 2007, 129, 6348-6349; c) S. Guo, Y. Fang, S. Dong, E. Wang, J. Phys. Chem. C 2007, 111, 17104-17109; d) H.-P. Liang, H.-M. Zhang, J.-S. Hu, Y.-G. Guo, L.-J. Wan, C.-L. Bai, Angew. Chem. Int. Ed. 2004, 43, 1540-1543; e) B. C. H. Steele, A. Heinzel, Nature 2001, 414, 345-352.

[105] a) Y. Kim, H. J. Kim, Y. S. Kim, S. M. Choi, M. H. Seo, W. B. Kim, J. Phys. Chem. C 2012, 116, 1809318100; b) O. Petrii, J. Solid State Electrochem. 2008, 12, 609-642; c) C. Cui, L. Gan, M. Heggen, S. Rudi, P. Strasser, Nat. Mater. 2013, 12, 765-771; d) C. Cui, L. Gan, H.-H. Li, S.-H. Yu, M. Heggen, P. Strasser, Nano Letters 2012, 12, 5885-5889; e) C. Cui, L. Gan, M. Neumann, M. Heggen, B. Roldan Cuenya, P. Strasser, J. Am. Chem. Soc. 2014, 136, 4813-4816; f) L. Gan, C. Cui, S. Rudi, P. Strasser, Top. Catal. 2014, 57, 236-244; g) L. Gan, M. Heggen, S. Rudi, P. Strasser, Nano Letters 2012, 12, 5423-5430; h) F. Hasché, T.-P. Fellinger, M. Oezaslan, J. P. Paraknowitsch, M. Antonietti, P. Strasser, ChemCatChem 2012, 4, 479-483; i) F. Hasche, M. Oezaslan, P. Strasser, Phys. Chem. Chem. Phys. 2010, 12, 15251-15258; j) F. Hasché, M. Oezaslan, P. Strasser, ChemCatChem 2011, 3, 1805-1813; k) S. Koh, J. Leisch, M. F. Toney, P. Strasser, J. Phys. Chem. C 
2007, 111, 3744-3752; I) S. Koh, P. Strasser, J. Am. Chem. Soc. 2007, 129, 12624-12625; m) S. Koh, C. Yu, P. Mani, R. Srivastava, P. Strasser, J. Power Sources 2007, 172, 50-56; n) Z. Liu, C. Yu, I. Rusakova, D. Huang, P. Strasser, Top. Catal. 2008, 49, 241-250; o) P. Mani, R. Srivastava, P. Strasser, J. Phys. Chem. C 2008, 112, 2770-2778; p) M. Oezaslan, F. Hasché, P. Strasser, J. Electrochem. Soc. 2012, 159, B394-B405; q) M. Oezaslan, F. Hasché, P. Strasser, J. Electrochem. Soc. 2012, 159, B444-B454; r) M. Oezaslan, M. Heggen, P. Strasser, J. Am. Chem. Soc. 2011, 134, 514-524; s) R. Srivastava, P. Mani, N. Hahn, P. Strasser, Angew. Chem. Int. Ed. 2007, 46, 89888991 ; t) P. Strasser, S. Koh, T. Anniyev, J. Greeley, K. More, C. Yu, Z. Liu, S. Kaya, D. Nordlund, H. Ogasawara, M. F. Toney, A. Nilsson, Nat. Chem. 2010, 2, 454-460; u) P. Strasser, S. Koh, J. Greeley, Phys. Chem. Chem. Phys. 2008, 10, 3670-3683; v) R. Yang, J. Leisch, P. Strasser, M. F. Toney, Chem. Mater. 2010, 22, 4712-4720; w) N. Menzel, E. Ortel, R. Kraehnert, P. Strasser, ChemPhysChem 2012, 13, 1385-1394.

[106] C. A. Reiser, L. Bregoli, T. W. Patterson, J. S. Yi, J. D. Yang, M. L. Perry, T. D. Jarvi, Electrochem. Solid-St. Lett. 2005, 8, A273-A276.

[107] a) A. Kumar, V. Ramani, J. Electrochem. Soc. 2013, 160, F1207-F1215; b) A. Kumar, V. Ramani, ACS Cat. 2014, 4, 1516-1525; c) A. Kumar, V. K. Ramani, Appl. Cat. B: Env. 2013, 138-139, 43-50; d) C.-P. Lo, V. Ramani, ACS Appl. Mater. Interf. 2012, 4, 6109-6116; e) C.-P. Lo, G. Wang, A. Kumar, V. Ramani, Appl. Cat. B: Env. 2013, 140-141, 133-140; f) J. Parrondo, T. Han, E. Niangar, C. Wang, N. Dale, K. Adjemian, V. Ramani, PNAS 2014, 111, 45-50.

[108] a) X. Zhou, Y. Gan, J. Du, D. Tian, R. Zhang, C. Yang, Z. Dai, J. Power Sources 2013, 232, 310-322; b) V. Bansal, A. P. O'Mullane, S. K. Bhargava, Electrochem. Comm. 2009, 11, 1639-1642.

[109] a) J. Zhao, W. Chen, Y. Zheng, X. Li, J. Power Sources 2006, 162, 168-172; b) J. Yang, J. Y. Lee, H.P. Too, S. Valiyaveettil, J. Phys. Chem. B 2005, 110, 125-129.

[110] a) J. Gao, X. Ren, D. Chen, F. Tang, J. Ren, Scripta Materialia 2007, 57, 687-690; b) M. R. Kim, D. K. Lee, D.-J. Jang, Appl. Cat. B: Env. 2011, 103, 253-260; c) J. Yang, L. Lu, H. Wang, H. Zhang, Scripta Materialia 2006, 54, 159-162; d) W. Zhang, J. Yang, X. Lu, ACS Nano 2012, 6, 7397-7405; e) J. Zhai, M. Huang, Y. Zhai, S. Dong, J. Mater. Chem. 2008, 18, 923-928; f) K. J. J. Mayrhofer, V. Juhart, K. Hartl, M. Hanzlik, M. Arenz, Angew. Chem. Int. Ed. 2009, 48, 3529-3531; g) F. Cheng, H. Ma, Y. Li, J. Chen, Inorg. Chem. 2007, 46, 788-794; h) Q.-S. Chen, S.-G. Sun, Z.-Y. Zhou, Y.-X. Chen, S.-B. Deng, Phys. Chem. Chem. Phys. 2008, 10, 3645-3654; i) R. Minch, M. Es-Souni, Chem. Comm. 2011, 47, 6284-6286; j) H. A. Gasteiger, N. Marković, P. N. Ross, E. J. Cairns, J. Electrochem. Soc. 1994, 141, 1795-1803; k) F. Ye, J. Yang, W. Hu, H. Liu, S. Liao, J. Zeng, J. Yang, RSC Adv. 2012, 2, 7479-7486; I) J. W. Hong, S. W. Kang, B.-S. Choi, D. Kim, S. B. Lee, S. W. Han, ACS Nano 2012, 6, 2410-2419; m) H. Zhang, M. Jin, J. Wang, M. J. Kim, D. Yang, Y. Xia, J. Am. Chem. Soc. 2011, 133, 10422-10425; n) Q. Yuan, Z. Zhou, J. Zhuang, X. Wang, Chem. Comm. 2010, 46, 1491-1493; o) C. M. Sánchez-Sánchez, J. Solla-Gullón, F. J. Vidal-Iglesias, A. Aldaz, V. Montiel, E. Herrero, J. Am. Chem. Soc. 2010, 132, 5622-5624; p) V. R. Stamenkovic, B. Fowler, B. S. Mun, G. Wang, P. N. Ross, C. A. Lucas, N. M. Marković, Science 2007, 315, 493-497; q) J. Zhang, H. Yang, J. Fang, S. Zou, Nano Lett. 2010, 10, 638-644; r) Y.-Y. Chu, Z.-B. Wang, Z.-Z. Jiang, D.-M. Gu, G.-P. Yin, J. Power Sources 2012, 203, 17-25; s) X. Yu, D. Wang, Q. Peng, Y. Li, Chem. Comm. 2011, 47, 8094-8096; t) B. Y. Xia, H. B. Wu, X. Wang, X. W. Lou, J. Am. Chem. Soc. 2012, 134, 13934-13937; u) D. Wang, Y. Li, Adv. Mater. 2011, 23, 1044-1060; v) D. Xu, Z. Liu, H. Yang, Q. Liu, J. Zhang, J. Fang, S. Zou, K. Sun, Angew. Chem. Int. Ed. 2009, 48, 4217-4221.

[111] a) Y. Jin, Y. Shen, S. Dong, J. Phys. Chem. B 2004, 108, 8142-8147; b) H. Ye, R. M. Crooks, J. Am. Chem. Soc. 2005, 127, 4930-4934.

[112] D. Lee, H. Y. Jang, S. Hong, S. Park, J. Colloid Interf. Sc. 2012, 388, 74-79.

[113] a) X.-W. Zhou, R.-H. Zhang, Z.-Y. Zhou, S.-G. Sun, J. Power Sources 2011, 196, 5844-5848; b) L. Wang, Y. Yamauchi, Chem. Eur. J. 2011, 17, 8810-8815; c) H. Zhang, Y. Yin, Y. Hu, C. Li, P. Wu, S. 
Wei, C. Cai, J. Phys. Chem. C 2010, 114, 11861-11867; d) Y. Hu, Q. Shao, P. Wu, H. Zhang, C. Cai, Electrochem. Comm. 2012, 18, 96-99; e) S. J. Bae, S. J. Yoo, Y. Lim, S. Kim, Y. Lim, J. Choi, K. S. Nahm, S. J. Hwang, T.-H. Lim, S.-K. Kim, P. Kim, J. Mat. Chem. 2012, 22, 8820-8825.

[114] Y. Hu, P. Wu, H. Zhang, C. Cai, Electrochim. Acta 2012, 85, 314-321.

[115] a) J. Ge, W. Xing, X. Xue, C. Liu, T. Lu, J. Liao, J. Phys. Chem. C 2007, 111, 17305-17310; b) Z. Liu, B. Zhao, C. Guo, Y. Sun, Y. Shi, H. Yang, Z. Li, J. Colloid Interf. Sc. 2010, 351, 233-238.

[116] W. P. Zhou, A. Lewera, R. Larsen, R. I. Masel, P. S. Bagus, A. Wieckowski, J. Phys. Chem. B 2006, 110, 13393-13398.

[117] a) B. Hammer, J. K. Nørskov, Surf. Sc. 1995, 343, 211-220; b) M. Mavrikakis, B. Hammer, J. K. Nørskov, Phys. Rev. Lett. 1998, 81, 2819-2822; c) A. Ruban, B. Hammer, P. Stoltze, H. L. Skriver, J. K. Nørskov, J. Mol. Cat. A: Chem. 1997, 115, 421-429.

[118] a) C. Hu, Y. Guo, J. Wang, L. Yang, Z. Yang, Z. Bai, J. Zhang, K. Wang, K. Jiang, ACS Appl. Mat. Interf. 2012, 4, 4461-4464; b) Y. Jiang, Y. Lu, D. Han, Q. Zhang, L. Niu, Nanotechnology 2012, 23, 105609; c) Z. Liu, B. Zhao, C. Guo, Y. Sun, F. Xu, H. Yang, Z. Li, J. Phys. Chem. C 2009, 113, 1676616771; d) Z. Bai, L. Yang, J. Zhang, L. Li, J. Lv, C. Hu, J. Zhou, Cat. Comm. 2010, 11, 919-922; e) C.L. Lee, C.-M. Tseng, R.-B. Wu, K.-L. Yang, Nanotechnology 2008, 19, 215709; f) W. Wang, B. Zhao, P. Li, X. Tan, J. Nanopart. Res. 2008, 10, 543-548.

[119] L. Yang, C. Hu, J. Wang, Z. Yang, Y. Guo, Z. Bai, K. Wang, Chem. Comm. 2011, 47, 8581-8583.

[120] a) G. Centi, S. Perathoner, Eur. J. Inorg. Chem. 2009, 2009, 3851-3878; b) P. Trogadas, T. F. Fuller, P. Strasser, Carbon 2014, 75, 5-42.

[121] a) K. Lee, J. Zhang, H. Wang, D. P. Wilkinson, J. Appl. Electrochem. 2006, 36, 507-522; b) J. Liu, G. Cao, Z. Yang, D. Wang, D. Dubois, X. Zhou, G. L. Graff, L. R. Pederson, J.-G. Zhang, ChemSusChem 2008, 1, 676-697; c) Y. Shao, J. Liu, Y. Wang, Y. Lin, J. Mat. Chem. 2009, 19, 46-59; d) Y. Shao, J. Sui, G. Yin, Y. Gao, Appl. Cat. B: Env. 2008, 79, 89-99; e) H. Tang, J. H. Chen, Z. P. Huang, D. Z. Wang, Z. F. Ren, L. H. Nie, Y. F. Kuang, S. Z. Yao, Carbon 2004, 42, 191-197.

[122] a) K. P. De Jong, J. W. Geus, Cat. Rev. 2000, 42, 481-510; b) Z. R. Ismagilov, M. A. Kerzhentsev, N. V. Shikina, A. S. Lisitsyn, L. B. Okhlopkova, C. N. Barnakov, M. Sakashita, T. lijima, K. Tadokoro, Cat. Today 2005, 102-103, 58-66; c) J.-H. Zhou, Z.-J. Sui, P. Li, D. Chen, Y.-C. Dai, W.-K. Yuan, Carbon 2006, 44, 3255-3262.

[123] J.-S. Zheng, X.-S. Zhang, P. Li, X.-G. Zhou, W.-K. Yuan, Cat. Today 2008, 131, 270-277.

[124] M. Tsuji, M. Kubokawa, R. Yano, N. Miyamae, T. Tsuji, M.-S. Jun, S. Hong, S. Lim, S.-H. Yoon, I. Mochida, Langmuir 2006, 23, 387-390.

[125] M. Takasaki, Y. Motoyama, K. Higashi, S.-H. Yoon, I. Mochida, H. Nagashima, Chem. Asian J. 2007, 2, 1524-1533.

[126] a) C. Vix-Guterl, S. Boulard, eacute, verine, J. Parmentier, J. Werckmann, J. Patarin, Chem. Lett. 2002, 31, 1062-1063; b) Y. D. Xia, R. Mokaya, Adv. Mat. 2004, 16, 886-891; c) L.-C. Sang, A. Vinu, M.-O. Coppens, J. Mat. Chem. 2011, 21, 7410-7417.

[127] a) G. Gupta, D. A. Slanac, P. Kumar, J. D. Wiggins-Camacho, X. Wang, S. Swinnea, K. L. More, S. Dai, K. J. Stevenson, K. P. Johnston, Chem. Mater. 2009, 21, 4515-4526; b) C. Liang, S. Dai, J. Am. Chem. Soc. 2006, 128, 5316-5317.

[128] a) B. Güvenatam, B. Fıçıcılar, A. Bayrakçeken, İ. Eroğlu, Int. J. Hydrogen En. 2012, 37, 1865-1874; b) S.-H. Liu, M.-T. Wu, Y.-H. Lai, C.-C. Chiang, N. Yu, S.-B. Liu, J. Mat. Chem. 2011, 21, 1248912496; c) S. Song, Y. Liang, Z. Li, Y. Wang, R. Fu, D. Wu, P. Tsiakaras, Appl. Cat. B: Env. 2010, 98, 132-137; d) F. A. Viva, M. M. Bruno, E. A. Franceschini, Y. R. J. Thomas, G. Ramos Sanchez, O. Solorza-Feria, H. R. Corti, Int. J. Hydrogen En. 2014, 39, 8821-8826.

[129] a) G. S. Chai, I. S. Shin, J. S. Yu, Adv. Mat. 2004, 16, 2057-2061; b) F. Su, J. Zeng, X. Bao, Y. Yu, J. Y. Lee, X. S. Zhao, Chem. Mater. 2005, 17, 3960-3967. 
[130] a) C. Galeano, J. C. Meier, V. Peinecke, H. Bongard, I. Katsounaros, A. A. Topalov, A. Lu, K. J. J. Mayrhofer, F. Schüth, J. Am. Chem. Soc. 2012, 134, 20457-20465; b) C. Galeano, J. C. Meier, M. Soorholtz, H. Bongard, C. Baldizzone, K. J. J. Mayrhofer, F. Schüth, ACS Cat. 2014, 3856-3868; c) B. Fang, J. H. Kim, M. Kim, M. Kim, J.-S. Yu, Phys. Chem. Chem. Phys. 2009, 11, 1380-1387.

[131] a) K. Koch, B. Bhushan, W. Barthlott, Progress in Materials Science 2009, 54, 137-178; b) L. H. Shu, K. Ueda, I. Chiu, H. Cheong, CIRP Annals - Manufacturing Technology 2011, 60, 673-693.

[132] a) M.-O. Coppens, in Fractal Geometry and Applications: A Jubilee of Benoit Mandelbrot, Vol. 72 (Eds.: B. Mandelbrot, M. Lapidus, M. van Frankenhuijsen), Proceedings of Symposia in Pure Mathematics, 2004, pp. 507-532; b) M.-O. Coppens, in Multiscale Methods (Ed.: J. Fish), Oxford University Press, Oxford, 2009, pp. 536-560.

[133] a) A. Arvay, J. French, J. C. Wang, X. H. Peng, A. M. Kannan, Int. J. Hydrogen Energ. 2013, 38, 3717-3726; b) J. P. Kloess, X. Wang, J. Liu, Z. Shi, L. Guessous, J. Power Sources 2009, 188, $132-$ 140; c) R. Roshandel, F. Arbabi, G. K. Moghaddam, Renew. Energ. 2012, 41, 86-95.

[134] S. Gheorghiu, S. Kjelstrup, P. Pfeifer, M.-O. Coppens, in Fractals in biology and medicine, Springer, 2005, pp. 31-42.

[135] A. Z. Weber, J. Newman, Chem. Rev. 2004, 104, 4679-4726.

[136] a) T. F. Fuller, J. Newman, J. Electrochem. Soc. 1993, 140, 1218-1225; b) T. Berning, D. M. Lu, N. Djilali, J. Power Sources 2002, 106, 284-294; c) S. Mazumder, J. V. Cole, J. Electrochem. Soc. 2003, 150, A1503-A1509; d) S. Dutta, S. Shimpalee, J. W. Van Zee, J. Appl. Electrochem. 2000, 30, 135-146; e) W.-k. Lee, S. Shimpalee, J. W. Van Zee, J. Electrochem. Soc. 2003, 150, A341-A348; f) S. Um, C. Y. Wang, K. S. Chen, J. Electrochem. Soc. 2000, 147, 4485-4493; g) P. P. Mukherjee, Q. Kang, C.-Y. Wang, En. Env. Sc. 2011, 4, 346-369; h) P. P. Mukherjee, C.-Y. Wang, Q. Kang, Electrochim. Acta 2009, 54, 6861-6875; i) Q. Kang, D. Zhang, S. Chen, Phys. of Fluids (1994present) 2002, 14, 3203-3214; j) X. Shan, H. Chen, Phys. Rev. E 1993, 47, 1815-1819; k) X. Shan, H. Chen, Phys. Rev. E 1994, 49, 2941-2948; I) J. T. Gostick, M. A. loannidis, M. W. Fowler, M. D. Pritzker, J. Power Sources 2007, 173, 277-290; m) P. K. Sinha, C.-Y. Wang, Electrochim. Acta 2007, 52, 7936-7945; n) E. Antolini, Appl. Cat. B: Env. 2009, 88, 1-24; o) W. Bi, T. F. Fuller, J. Power Sources 2008, 178, 188-196; p) W. Bi, Q. Sun, Y. Deng, T. F. Fuller, Electrochim. Acta 2009, 54, 1826-1833; q) N. Cabrera, N. F. Mott, Rep. Prog. Phys. 1949, 12, 163; r) A. Damjanovic, L. S. R. Yeh, J. F. Wolf, J. Electrochem. Soc. 1980, 127, 1945-1950; s) A. Damjanovic, L. S. R. Yeh, J. F. Wolf, J. Electrochem. Soc. 1980, 127, 1951-1954; t) R. M. Darling, J. P. Meyers, J. Electrochem. Soc. 2003, 150, A1523-A1527; u) J. P. Meyers, R. M. Darling, J. Electrochem. Soc. 2006, 153, A1432-A1442; v) N. F. Mott, Trans. Faraday Soc. 1939, 35, 1175-1177; w) N. F. Mott, Trans. Faraday Soc. 1947, 43, 429-434; xJ. L. Ord, F. C. Ho, J. Electrochem. Soc. 1971, 118, 46-51; y) W. Bi, G. E. Gray, T. F. Fuller, Electrochem. Solid St. Lett. 2007, 10, B101-B104; z) E. L. Redmond, P. Trogadas, F. M. Alamgir, T. F. Fuller, ECS Trans. 2013, 50, 1369-1376; aa) P. Trogadas, T. F. Fuller, ECS Trans. 2011, 41, 761-773; ab) P. Trogadas, T. F. Fuller, in Polymer Electrolyte Membrane and Direct Methanol Fuel Cell Technology, Vol. 1 (Eds.: C. Hartnig, C. Roth), Woodhead Publishing, 2012, pp. 194-218.

[137] S. Kjelstrup, M.-O. Coppens, J. G. Pharoah, P. Pfeifer, Energy \& Fuels 2010, 24, 5097-5108.

[138] a) A. Bejan, Shape and Structure, from Engineering to Nature, Cambridge University Press, Cambridge UK, 2000; b) D. Tondeur, L. Luo, Chem. Eng. Sc. 2004, 59, 1799-1813.

[139] a) M. Florens, B. Sapoval, M. Filoche, Comp. Phys. Comm. 2011, 182, 1932-1936; b) B. Mauroy, M. Filoche, E. R. Weibel, B. Sapoval, Nature 2004, 427, 633-636; c) B. Sapoval, Solid State lonics 1995, 75, 269-273.

[140] D. Christensen, J. Nijenhuis, J. R. van Ommen, M. O. Coppens, Ind. Eng. Chem. Res. 2008, 47, 3601-3618.

[141] C. D. Murray, PANS 1926, 12, 207-214. 
[142] a) J. Currie, University of Toronto (Toronto), 2010; b) P. Domachuk, K. Tsioris, F. G. Omenetto, D. L. Kaplan, Adv. Mater. 2010, 22, 249-260.

[143] B. Mandelbrot, The Fractal Geometry of Nature, W.H. Freeman, New York, 1982. 


\section{Supplementary information}
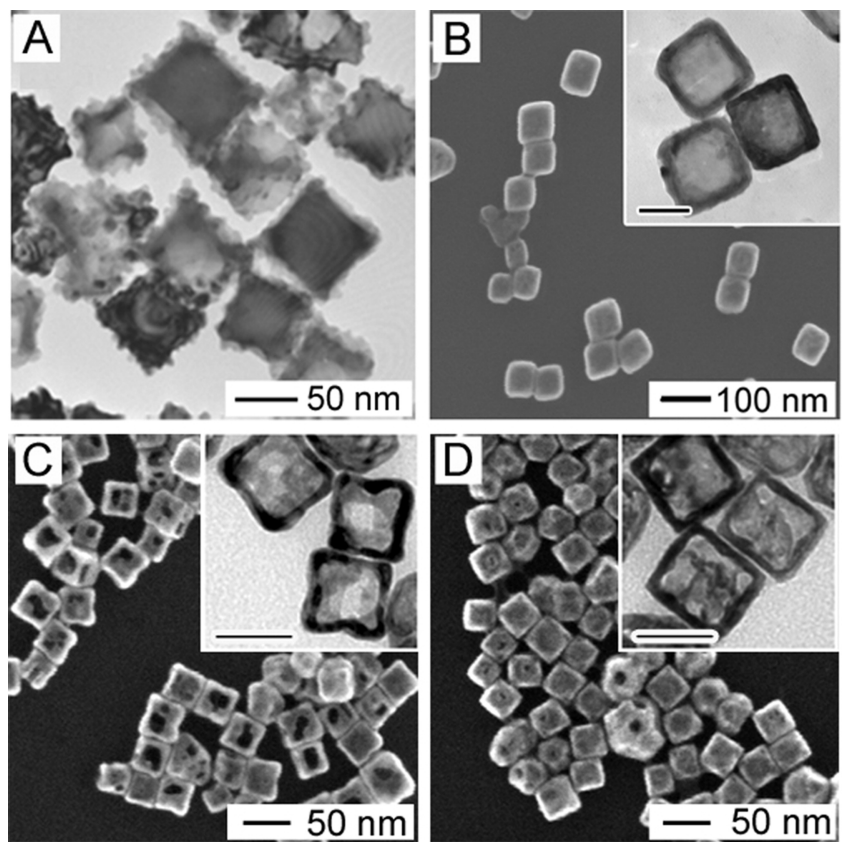

Figure S 1. a) TEM of Pt/Ag nanocubes from the galvanic replacement reaction between $\mathrm{Ag}$ nanocubes and $\mathrm{Na}_{2} \mathrm{PtCl}{ }_{4}$ solution. b) SEM and TEM (inset) of $\mathrm{Pd} / \mathrm{Ag}$ nanocubes from the galvanic replacement reaction between $\mathrm{Ag}$ nanocubes and $\mathrm{Na}_{2} \mathrm{PdCl}{ }_{4}$ solution. $\mathrm{c}$, d) SEM and TEM (inset) of $\mathrm{Ag} / \mathrm{Au} / \mathrm{Pd}$ nanocubes from the galvanic replacement reaction between $\mathrm{Ag}$ nanocubes and (c) $\mathrm{Na}_{2} \mathrm{PdCl}_{4}$ solution, followed by $\mathrm{HAuCl}{ }_{4}$ solution, and (d) $\mathrm{HAuCl}_{4}$ solution, followed by $\mathrm{Na}_{2} \mathrm{PdCl}_{4}$ solution. ${ }^{[33 \mathrm{~b}]}$ Copyright ${ }^{\odot} 2008$ American Chemical Society.

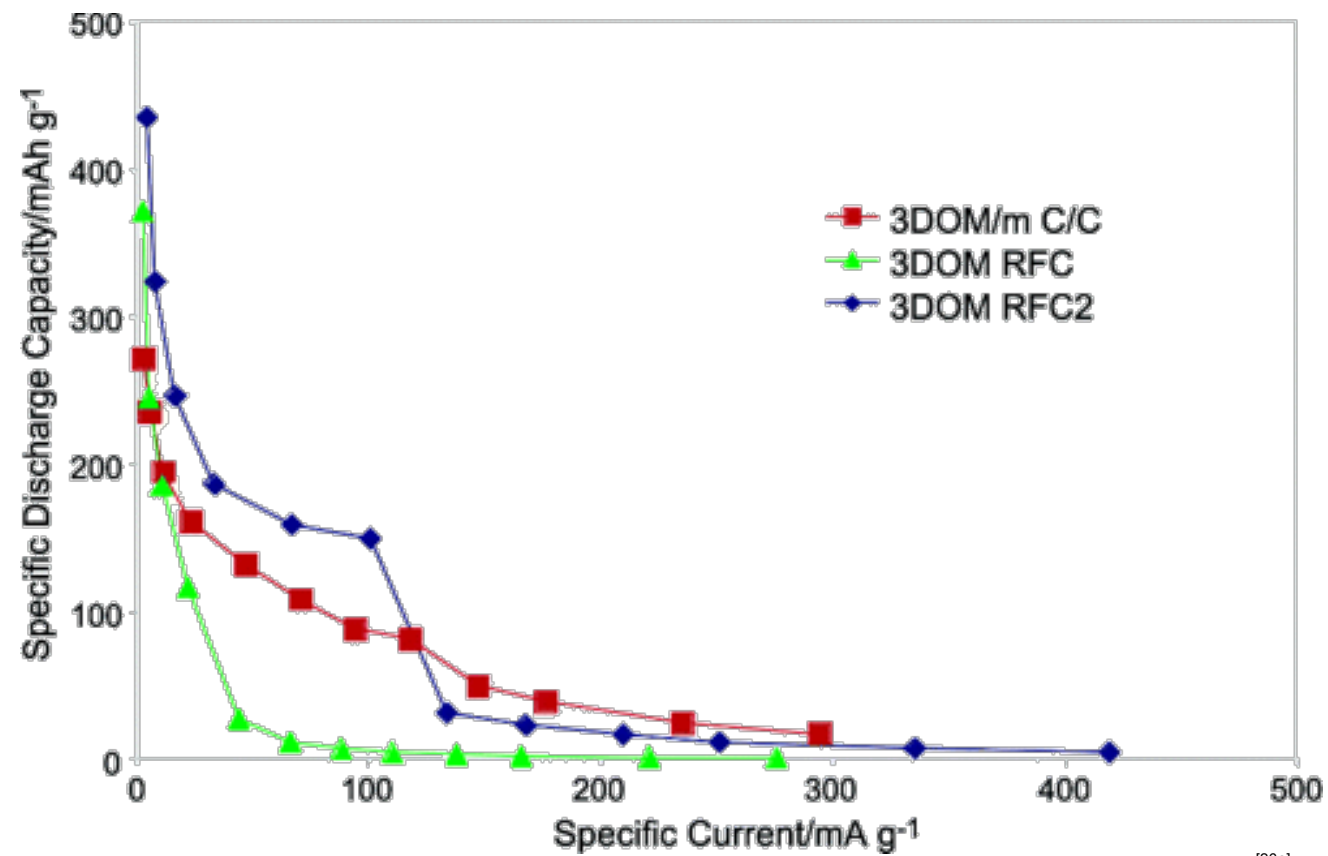

Figure S 2. Specific discharge capacities of 3DOM resorcinol-formaldehyde carbon (RFC), 3DOM RFC2, and 3DOM/mC/C. ${ }^{[26 a]}$ Copyright ${ }^{\odot}$ 2006 American Chemical Society. 

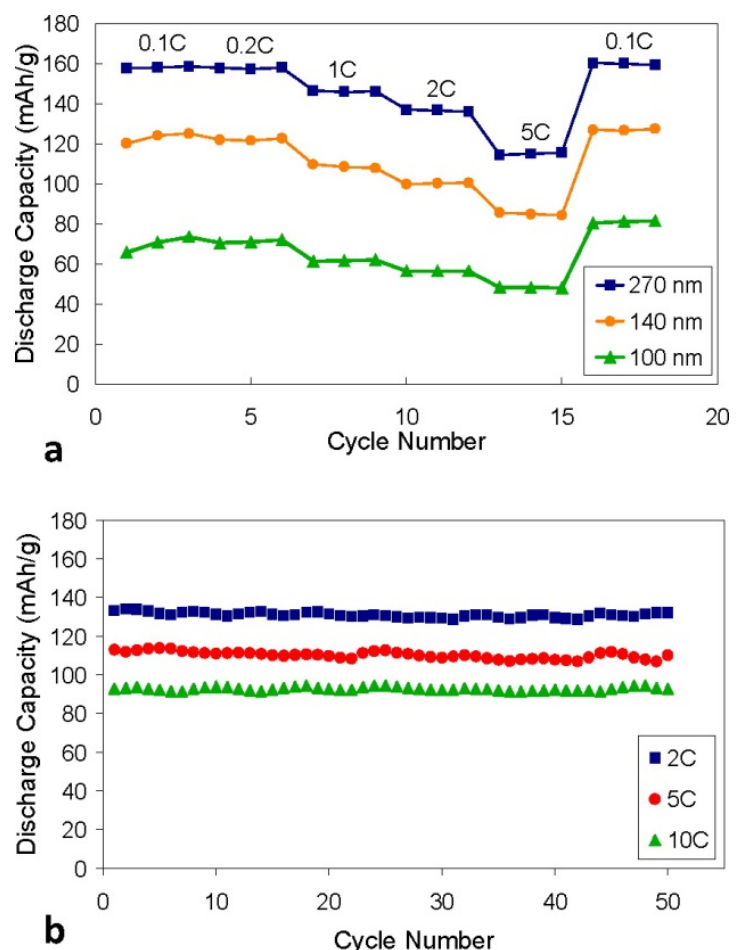

Figure S 3. a) Comparison of discharge capacity for $\mathrm{LiFePO}_{4}$ calcined at $700^{\circ} \mathrm{C}$ and templated with differently sized colloidal crystal templates and b) cyclability of $\mathrm{LiFePO}_{4}$ sample templated with $270 \mathrm{~nm}$ colloidal crystal and calcined at $700^{\circ} \mathrm{C} .{ }^{[600]}$ Copyright ${ }^{\odot} 2009$ American Chemical Society.
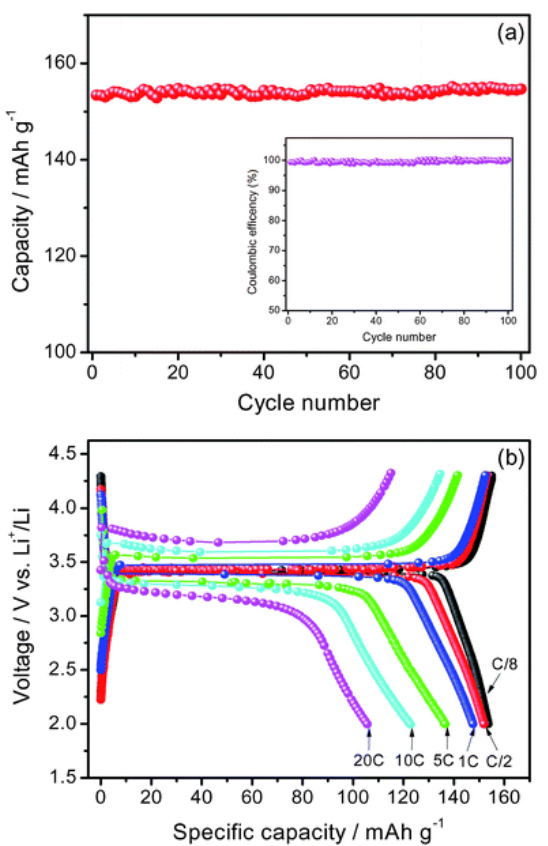

Figure S 4. a) 8 hour capacity of the 3D nanoporous spherical LiFePO $4 / \mathrm{C}$; b) Charge-discharge curves at various capacity rates. ${ }^{[63]}$ Copyright $^{\oplus} 2011$ Royal Society of Chemistry. 


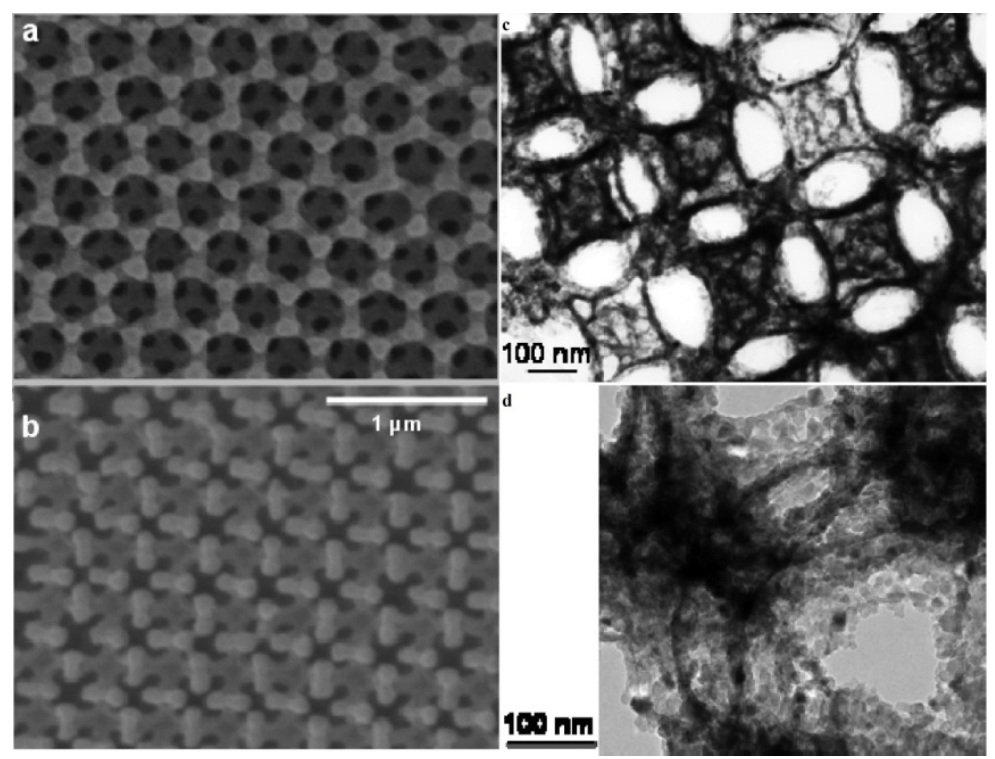

Figure S 5. a and b) SEM micrographs of 3DOM LiMn $\mathrm{O}_{4}$, corresponding to $\{1,1,1\}$ and $\{1,0,0\}$ surfaces, respectively; c and d) TEM micrographs, showing the macropore walls formed by $\mathrm{LiMn}_{2} \mathrm{O}_{4}$ nanocrystals. ${ }^{[65]}$ Copyright ${ }^{\circ} 2008$ American Chemical Society.

\section{Computational Modeling (Supplementary Information complementing Section 3.2)}

Computational modeling has been extensively employed to study the effect of operational parameters as well as cell components on fuel-cell performance ${ }^{[58 \mathrm{~s}, 135]}$, without accounting for the structure of the material. Many numerical models have been developed with increasingly less restrictive assumptions and more physical complexities to provide solutions for the equations that incorporate the electrochemical kinetics and thermodynamics, as well as heat, mass, charge and momentum transport. ${ }^{[58 s, 135-136]}$

1D and pseudo-2D models have been developed to investigate the effect of water and heat management on fuel-cell performance. ${ }^{[58 \mathrm{~s}, 135]}$ Initial models solely investigated the water transport through the membrane and GDL/catalyst layer. ${ }^{[58 s,}$

${ }^{135]}$ Pseudo-2D models reveal that fuel cell performance is improved when gas streams are saturated with water at a higher temperature than the operating temperature, due to improved heat transfer. Evaporation of liquid water results in a high heat transfer coefficient and leads to good temperature stability. ${ }^{[136 a]}$

Other models have been used to examine water transport throughout fuel cells using computational fluid dynamics, without considering water diffusion through the membrane or electro-osmotic drag in the membrane. ${ }^{[136 b, 136 c]}$ As a result, these models do not adequately describe water transport phenomena through the membrane at low humidity. ${ }^{[58 s]}$ This can be achieved by considering water transport through all the fuel-cell components, which enables the study of water management in fuel cells at low humidity. ${ }^{[136 d-f]}$

However, these macroscopic models could not investigate two-phase transport and the effect of pore morphology, because they lack realistic two-phase correlations such as those for capillary pressure and permeability as a function of water saturation. ${ }^{[136 \mathrm{~g}]}$ Thus, lattice Boltzmann (LB), pore morphology (PM) and pore network (PN) models are preferred. ${ }^{[136 \mathrm{~g}, 136 \mathrm{~h}]}$

LB models simulate the fluid motion of a collection of particles through the catalyst/gas diffusion layer by following the evolution of a Boltzmann equation instead of solving the Navier-Stokes equations. The degrees of freedom of the system are reduced as the group of particles moves on a regular lattice, making a pore-scale simulation computationally tractable ${ }^{[136 g-k]}$. At low saturation levels, liquid water forms a fractal front governed by invasion percolation, as it penetrates into the wetting phase in the shape of fingers; at high saturation levels, several penetrating saturation fronts merge to form a stable front (Fig. S6). ${ }^{[136 \mathrm{~h}]}$ 


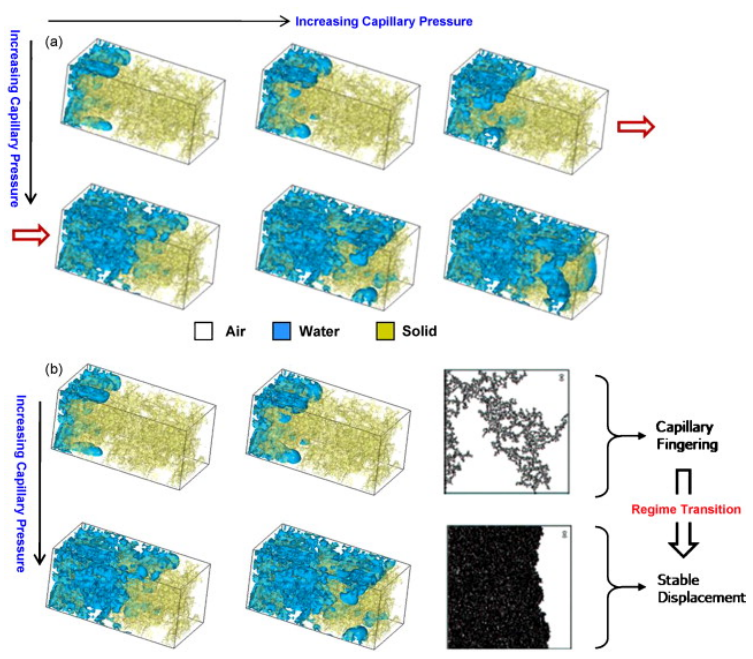

Figure S 6. Advancing liquid water front with increasing capillary pressure through the catalyst layer. ${ }^{[136 \mathrm{~h}]}$ Reprinted from ${ }^{[136 \mathrm{~h}]}$ with permission from Elsevier.

Pore morphology models can be used to simulate the drainage process based on $3 \mathrm{D}$ structural analysis to predict the relationship between saturation and capillary pressure. ${ }^{[136 g]}$ Pore network models utilize a network of wide pore spaces interconnected by narrower regions, called throats, to simulate two-phase transport under fuel cell operating conditions. ${ }^{[136 l,}$ $136 \mathrm{~m}]$

Several 1D models have also been developed to investigate $\mathrm{Pt}$ and carbon support oxidation under PEFC operating conditions. ${ }^{[136 n-x]}$ The major cause of Pt surface area loss in low temperature PEFCs is Pt coarsening (Pt dissolution and redeposition analogous to Ostwald ripening) and $\mathrm{Pt}$ diffusing away from the cathode, which is subsequently reduced by hydrogen permeating from the anode. ${ }^{[1360,136 p, 136 y-a b]}$ Relative humidity is reported to have a significant effect on the loss of cathode Pt mass and Pt electrochemically active surface area, while reactant gas partial pressure does not affect cathode electrocatalyst degradation. Thus, preliminary studies on Pt electrocatalyst degradation showed very promising results, even though more research is needed to further understand the Pt dissolution mechanism.

It is clear from this brief, by no means comprehensive overview that further development of multi-scale modeling approaches is required to account for not only the steady state, but also the dynamics of the complex, multi-phase phenomena occurring in electrocatalysts and fuel cells. This is especially so in view of the tremendous progress in capabilities to synthesize hierarchically structured nanomaterials; these experimental synthetic capabilities can only be truly taken advantage of if they are complemented by simulations that allow to interpret experiments, and guide the engineering of better electrochemical devices. 